\title{
DOES PRIVATE SCHOOL COMPETITION IMPROVE PUBLIC SCHOOL PERFORMANCE? THE CASE OF NEPAL
}

\author{
Amrit Thapa
}

Submitted in partial fulfillment of the requirements for The degree of Doctor of Philosophy

Under the Executive Committee of the Graduate School of Arts and Sciences

\section{COLUMBIA UNIVERSITY}

2011 
(C) 2011

Amrit Thapa

All Rights Reserved 


\begin{abstract}
DOES PRIVATE SCHOOL COMPETITION IMPROVE PUBLIC SCHOOL PERFORMANCE? THE CASE OF NEPAL
\end{abstract}

Amrit Thapa

In developed countries, the evidence on the impact of school type on student performance is mixed. Researchers are also interested in finding out the effect of private school competition on educational outcomes. The evidence on this for developed countries is mixed as well. What is the effect in developing countries? There are not sufficient studies for developing countries to reach one conclusion. Using data from the survey of the Ministry of Education, Nepal-2005 for School Leaving Certificate Exam (SLC), this dissertation attempts to seek answers to the above two issues for the case of Nepal. The first part of this study analyzes private and public school performance using OLS and logistic models. The study adopts the propensity score matching technique to account for the selection bias problem. The second part of this dissertation attempts to explore the impact of private school competition on public school performance using the number of private schools in the neighborhood as a continuous measure of competition. A binary measure of competition is also used where school is defined to face competition if there is more than one private school in the vicinity of the sample public school. However, in this analysis, there exists an identification problem because private school enrollment is likely to be correlated with public school performance. To address this problem, the study uses the existence of a motorable road within an hour's walking distance from the sample school as an instrument for number of private schools in the neighborhood. 
The results from the OLS and logistic estimation on the effect of school type on student performance show that public schools consistently have a negative relationship with student performance. On the impact of private school competition on public school performance, the OLS results show no significant relationship using both continuous and binary measures of competition. In contrast, the IV method indicates a positive and significant impact of private school competition on public school performance, which holds true for both types of measures of private school competition. 


\section{TABLE OF CONTENTS}

Chapter $\quad$ Page

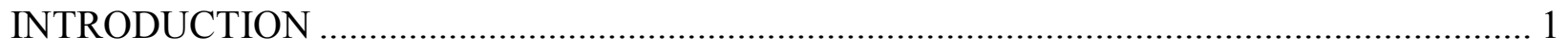

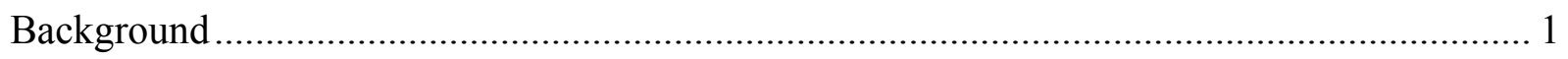

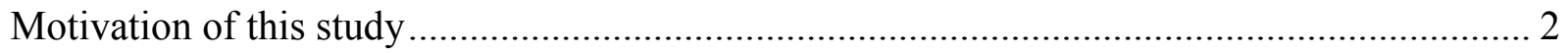

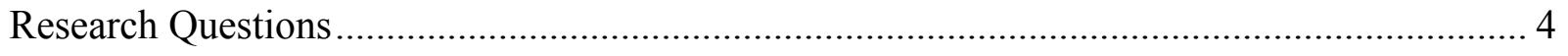

Significance of the Study ........................................................................................... 4

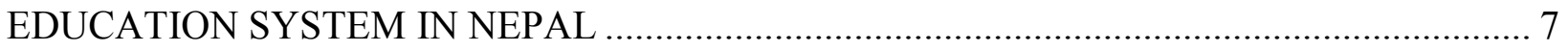

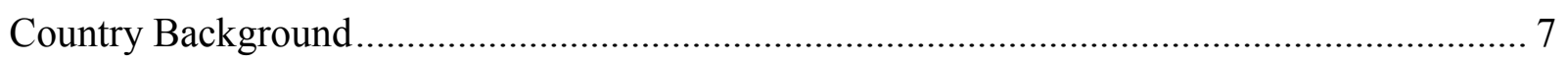

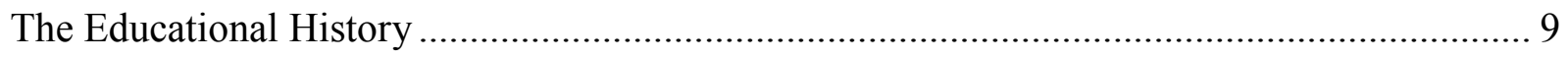

The Present Education System ............................................................................. 10

Education Administration and Governance in Nepal ..................................................... 12

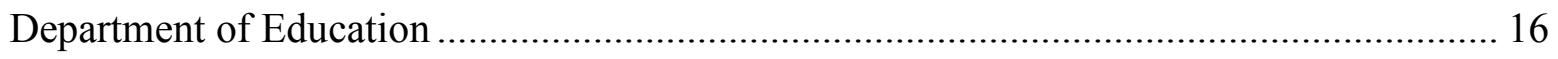

Other Agencies under the Ministry of Education ................................................. 18

Education Expenditure and Finance in Nepal......................................................... 22

Financing of Education in Nepal .......................................................................... 24

Challenges and Problems in Education Finance ...................................................... 27

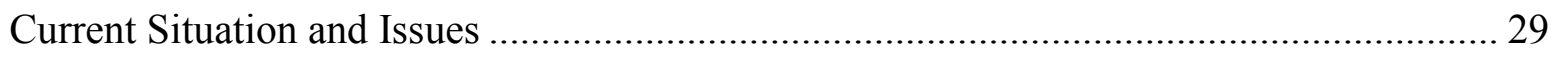

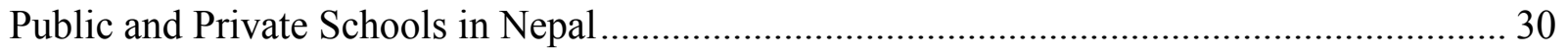

Private Schools: Evolution and Current Issues ...................................................... 36

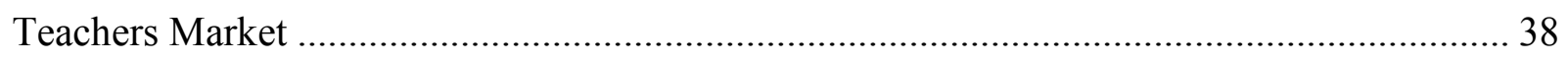

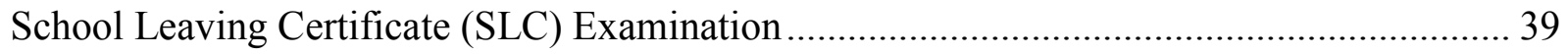




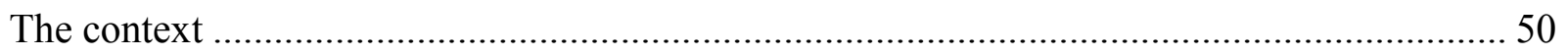

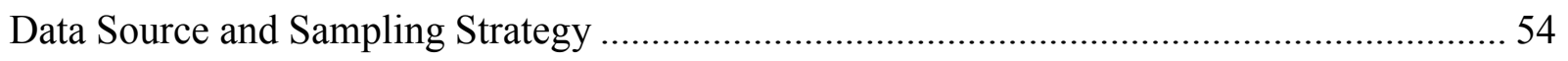

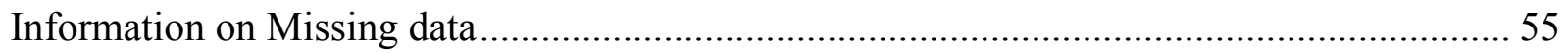

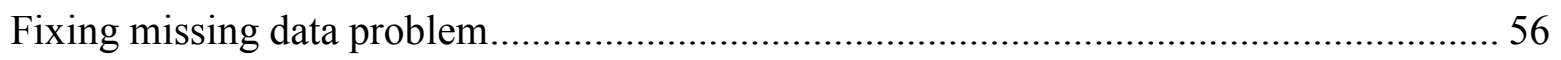

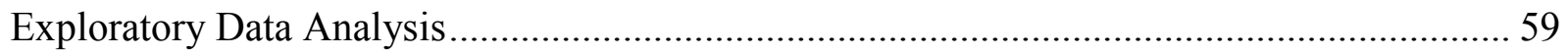

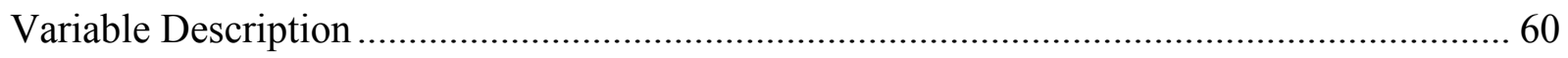

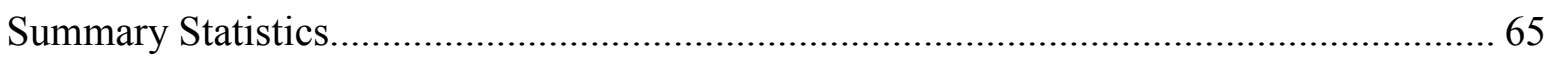

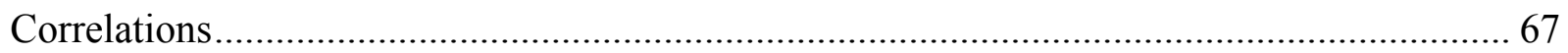

AN ANALYSIS OF PRIVATE AND PUBLIC SCHOOL PERFORMANCE IN NEPAL ........ 72

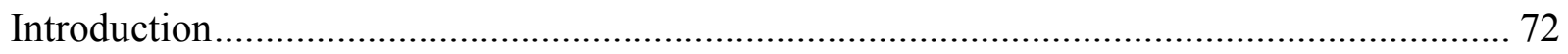

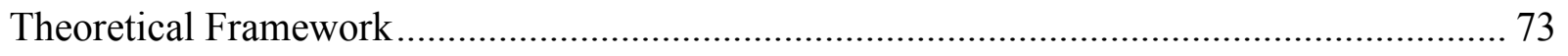

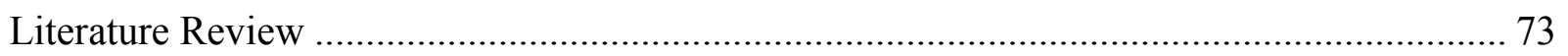

Evidence on Developed Countries..................................................................... 73

Evidence on student performance in developing countries ...................................... 81

Evidence on student performance in Nepal ........................................................ 82

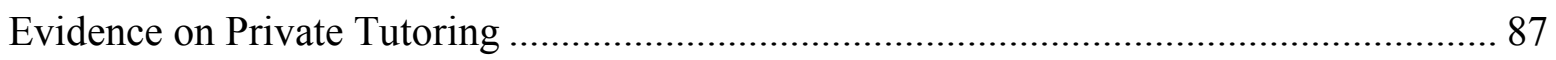

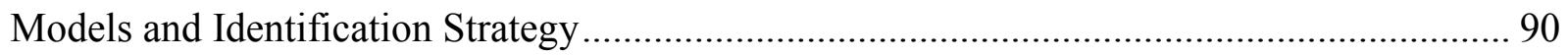

The Basic Empirical Model .................................................................................... 90

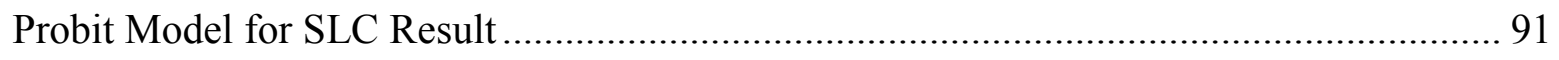

Probit Model for The Medium of Exam .................................................................... 92

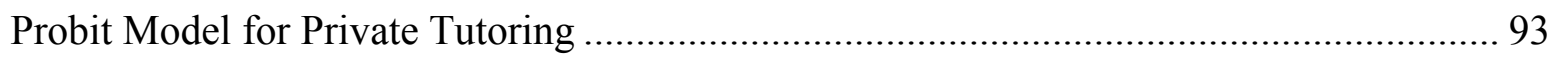

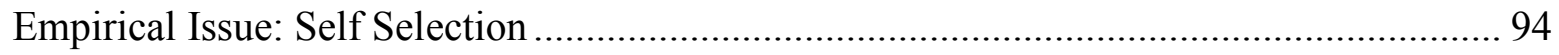


Propensity Score Matching ........................................................................................... 94

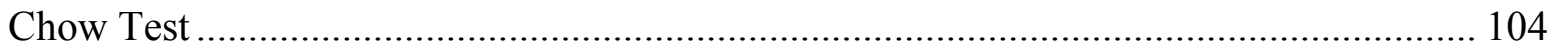

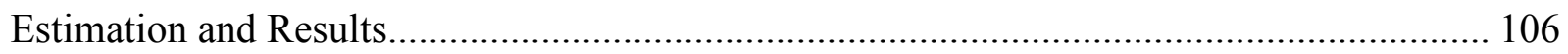

Specification and Diagnostic Analysis ....................................................................... 106

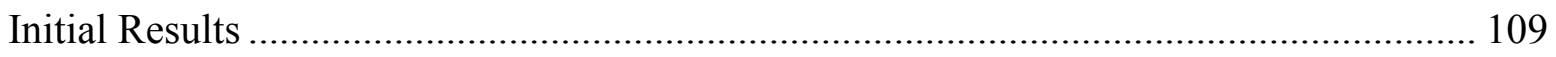

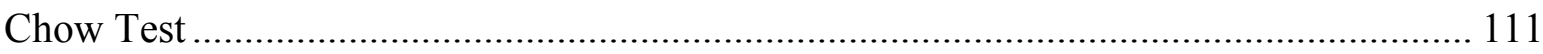

Blinder- Oaxaca Decomposition.................................................................................. 114

Results from Propensity Score Matching …………………........................................ 115

Results from Probit Models ...................................................................................... 117

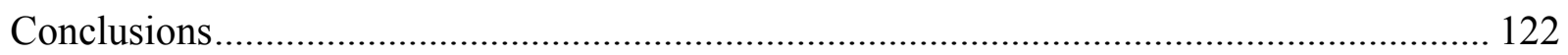

THE IMPACT OF PRIVATE SCHOOL COMPETITION ON PUBLIC SCHOOLS .............. 130

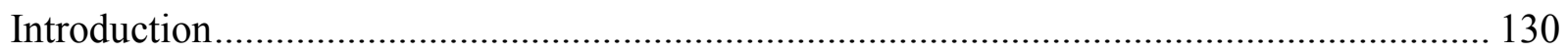

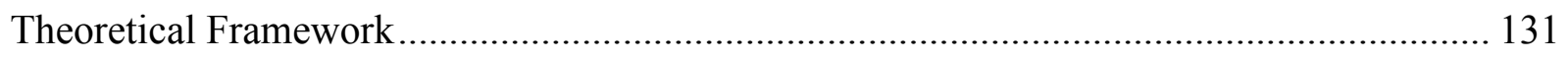

Background on Education Market and Competition ....................................................... 131

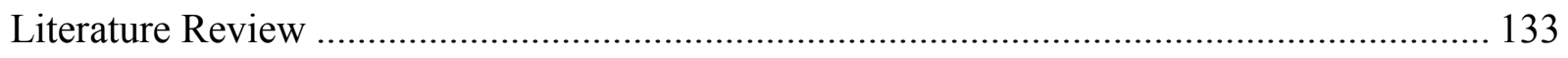

Evidence Using Herfindahl Index ............................................................................ 135

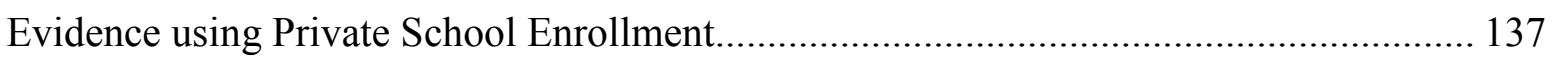

Evidence Using Other Measures of Competition .......................................................... 138

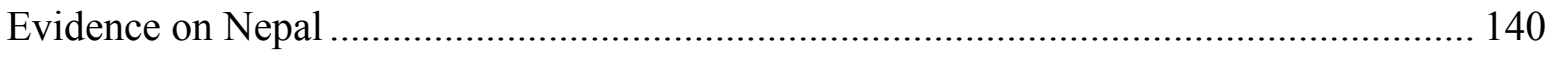

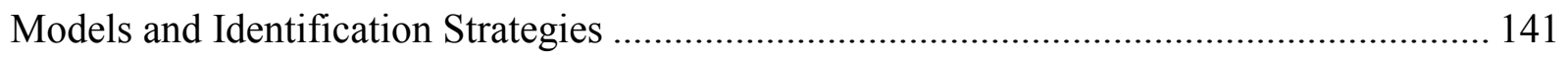

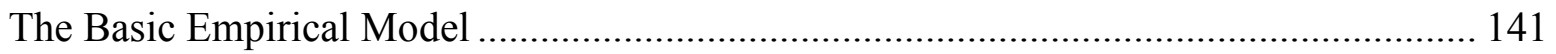

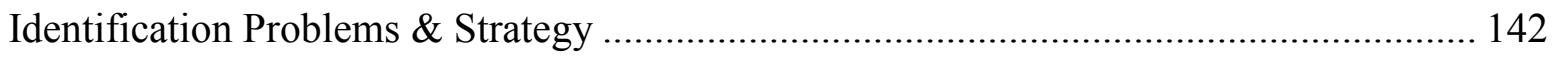

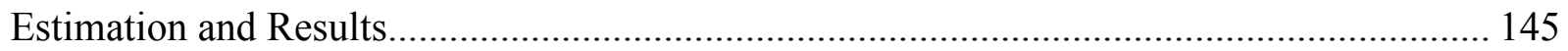


Specification and Diagnostic Analysis .......................................................................... 145

Validity Check for Instrument Variable ...................................................................... 148

Power Check of the instrument ................................................................................. 150

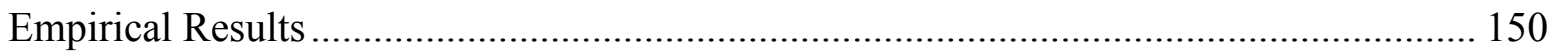

Continuous Measure of Private School Competition........................................................ 150

Binary Measure of Private School Competition ......................................................... 154

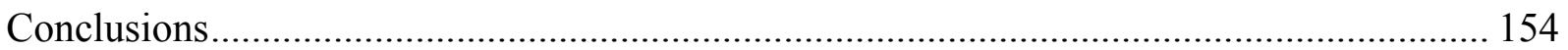

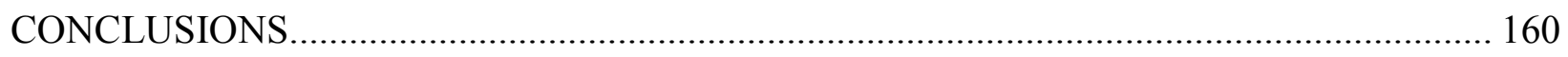

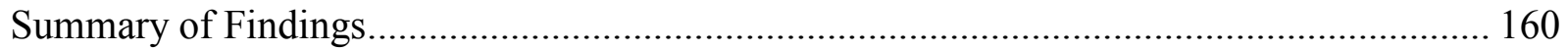

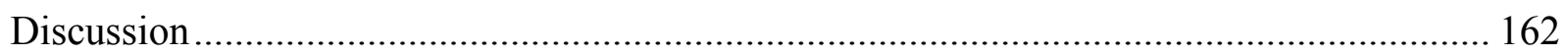

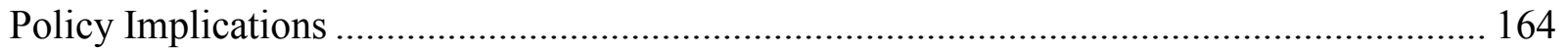

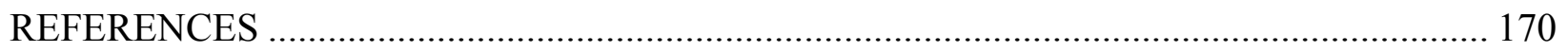

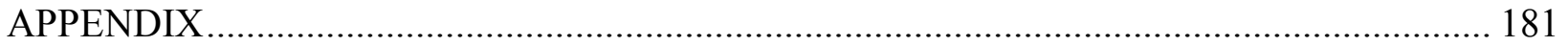




\section{LIST OF FIGURES}

Figure 2.2. Number of Schools by School-Type and Level ...................................................... 11

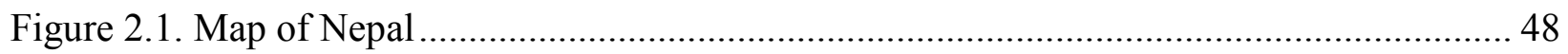

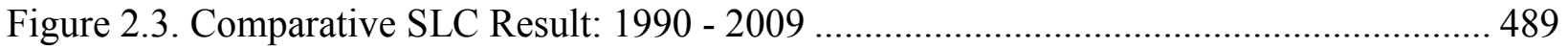

Figure 4.1. The distribution of residuals of the regression equation in the basic model ............ 107

Figure 4.2. Residuals Plotted against the fitted values .......................................................... 108

Figure 4.3. Detecting outliers: Leverage vs. normalized residual squared ................................. 109

Figure 5.1. The Distribution of Residuals of the OLS Regression Equation.............................. 146

Figure 5.2. Residuals Plotted against the fitted values ............................................................ 147

Figure 5.3. Detecting Outliers: Leverage vs. Normalized Residual Squared ............................. 147

Figure A.1. Box Plot Diagrams of Variables used in the Study ……....................................... 182

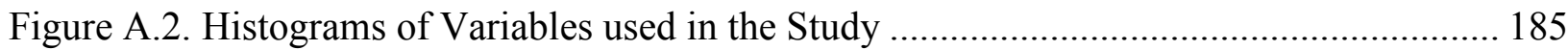




\section{LIST OF TABLES}

Table 2.4. Gross Enrollment Rate (GER) and Net Enrollment Rate (NER) by level and gender 12

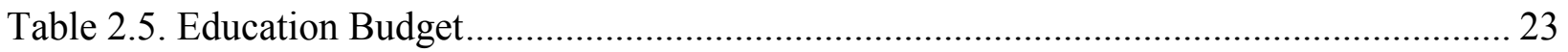

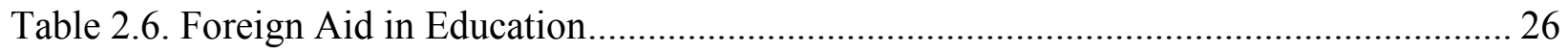

Table 2.7. Performance in SLC Exam -2004 by School-type and Gender ............................... 38

Table 2.1. Basic Statistics of Nepal and South Asia ........................................................... 43

Table 2.2. Total Schools by School-Type, Level and Development Region............................. 44

Table 2.3. Percentage of Public and Private School's Enrollment in Total Enrollment by Level

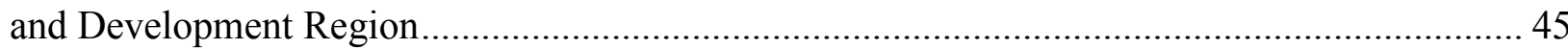

Table 2.8. Percentage Trained Teachers and Student-Teacher Ratio in Public and Private Schools

Table.2.9. Comparative Regular SLC Result (1990 -2009)................................................ 47

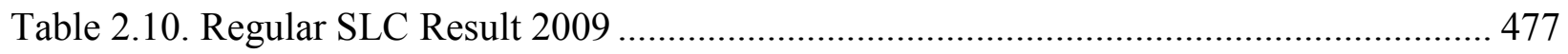

Table 3.1. Original and Modified Sampling Frames ........................................................ 56

Table 3.2. Variables Between 5 to 25 Percent Missing Values ............................................ 57

Table 3.3. Mean score and pass rates in SLC by School-Type and Gender ............................. 66

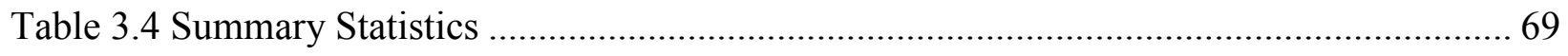

Table 3.5. Correlation Coefficient: SLC Outcome and school type ..................................... 71

Table 3.6. Correlation Table: SLC Score and Private School Competition ............................. 71

Table 4.2. Summary of estimates of the effect of school type on student's performance in SLC

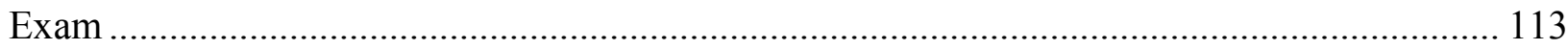


Table 4.5. Estimates from Oaxaca-Blinder Decomposition 115

Table 4.6. Average Treatment Effect on the Treated Estimated by Nearest Neighbor Matching

Table 4.1 Variance Inflation Factor 125

Table 4.3. OLS Estimates of the Effect of School Type on Student's Performance in SLC Exam 126

Table 4.4. Probit Estimates of the Effect of School Type on Student's SLC Result. 128

Table 5.2. First-stage equation of 2SLS. 149

Table 5. 3. Estimates of Private School Competition on Public School Student's SLC score... 152

Table 5.1. Variance Inflation Factor. 157

Table 5.4. Estimates of Effect of Private School Competition on Student's SLC Performance by

School Type 158

Table 6.1 Variables that are consistently significant in explaining student's SLC performance 167

Table A.1. Agencies under the Ministry of Education, Nepal 181 


\section{ACKNOWLEDGEMENTS}

My heartfelt thanks to my advisor, Professor Henry M. Levin, for his great help, support, guidance and encouragement throughout the four years of my doctoral study. He is not only an inspiring teacher and devoted professor, who teaches by setting a good example, but also a very kind soul. It has been a blessing for me to know, interact and learn from him.

I sincerely thank Professor Mun C. Tsang, Professor Francisco Rivera-Batiz, Professor Ira Gang and Professor Randall Reback for having accepted to be on my dissertation committee and take the time to read and comment my work. In addition, I would like to thank Professor Jennifer Hill, Professor Thomas Bailey and Professor Judith Scott-Clayton for their valuable comments.

I am very grateful to Dr. Saurav Bhatta and the Ministry of Education of Nepal for helping me with the necessary data for this dissertation. Dr. Bhatta's prior study and valuable suggestions have indeed been a significant help for this work. I would also like to thank all my friends in the Economics and Education program for sharing their knowledge and being so helpful during my years at Teacher College. Finally, I am grateful to the Program in Economic Policy and Management (PEPM) at School of International and Public Affairs for awarding me with the teaching fellow position from 2009 to 2011, and for providing the financial assistance for my final dissertation defense. 


\section{DEDICATIONS}

To my beloved Swami, Bhagawan Sri Sathya Sai Baba, for His ever flowing Divine Grace and Blessings.

To Nepal, my motherland.

To my parents for their immense love, care and blessings. This work is my humble gift to them.

To all my teachers, from my primary school till today who have been idols for me to observe, listen, learn and be inspired by.

To Hal, for his continuous help, encouragement and support. God bless him.

To my wife, my best friend and co-traveler of this journey of life.

To my brother, Amrish and sister, Amrita, for being so full of love.

To all my friends and the members of Sai family for their well wishes and goodness of heart. 
Chapter 1

INTRODUCTION

\section{Background}

The issue of private versus public education has been of great significance both to the developed as well as developing countries. Further, the study of the dynamics that occur between public and private schools is attracting educational researchers around the world. The definition of public and private schools vary depending on who owns, manages and/or finances education. The concept of private and public may also vary depending on different education systems; and, for the purposes of comparisons it should be defined in a broad sense (Walford, 1999). In its pure form, we define public schools as those which are owned managed and financed by the state. On the other hand, private schools are those owned, managed and financed by parents' association, business, non-profit organization or a religious institution and sometimes by the government. However, schools need not be categorized as fully public or fully private; and could be a combination of both. For example, community managed schools are schools funded by the government, but managed by some non-government body, such as a community. The inclination of any school towards a particular system (public or private) depends on the degree of i) the prevailing provision (or management) and ii) financing of education. When one of these

dimensions is not under total government control, and responsibilities between public and private sectors over education are shared, we say that public education is privatized. One common 
example of this initiative is the government voucher schemes or subsidies to finance student's education in private schools (see Friedman, 1962).

Recent trends around the world also show that many developed and developing countries are seeking partnerships between the public and private sector to share costs and improve the provision of education. Governments in these countries are looking for alternative mechanisms of education delivery and financing outside of the public realm. These initiatives are promoted by budgetary stringencies and a greater reliance on the market to correct inefficiencies (CuellarMarchelli, 2003). Another important aspect of public-private school dynamics is the growing competition in the private sector, and its impact on school and student performance. Along with the study of public and private school performance, this dissertation focuses on the impact of private school competition on public school performance for the case of Nepal using data from the School Leaving Certificate (SLC) exam ${ }^{1}$. A background on the country and a discussion on the education system in Nepal, including the SLC exam are discussed in the second chapter of this dissertation.

\section{Motivation of this study}

Though Nepal's education system has progressed significantly over the last few decades ${ }^{2}$, it continues to face huge challenges amidst its prolonged political instability. For example, the NER for primary students in 1980 was just around 16 percent, but by 2003 , it had risen to 83.5 percent (MOES, 2005a). Similarly, the number of schools and colleges has risen exponentially

\footnotetext{
${ }^{1}$ This is equivalent to $10^{\text {th }}$ grade final examination, and the exam is administered by the government of Nepal every year.

${ }^{2}$ Recent educational statistics on Nepal is presented in chapter 2.
} 
over the last few decades. The retention of students, especially at the primary level, has always posed a big challenge to this country of 28 million. Still, 19 percent of the total school age population (age 5 to 16) are not in school. At the secondary level, the figure is even more alarming with 40 percent out of school (MOE, 2008). There is a very low participation rate in the upper stages of schooling. The literacy rate was only 55.6 percent in 2009 (MOE, 2010). Disparities in gender, ethnic and economic groups, and locations are increasing year by year. For example, only 43.3 percent of Nepal's women are literate, compared to 70.7 percent of men (MOE, 2010). Schooling quality in public schools interpreted in terms of achievement rates is found to be very low. In addition, the public schools are left behind, and there is much disparity between the private and public schools in terms of quality and student performance. For example, based on the 2004 SLC results, compared to an average pass rate of 85 percent for private schools, the pass rate of public schools was only 38 percent. Similarly, while an overwhelming majority of private schools had pass rates in the 80-100 percent range, less than 7 percent of the public schools had such high pass rates. Furthermore, the average SLC score of private schools was around 39 percent above that of public schools (Bhatta, 2004). Given this consistent low performance of public school performance, private school competition is increasing day by day, especially in the urban areas. This increase in private school competition can also be attributed to various other reasons such as the ease of establishing a private school, the profitability of private schools, and the absence of limiting regulations on these schools by the government. In such a scenario, in addition to comparing private and public school performance, it is interesting to pose a question if private school competition has any impact on public school performance. In this regard, although there are many studies with data from developed countries, there is hardly any study in the case of developing countries. So far, to the 
best of my knowledge, there has not been a single study on this topic that uses data from Nepal. This study attempts to fill this gap in the literature using data from the Nepalese Ministry of Education's Survey and by applying various empirical techniques.

\section{Research Questions}

There are two main research questions in this study:

i) Do private school students perform better than their public school counterparts after controlling for student, family, school and teacher characteristics?

ii) Keeping other things constant, does private school competition have any impact on public school performance in the case of Nepal?

The empirical models associated with the first and the second research questions are presented in Chapters 4 and 5, respectively.

\section{Significance of the Study}

The study of private versus public schooling is a topic of great interest at the present time. The topic is more interesting in the case of developing countries where demand for a better education system is rising day by day. In such a situation, a genuinely comparative study on the performance of private and public education becomes crucial to both education researchers and the policy makers. In addition, given the new movements of privatization of education in developing countries, the study of the effect of private school competition on educational outcomes is of even more importance. 
This study is unique in several ways. First, the data for this study come from Nepal, a focus of very few Economics of Education researchers. Many people around the world have been taking a keen interest in Nepal, which has taken some significant turns over the years: from autocratic regimes to a democratic kingdom, to a Federal Democratic Republic. Nepal is at a turning point in its political history. It needs good information for both policy makers and the general public. Education is a crucial sector and the delivery of good education is very critical for the development of this poor nation. Unfortunately, very little literature is available that examines educational developments and their dynamics in Nepal. The Nepalese population has been shifting to private schools without clear evidence of their superiority and with great financial sacrifice for the majority of the population. In this context, this dissertation explores public and private schooling and examines the public-private linkages in the education sector. Thus, it can help fill this gap in the literature. Secondly, School Leaving Certificate (SLC) examinations are, by far, the most important school-level exams for the majority of Nepalese (Bhatta, 2005). This study uses data on the SLC examination collected by the SLC study team under the sponsorship of the Ministry of Education, which is one of the most comprehensive data sets collected so far in Nepal relating to SLC examinations. In Nepal, there are just a few studies that explore private and public school performance, and they lack systematic empirical evidence. Even among those that use empirical models, they fail to take account of the selection bias problem that usually cripples such an analysis. By this I refer to the fact that the two groups of schools do not enroll the same types of students. For example, private schools have more resources and certainly have students from families with higher socio-economic status for peer effects. These are omitted variables or non-observables. Thus, it is very likely that these differences account for the overall differential in achievement between public and private 
schools rather than the sponsorship. This study adopts the propensity score matching and instrumental variable method to address such problems. This makes the study richer as compared to those that do not account for such serious methodological issues. Moreover, this study is one of the first empirical studies on the impact of private school competition on public school performance in a developing county. Therefore, in addition to Nepal, this study may also provide some insights for other countries that share similar characteristics in the education sector.

The rest of the dissertation is organized in the following way. Chapter 2 presents an overview of education system in Nepal. The chapter discusses historical developments in the field of education in Nepal, features of public and private schooling in Nepal, and a description of School Leaving Certificate (SLC) exam. Chapter 3 deals with the data source, the missing data problem, method used to address this, and a description of the study variables. Chapter 4 presents a comparative analysis of private and public school performance. The chapter includes the guiding theoretical framework, the relevant literature, the model and identification strategy, and the study findings. Chapter 5 addresses the second research question, and studies the impact of private school competition on public school performance. Similar to the structure of Chapter 4, this chapter discusses the relevant background, the previous literature, the model and identification strategy and the empirical results. Finally, Chapter 6 concludes with a discussion on the policy implications of the findings of this study. 


\section{Chapter II}

\section{EDUCATION SYSTEM IN NEPAL}

\section{Country Background}

Nepal is a tiny landlocked country in Asia located between India and China with population of about 28 million. After the overthrow of King Gyanendra in 2005 by the people's movement, the country became a Federal Democratic Republic. Geographically, the country is divided into five development regions, 14 zones and 75 districts ${ }^{3}$. The five development regions are: Eastern, Central, Western, Mid -Western, and Far-Western. Kathmandu, the capital of the country, and the only metropolitan city of the nation, is located in the Central region. In terms of ecological belts, it is divided into three regions: Mountain, Hill and the Plains, where the Mountain region lies in the north sharing a boarder with Tibet, and the Plains shares a boarder with India in the south. The hilly region is the central region that includes the Kathmandu Valley ${ }^{4}$, which has a population of around 1.5 million.

The majority of the population in Nepal belongs to the Hindu religion. According to the 2001 Census, Hindus comprise 88.87 percent and Buddhists 8.59 percent of the total population, whereas the rest of the population belongs to other religions (CBS, 2002). The Hindu system is further categorized into four castes: Brahmin, Chhetri, Vaisyas (Newars) and Sudra (Dalits), where Brahmin is the highest caste, and Dalits are the lowest and most disadvantaged caste. Besides this, there are ethnic groups (Janjatis) that belong to the community which have their

\footnotetext{
${ }^{3}$ Map of Nepal with 5 development regions and 75 districts is given in Figure 2.1

${ }^{4}$ Note that Kathmandu Valley consists of three major districts: Lalitpur, Bhaktapur and Kathmandu. The capital of the country refers to Kathmandu district.
} 
own mother tongues and traditional cultures, and yet do not fall under the conventional four-fold Hindu hierarchical caste structure. Historically, many of these Janajati groups used to occupy a particular habitat or territory, and thus many of them claim that they are the true "first settlers" (Adivasi) of Nepal. As per the census report of 2001, of the total population, 65 percent belong to the Hindu caste system, 31 percent belong to Janjatis (ethnic groups), and 4 percent belong to the other caste/ethnicity. There are at least 92 languages spoken as mother tongues in various parts of the country (CBS, 2002).

Although Nepal is known to the world as land of the Himalayas, and is very rich in biodiversity, cultural and linguistic diversity, it is still one of the poorest countries in the world. As shown in Table 2.1 that reports the basic national indicators for $\mathrm{Nepal}^{5}$, its poverty rate ${ }^{6}$ is 30.8 percent with GDP per capita of only $\$ 473$ (CBS, 2010). Life expectancy at birth is 64.1 years, and the literacy rate for citizens 15 years and older is 55.6 percent, 70.7 for males and 43.3 for females (CBS, 2010). According to the United Nations Development Programme (UNDP, 2010), the human development index (HDI) ranks Nepal at 144 out of 169 countries with an HDI value of 0.428 . The country's economy has suffered badly due to prolonged political disturbances in the country, especially the Maoist guerrilla war that spanned the years from 1996 to 2005. Although the war has now ended, the country is not still able to recuperate from the damage sustained in all sectors of the economy. The education sector is also one of the most affected. The sections below discuss Nepal's educational history and the education system at present including the description of the SLC examination.

\footnotetext{
${ }^{5}$ Also presented in Table 2.1 is Statistics on South Asia for comparison purpose.

${ }^{6}$ The poverty rate is around 55 percent using the international definition of those earning $\$ 1.25$ a day.
} 


\section{The Educational History}

Nepal has come a long way in the education sector. Modern education in Nepal is believed to have begun with the establishment of the first school in 1853 . However, this school was confined only to the ruling families and their courtiers. The general population gained access to education only after 1951 when a popular movement overthrew an autocratic family regime and initiated a democratic system. In 1951-52, the adult literacy rate $(15+)$ of the country was just 5 per cent with about 10,000 students in just 300 schools and two colleges (CBS, 2003).

With the introduction of a comprehensive Education Plan in 1971, the education sector began to expand. The National Education Sector Plan (NESP) of 1971, financed by USAID, attempted to create a single unified system of public education in order to empower district education offices to run schools. However, under this law there was no inclusion of School Management Communities (SMCs). Due to this situation, only elite groups who utilized SMCs benefited from public education, and local communities were left out. As centralized rural development initiatives failed, there was demand for decentralization of state services. As a result, the Decentralization act of 1982 and its by-Laws from 1984 tried to empower local panchayats $^{7}$ by giving them functional responsibilities in various central political programs (Carney \& Bista, 2009). By the late 1980s, the need for urgent reform in schooling was felt and hence a comprehensive US- funded study was undertaken called 'Improving Efficiency of Educational Systems' (IEES). This study identified systematic management weaknesses in the central educational bureaucracy and recommended renewed decentralization of educational management (MOEC/ USAID, 1988).

\footnotetext{
${ }^{7}$ A village council in Nepal, India and Southern Pakistan is referred as Panchayat.
} 
After the people's movement of 1990 established a democracy in the country, education development was realized more successfully and more rapidly. A simple example was seen in the rapid rise of the Net Enrollment Ratio (NER). The NER for primary students in 1980 was just around 16 percent, but by 2003 it had risen to 83.5 percent (MOES, 2005a). Yet, the quality of public schools still remained very poor and; the demand for private schools increased rapidly. The private sector started to expand in size dominated by resource- rich families. By 1998, there was a significant growth in the private sector due to the prevailing school liberalization policy (Carney \& Bista, 2009). The problems arising from this expansion were rampant fee charge and considerable variability in the quality of private schools. Eventually, the Government's poor performance and laissez-faire approach was aggravated by Maoist activists keen to bring changes to the country. In spite of the fact that Maoists had ended the war and joined the mainstream politics after the people's movement in 2005 , political instability and disturbances continue to cripple most of the key sectors of the country, including the education sector.

\section{The Present Education System}

The structure of the present education system constitutes six sections: Pre-primary (below Grade 1); Primary (Grade 1 to 5); Lower Secondary (Grade 6 to 8); Secondary (Grade 9 and 10); Higher Secondary (Grade 11 and 12); and Higher Education (University level) (MOE, 2010). Table 2.2 gives the present number of total schools by school level, school type and development region in the country. As shown in the table, there are presently 31,655 primary schools, 11,341 lower secondary schools, 6,928 secondary schools, and 2,512 higher secondary schools in the 
country. Out of these, the central region has 9,538 schools, the highest among all the regions, with 2,213 schools in the Kathmandu valley alone.

In terms of school type, as figure 2.2 shows, presently there are 41,959 public schools and 10,477 private schools in the country, with predominance in the number of 31,655 primary schools. In percentage terms, public schools constitute around 80 percent of these schools and private schools only 20 percent. At the secondary grades $\left(9^{\text {th }}\right.$ and $\left.10^{\text {th }}\right)$, there are 4,715 public schools and 2,213 private schools. In higher education, there are five universities with 834 constituent and affiliated campuses. In total, including all levels of education, there are 7.9 million students and 251,805 teachers involved in this teaching learning process. Table 2.3 reports the percentage of enrollment of the total enrollment in public and private schools. In the secondary grade, the percentage of public and private school enrollment of the total enrollment is 83.1 percent and 16.9 percent, respectively.

Figure 2.2. Number of Schools by School-Type and Level

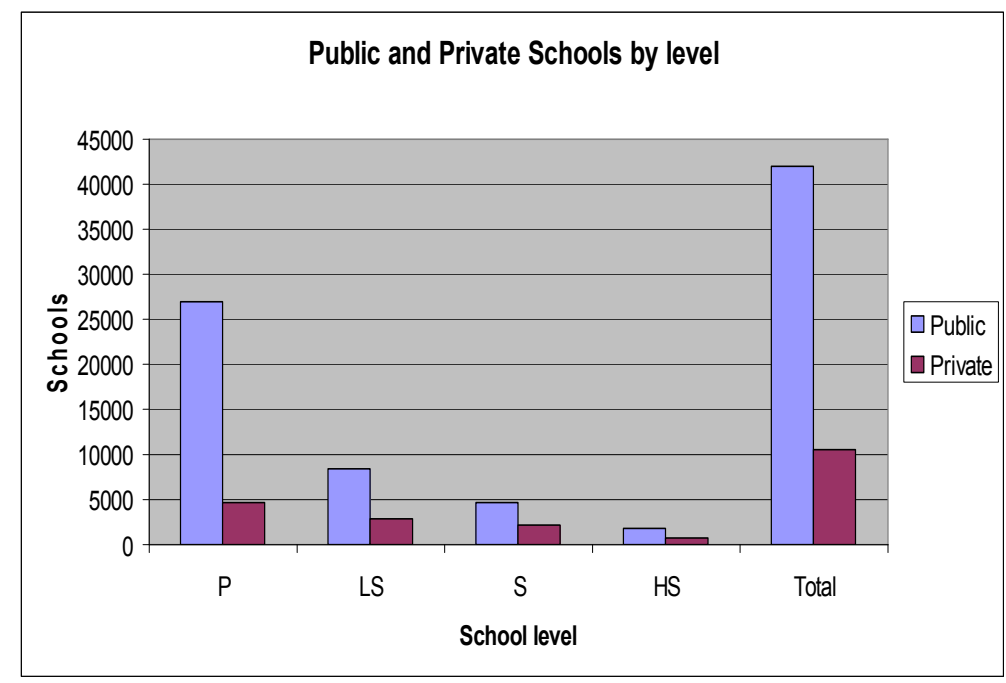

Source: MOE (2010) 
Table 2.4 shows the gross enrollment ratio and net enrollment ratio by school levels ${ }^{8}$. As shown in the table, in 2009, the combined gross enrollment ratio (GER) ${ }^{9}$ was 98.6 percent, with 141.4 percent, 88.7 percent and 65.7 percent enrollment at the primary, lower secondary and secondary levels, respectively. The combined net enrollment rate (NER) was 65.9 percent, with 93.7 percent, 63.2 percent and 40.8 percent enrolled in primary, lower secondary and secondary levels, respectively.

Table 2.4. Gross Enrollment Rate (GER) and Net Enrollment Rate (NER) by level and gender

\begin{tabular}{lcccccc}
\hline Levels & \multicolumn{3}{c}{ GER } & & & NER \\
& & & & & & \\
\hline Primary & 146.1 & 137.1 & 141.4 & 92.6 & 94.7 & 93.7 \\
LS & 89.3 & 88.2 & 88.7 & 61.9 & 64.3 & 63.2 \\
Secondary & 64.5 & 66.8 & 65.7 & 40.1 & 41.4 & 40.8 \\
HS & 24.6 & 22.6 & 23.6 & 6.8 & 6.8 & 6.8 \\
Combined & 100.0 & 97.4 & 98.6 & 64.9 & 66.8 & 65.9 \\
\hline
\end{tabular}

Source: MOE (2010)

Note: Combined is for Primary, Lower Secondary and Secondary Grades

\section{Education Administration and Governance in Nepal}

The Ministry of Education (MOE), established in the country after the dawn of democracy in 1951, is the supreme body of all educational organizations and responsible for the

\footnotetext{
${ }^{8}$ The Gross Enrollment Ratio (GER) is given by the ratio of actual students enrolled to the number of potential students enrolled. The Net Enrollment Ratio (GER) is given by enrollment of the official age group for a given level of education expressed as a percentage of the corresponding population.

${ }^{9}$ Combined is for primary, lower secondary and secondary grades.
} 
overall development of education in the country. In 2002, it was renamed the Ministry of Education and Sports. Again in 2008, with the decision of the cabinet, it was renamed as the Ministry of Education and has remained so until the present. A Cabinet Minister at the political level heads the Ministry whereas two secretaries head the MOE at the bureaucratic level (MOE, 2010).

The Ministry is responsible for formulating educational policies and plans, and managing and implementing them across the country through the institutions under its jurisdiction. For example, the Central Level Agencies (CLAs) under the Ministry are responsible for designing and implementing programs and monitoring them. Five regional Education Directorates (REDs) are responsible for monitoring the programs undertaken by the district level organizations. There are 75 District Education Offices (DEOs) at the district level and 1,091 Resource Centers (RCs) at the sub- district level as the main implementing agencies for the educational policies, plans and programs at the local levels. At the function level, the Ministry oversees the following four divisions, each headed by a joint secretary who is a gazetted first class officer: i) An administrative division ii) A higher education and educational management division iii) A planning division, and iv) A monitoring, evaluation and inspection division. The main functions of the administration division are personal management and development. It is responsible for recruitment, transfers, promotions and capacity building of the staff as well as procurement and property management. The major areas of work of higher education and educational management division are related to school education scholarship and higher and technical education. The planning division assumes responsibility for policy development and analysis. This division is the entry point for donor agencies in the education sector and coordinates foreign aid for designated for implementing programs and projects in education. The monitoring, 
evaluation and supervision division carries out monitoring activities in conjunction with program implementation and maintains a database on educational statistics (MOE, 2010).

The Ministry of Education has undertaken many programs and projects since its establishment. Among the completed projects are the following. With the help of the Asian Development Bank (ADB), it completed the Teacher Education Project (TEP) that was implemented from 2002 to 2009 with the total budget of US \$24.1 million. The main objectives of the project were i) to conduct quality pre-service, in-service and refresher training for primary teachers ii) improve institutional capacity to conduct training programs, and iii) improve the participation of women and disadvantaged groups in teaching careers. Another project named the School Management Transfer and Incentive Program was implemented from 2003 to 2008. With the assistance of the World Bank, the total budget of the project was US\$ 5.11 million. The objectives of the project were i) to increase parent's participation in the management of community schools ii) improve the access, quality and capacity of students in the community school, and iii) make all stakeholders accountable by increasing the transparency of functions of the community school. In the area of secondary education, the Ministry, with the help of grant from Denmark and a loan from the Asian Development Bank (total budget US \$ 75 million) completed a program entitled Secondary Education Support Program (SESP). The aim of the program were i) to improve the quality and relevance of public secondary schooling ii) to improve access to public secondary schooling, with a particular emphasis on girls, students with disabilities and students from poor and disadvantaged groups and districts, and iii) to develop institutional capacity and management of central and district education institutions and public secondary schools based upon a decentralized system of planning and management. Another widely known program is Education for All (EFA). This was implemented from 2004 to 2009 
with the help of multiple international organizations and donor nations and with a total budget of US\$ 814.5 million. The major objectives of this program were to: i) ensure access and equity in primary education ii) enhance the quality and relevance of primary education iii) improve efficiency and institutional capacity. With the partnership of the World Food Program (WFP), the MOE also undertook Food for Education Program (FEP) from 2002 to 2011 with the total budget of US\$ 224.25 million. The objective of the program was to increase access to basic primary education and improve the nutrition and health of children within regions with food deficits and low access to education. Partnering with the United Nation Population Fund, the MOE undertook the Population Education Program over the period 2008 to 2010 with the total budget of US\$ 2.2 million. The goals of the program were to i) include reproductive health issues in school curriculum ii) develop policy programs for gender equity, and iii) increase national support for gender equity.

There are many programs that are on-going. For example, with the partnership of the Asian Development Bank (ADB), the Ministry has been implementing the Skills for Employment Project (SEP) since 2005 with a total budget of US\$ 25 million. The project's specified aims are to: i) increase access to market oriented short-term skills training particularly for women, Dalits (oppressed caste) and the disadvantaged ii) strengthen training for providers to enhance access and improve the relevance and quality of training, and iii) develop and articulate a new national policy to achieve greater integration, relevance and efficiency in the Technical Education and Vocational Training (TEVT) sector. Another ongoing project being implemented since 2007 and with the assistance of the World Bank is the Second Higher Education Project (SHEP). The project has a total budget of US\$ 60 million with goals to: i) enhance the quality and relevance of higher education and research through a set of incentives for promoting effective management 
and financial sustainability of academic institutions, and ii) improve access for academically qualified under-privileged students, including girls, Dalits and educational disadvantaged Janjati to higher education through financial assistance and enhancing the capacity of higher secondary schools. Another big and important project that the MOE has been implementing since 2009 with the help of the World Bank, ADB, Denmark and Norway is the School Sector Reform Program (SSRP). With a total budget of US\$ 2,626 million, the project aims to: i) strengthen the policy-

making process in education ii) reform the educational sector through an integrated approach and iii) expand and consolidate the concept of Education for All (EFA) best practices and lesson learnt, and iv) build the capacity of stakeholders.

There are various agencies under MOE at the central, regional, district and local levels that help in the functioning of these efforts to achieve the Ministry's objective and goals. This is presented in Table A.1 of the appendix section.

\section{Department of Education}

One of the principle agencies under the MOE is the Department of Education (DOE). The DOE was established in 1999 to institutionalize and regularize activities related to the Basic and Primary Education Program (BPEP). After the establishment of the Department, most of the activities performed by the BPEP were shifted to the Department and the BPEP as a project ceased to function. Due to this, basic and primary education related activities carried out by the Department were also referred to as BPEP II. Presently, the Department, with its direct line of command with the regional and district offices and with full administrative and financial authority takes the responsibility off implementing and monitoring educational programs in the country. The Department is headed by the Director General, a gazetted first class senior officer 
belonging to education service cadre. The five Regional Education Directorates (REDs) and 75 District Education Offices (DEOs) fall under DOE and perform their tasks to meet the Department's objectives. The Department has the following three divisions each headed by a director, a gazetted first class officer: i) An administration division ii) A planning and monitoring division, and iii) An educational management division. The main role of the administrative division is to take responsibility relating to general and personnel administration, financial administration, educational materials distribution and physical services. The planning and monitoring division is in charge of planning, monitoring, research and development. Finally, the educational management division is entrusted with the responsibility relating early childhood education, basic and primary education, women's education, special education and educational statistics. The roles of the Department of Education as specified by the Ministry of Education include: i) providing equal access to education ii) developing quality reforms iii) improving internal and external efficiencies, and iv) developing education as a development-friendly venture. Soon after the establishment of the Department of Education, a few important programs were put forth. For basic and primary education, these programs included improvements of access to primary education, school management, and the upgrading of teachers' standards at the primary level. In terms of increasing women's access to education, the programs included increasing female enrollment, encouraging greater numbers of educated women to go into teaching as a profession, increasing the competition rate of the primary education of female students, and providing scholarships to female students at various levels. Finally, to improve general literacy levels, a campaign was instituted to eliminate illiteracy altogether (MOE, 2010). According to the education regulations of the DOE, public or government-aided schools are managed by School Management Committees (SMCs). The compositions of SMCs, 
academic content, textbooks, and examination systems are uniform throughout the country. The DOE is also responsible for appointing the teachers, including the head-teachers. In addition, the DOE nominates the District Education Committee (DEC) which in turn nominates the SMCs.

The government District Office, within the DEC, is headed by a District Education Officer in all of the 75 districts in the country. In fact, this is the most influential unit that designates tasks for each school to implement. It is the responsibility of the DEC to set the school calendar, provide teacher salaries, organize teacher training programs, perform supervisions, and audit the school accounts (MOE, 2010).

\section{Other Agencies under the Ministry of Education}

There are other important agencies that were established to help the MOE set its objectives. For example, National Center for Educational Development (NCED) was established in 1993 along with the nine Primary Teacher Training Center (PTTCs) in various parts of the country at the recommendation of the National Education Commission, 1992. Since 2004, the NCED has been the main body under the MOE that is responsible for human resource development in the education sector. Presently, the NCED conducts training programs through its 34 Educational Training Centers (ETCs) established at different strategic locations of the country. Another important academic institution under MOE is the Curriculum Development Center (CDC), which was established in 1997 with an aim of designing curricula and textbooks along with other instructional materials for school education. This center conducts annual as well as periodical discussions, interactions and dissemination programs on the usefulness of the instructional materials. In addition, it also conducts research-oriented programs to make education relevant, practical and competitive. 
The Office of the Controller of Examinations (COE) established as the secretariat of the SLC board in 1934 operates and manages the School Leaving Certificate (SLC) examinations in the country. Although the OCE mainly conducts the SLC examinations, it also organizes shortterm trainings, workshops, seminars and carries out researches related to school level evaluation system. In the non formal sector, Non Formal Education Center (NFEC) was established in 1951 along with Adult Education Section within the MOE in order to carry out adult literacy programs in the country. The center has been taking the responsibility of all non-formal education programs, primarily the basic literacy program as the only scheme for reducing illiteracy in the country. The agency under the MOE that keeps the record of public school teachers is called School Teacher Record Office (STRO). Established in 1998, the major functions of the STRO is keeping and provision of necessary data and information related to the permanent teachers of the community (public) schools. It also helps to facilitate delivery of post-service benefits to retired teachers like pension benefits, gratuities, family allowances, education allowances and children's allowances. The Teacher Service Commission (TSC) was established in 1999 to make recommendations to the government for the permanent appointment and promotion of the teachers of public schools. The commission provides the teaching license necessary to the candidates for securing the post of a teacher, and also provides suggestions on the issues related to service terms and conditions and facilities for the teachers.

With the introduction of the New Education System Plan (NESP) in 1971, the Regional Education Directorate (REDs) was established with the purpose of enhancing the efficiency of educational administration processes as well as to bring these closer to the people and the school. The five REDs are located in the 5 development regions of the country and are responsible for bringing out uniformity in district level programs and for coordinating, monitoring and 
supervising the school level teaching learning as well as development activities within the region. For the district level offices in the educational administration, the District Education Offices (DEOs) are established in each of the 75 districts of the country. With a major role to facilitate the task of school administration and supervision, each district is sub-divided into different supervision clusters ranging from 3 to 27 on the basis of school population and geographic locations. A Resource Center (RC) is established in each of the cluster with a Resource Person (RP) to provide professional support and services to the schools within the cluster. RPs are selected among the teachers of RC catchments areas. Presently, there are altogether 1,053 RCs through out the country, which are supervised, evaluated and monitored by a School Supervisor.

The Higher Secondary Education Board (HSEB) is responsible for the 10+2 education system in the country. Established in 1989 under the Higher Secondary Education Act, the board works towards the needs for addressing middle level manpower requirements and for importing necessary knowledge and skills to those students who want to continue their education at the undergraduate level. In the higher education division, the supreme body is the university senate, which is responsible for making policy decisions. The University Grants Commission (UGC) established under the University Grants Commission Act 1993 assists the government in managing the fiscal aspects and funding policies of higher education. The commission's major role is the proper allocation of grants obtained from different sectors for the management and development of the Universities in the country. Tribhuvan University, established in 1959 is the first university in the country. It was only after the establishment of this University that higher education within the country was available to the general Nepalese people. Presently there are five other universities located in different parts of the country. The main institution for 
conducting educational research in Nepal is the Center for Educational Research, Innovation, and Development (CERID), which is affiliated with Tribhuwan University. The CERID is headed by an Executive director and undertakes educational research projects, including collaborations with several foreign institutions. Likewise, commissions like the Nepal National Commission for UNESCO, established in 1954 that functions under the chairmanship of the education minister has been serving the Ministry in establishing mutual relationships amongst the member states of the UNESCO. The commission also advises the government of Nepal in the field of education, science, culture, social and communications that is within the jurisdiction of UNESCO (MOE, 2010).

In the private sector, the Private and Boarding Schools' Organization, Nepal (PABSON) is an active and widespread umbrella organization of Private and Boarding Schools in Nepal. It was established in 1991 AD and registered with the Government (the then HMG) of Nepal. PABSON is guided by its own constitution and acts as an umbrella organization for all its member schools. It performs its functions through various central, regional and district committees, sub-committees and departments, duly elected as per the provisions of its constitution. The PABSON is also acting as a nodal agency in coordinating with various government agencies, non-government agencies and other stake holders on all matters pertaining to school education, especially those concerned with private sector education. In addition, the other functions of the PABSON are i) coordinating with all education stake holders in trying to resolve all issues relating to private schools including framing policies to control private schools ii) determining criteria for basic fees structuring iii) protecting private investment in schools iv) safe guarding the interests of employees, and iv) ensuring the discharge of social responsibilities by private schools. 


\section{Education Expenditure and Finance in Nepal}

The government of Nepal has specified that the educational budget is distributed in the schools across the countries in the following ways (SMAERC, 2009). The first and the most usual method is called 'incrimination'. In this method, the budgeting decisions (increase or decrease) in education or some particular sub-sector for a particular year is done on the basis of the previous year. The second is called 'formula funding'. The kind of budgeting is based on some rationale so it is distributed only on the basis of some specified objective principle with emphasis on equitable opportunity, responsibility and accountability. The third is called 'program budgeting' with a special focus on a specific program. In this type of budgeting, the budget is allocated in such a way that it is sufficient to cover all expenditures required by the specified program. The fourth is the hybrid or mixed strategy, where resources are managed and mobilized in more than one way.

From 1975-1990, Nepal spent about 10 percent of its annual budget on education and this increased to 13 percent in the Eighth Five-Year Plan during 1992-1997. As a percentage of the Gross Domestic Product (GDP), this spending ranged between 1.3 percent and 2.0 percent between 1975 and 1990 (MOF, 2004). After 1990, these figures improved to a significant level. Table 2.5 reports data on the educational budget from 2000 to 2010. As seen in the table, the national effort on education (percent share of education in GDP) has slowly been increasing over the years. For example, in 2000, it was 2.5 percent and it was 3.8 percent in 2010 . The percentage of the government budget allocated to the education sector has been 15.3 percent on average in the last decade. At present, 16.3 percent of government budget is allocated to the 
education sector. The growth rate of the educational budget is also constantly increasing over the years with the ten-year average being 16.81 percent. The subsector distribution is dominated by primary education, which is more than 60 percent of the total education budget.

Table 2.5. Education Budget

\begin{tabular}{cccccc}
\hline $\begin{array}{c}\text { Fiscal } \\
\text { Year }\end{array}$ & $\begin{array}{c}\text { National } \\
\text { Budget (N.Rs) }\end{array}$ & $\begin{array}{c}\text { Education } \\
\text { Budget (N.Rs) }\end{array}$ & $\begin{array}{c}\text { \% of GDP } \\
\text { in } \\
\text { Education }\end{array}$ & $\begin{array}{c}\text { \% of } \\
\text { Education } \\
\text { Budget }\end{array}$ & $\begin{array}{c}\text { AGR of } \\
\text { Education } \\
\text { Budget }\end{array}$ \\
\hline 2000 & 77238226 & 10176074 & 2.5 & 13.17 & - \\
2001 & 91621335 & 11749579 & 2.8 & 12.82 & 15.5 \\
2002 & 99792219 & 14072847 & 3.0 & 14.1 & 19.8 \\
2003 & 96124796 & 14402421 & 3.1 & 14.98 & 2.3 \\
2004 & 102400000 & 15613274 & 3.1 & 15.25 & 8.4 \\
2005 & 111689900 & 18059654 & 3.5 & 16.17 & 15.7 \\
2006 & 126885100 & 21250447 & 3.6 & 16.75 & 17.7 \\
2007 & 143912300 & 23005525 & 3.7 & 15.99 & 8.3 \\
2008 & 168995600 & 28390000 & 3.6 & 16.8 & 23.4 \\
2009 & 236015897 & 39086407 & 3.7 & 16.56 & 37.7 \\
2010 & 285930000 & 46616672 & 3.8 & 16.30 & 19.3 \\
\hline
\end{tabular}

Source: MOE (2010), EFSF (2009)

Note: AGR= Annual Growth Rate

The major portion of government expenditures for school education in Nepal is usually spent on teacher and staff salaries and fringe benefits. For example, a study by Center for Educational Research, Innovation, and Development in mid- nineties found that in public primary schools, the expenditure on teacher and staff salaries was 86 percent, as compared to 63 percent in private primary schools. In public secondary schools, this expenditure on salaries was found to be 76 percent in the public sector as compared to only 52 percent in the private sector (CERID, 1996). A more recent paper by Ministry of Education by EFSG (2009) has stated that out of the total grants that a public school receives in an academic year, around 80 percent goes 
to teacher salary and construction support. The study also points out that the expenditure on teaching learning materials, capacity development of teachers, library development and computer education is very small.

\section{Financing of Education in Nepal}

The first modern school, Durbar High School was established in Nepal during the Rana regime in 1853 . The school was initiated with the view to providing education mostly to the children of the ruling class, but was not for the common people. School education was financed mostly by the national treasury and partly by community households. Besides this school-based education, the practice of home-based tutoring was also established where this would be financed by the households alone. This system still seems to be in practice, though in a somewhat modified way.

When the democracy was established in the country in 1951, the financing of education evolved in two ways: i) community financing in the case of schools established by the public, and ii) through a system of joint financial contribution - shared by the community (parents) as well as the government, in the case of government supported schools (SMAERC, 2009). The National Education System Plan was introduced in 1971. After this, schools that were established and run by community financing were transformed into government-owned entities, and were financed mostly by the government and partially by the parents through the tuition fees. However after 1980s, a more liberal approach was established by the government where new schools were allowed to open as a result of the efforts of the community or by private initiatives. Hence, with the introduction of the private schools in the country, there was a clear distinction on 
the two types of financing: government financing and parent/student financing. This system has remained in practice to the present time.

There are basically two types of financial assistance organized by the government and provided to public (community) schools. The first is earmarked grants. This includes teachers' salary, free textbooks (only for primary level), scholarships, remuneration for early childhood development programs and pre-primary classes. The second type involves block grants, which include the school's cost of administrative expenses, expenditures related to infrastructure development (based on school improvement program) and educational materials. Out of the total number of grants that a school receives in an academic year, around 80 percent goes to teacher salary and construction support. The private schools do not get any sort of financial assistance from the government.

The educational budget in Nepal is financed by two sources: the government of Nepal and foreign aid, which is received as grants or loans. There is a donor harmonization process in place as well for supporting the educational sector in Nepal. The development partners supporting the education sector have formed a consortium with pool and non-pool donors. Presently, there are 11 external donor partners involved in pool and two other donors (JICA and UNICEF) are involved in parallel funding. Table 2.6 provides data on foreign aid in the education sector in Nepal from 2000 to 2010. In 2010, 69 percent of the educational budget was financed by the government and the remaining 31 percent was financed by foreign aid. In the primary education budget alone, the foreign donations contributed to around 35 percent financing. Within the total foreign aid for education, 77 percent was grant funding and 23 percent was in the form of a loan. The growth rate of foreign aid in education has been increasing over the years, except in 2001 and 2002 where the growth rates were negative. In 
2009 , the annual growth rate of foreign aid was as high as 42 percent. The table also indicates that the percent of foreign aid in education improved from the low twenties to the high twenties after 2004 with the present share being as high as 30 percent. This shows that Nepal is still financially dependent on foreign donors for its educational budget. Unfortunately, this has undermined self-sustenance, increased foreign debt with heavy interest payments, and led to pursuance of donor-driven agendas.

Table 2.6. Foreign Aid in Education

\begin{tabular}{cccccc}
\hline Year & $\begin{array}{c}\text { Total FA in } \\
\text { Education }\end{array}$ & $\begin{array}{c}\text { \% of FA in } \\
\text { Education }\end{array}$ & $\begin{array}{c}\text { AGR FA in } \\
\text { Education }\end{array}$ & \% grant & \% loan \\
\hline 2000 & 2648268 & 26.02 & - & 57.70 & 42.30 \\
2001 & 2586095 & 22.01 & -2.3 & 65.79 & 34.21 \\
2002 & 2462706 & 17.5 & -4.8 & 85.17 & 14.83 \\
2003 & 2894966 & 20.1 & 17.6 & 73.06 & 26.94 \\
2004 & 3228318 & 20.68 & 11.5 & 67.31 & 32.69 \\
2005 & 5438077 & 30.11 & 68.4 & 56.49 & 43.51 \\
2006 & 5784145 & 27.22 & 6.4 & 64.51 & 35.49 \\
2007 & 6586495 & 28.63 & 13.9 & 61.12 & 38.88 \\
2008 & 7754090 & 27.31 & 17.7 & 71.56 & 28.44 \\
2009 & 11010323 & 28.17 & 42 & 73.94 & 26.06 \\
2010 & 14553823 & 31.22 & 18.2 & 76.70 & 23.30 \\
\hline
\end{tabular}

Source: MOE (2010)

Note: $A G R=$ Annual Growth Rate; FA = Foreign Aid

The major international donor agencies are the Nordic countries, Japan, the UK, European Union, World Bank and the Asian Development Bank (Carney \& Bista, 2009). The first major intervention in the primary education sector took place with the Basic and Primary Education Project (BPEP) in 1992 with the help of an international donor agency. The goal of 
this intervention was to provide better access, quality and efficient management in the education system. In recent years, the World Bank has been assisting Nepal in decentralizing the management of education and in improving the quality of education. For example, with the help of the World Bank's support, the government of Nepal launched the Community School Support Project (CSSP) in 2003 with the aim of increasing the role of parents on school management communities (SMCs). Taking the initiative for this project, the government has been successfully transferring public schools to community managed schools ${ }^{10}$. According to the World Bank's project assessment report, the number of Nepalese schools transferred by March 13, 2009 was 8,002 (World Bank, 2009). Some of the major achievements that the report claims are an increased enrollment in primary schools and a reduction in numbers of out-of-school children between 5-15 years old in the service areas of CSSP (World Bank, 2009).

\section{Challenges and Problems in Education Finance}

There are a few important challenges related to financing of education in Nepal. With regards to government's funding through grants to school, the delivery does not always occur in a timely fashion. Further, funding to schools does not always respond to the schools' needs as expressed in their plans, and funding by local bodies is inconsistent across the country. In addition, there is inadequate monitoring of how schools expend their funds. For example, schools inflate student numbers to receive funding for students above the prescribed student teacher ratios (EFSG, 2009).

\footnotetext{
${ }^{10}$ Community managed schools are unaided public school, which do not receive regular government grant, but runs with support from community, donations from other sources and school's own resources. For more on community managed schooling in Nepal see World Bank (2003), Carney (2003), Carney \& Bista (2009) and World Bank (2009).
} 
Besides these issues, there are several other serious concerns. The first relates to ensuring financial sustainability in the management of the schools. The budget allocated by the government is surely insufficient for running schools. The local authorities cannot levy taxes to support schools and primary schools are not allowed to charge fees of any kind. As a result, insufficient financial support has been always a big problem in public schools. Furthermore, due to the same financial constraint, the expansion of quality education in the public schools has been a huge challenge. The second challenge is tying up teacher salary and teacher performance. The present system does not provide teacher salary and allowances based on their performance. This is the reason why despite continued increases in investment in education the quality of public education has not improved comparably. Finally, the 'block grant' provided on the basis of the numbers of students in a school is not very scientific. This is not beneficial for those schools in remote areas with low number of students. In such cases, it is likely that resource poor schools receive fewer grants than resource rich schools (SMAERC, 2009).

Studies thus point out that inadequate resources and low administrative efficiency are two major problems related to the financing of the educational system in Nepal (Bhatta, 2004; SMAERC, 2009). These inadequate resources have an adverse effect on physical facilities, teachers and equipments needed for schools. Due to this deficiency of funds, the physical facilities are often in dilapidated conditions. The government provides salaries to teachers and is also responsible for the cost of continuing teacher training programs. Therefore, upgrading the skills of the teachers is always a problem. In addition, the teaching and learning materials such as materials for on science education are always inadequate. The government provides education up to the $10^{\text {th }}$ grade free of charge. However, many schools charge "non-tuition" fees to students to sustain their programs. As a result, the government's intention to provide free education hasn't 
been so helpful. The government also supports higher education by charging very minimal fees to the students. This too has added to the burden placed on governmental resources.

\section{Current Situation and Issues}

Although the interim constitution of Nepal 2007 has not made any direct reference to education financing, it mentions basic education as a fundamental right of all citizens and also emphasizes that every citizen shall have the right to a free education from the State up to secondary level. With the School Sector Reform Plan (SSRP) effective since 2009, the basic level of education has expanded to include grades 1 to 8 . The plan lists the following requirements for education funding (EFSG, 2009):

- The need for 85 percent of total education expenditure to be applied to comprehensive school education $(0-12)$.

- The suggestion that 4 percent of GDP and 20 percent of national expenditures be allocated to education.

- The need for 76 percent of the total education expenditure to be applied to basic education.

- The need for 37 percent of the cost of the SSRP to be met by donors.

Nepal is moving from a unitary system to federal structure of government. In this connection, the service delivery approaches and modalities including education service delivery are expected to be reshaped corresponding to functional structure of federalism. To facilitate the discussion on how education should be managed and financed in a federal state, the Education and Federalism Support Group (EFSG) was formed with the help of UNESCO Kathmandu. Some of the major recommendations made by EFSG (2009) are as follows: 
- The funding of school and vocational education should be the responsibility of the provincial governments, and the funding of higher education needs to be the responsibility of the federal government.

- Teachers should be recruited by local authorities but paid by provincial governments.

- The federal government should fund textbooks, provide assistance to poor families, programs targeting increased participation and research and development.

- With regard to revenue, provincial governments should determine education taxes.

- Regulation of private schools should be the responsibility of provincial governments.

- Donor coordination should be the responsibility of the federal government but should respond to the needs of provinces as expressed in related project plans.

\section{Public and Private Schools in Nepal}

In Nepal, schools that are financed, managed and regulated by government are defined as government or public schools, whereas schools that are financed, managed and regulated by parents' association, business, non-profit organization or a religious institution are defined as private schools. The Ministry of Education of Nepal categorizes public schools into two types: i) Aided community (public) schools, which receive regular government grant for teacher's salary and for other administrative purposes; ii) Unaided community (public) schools, which do not receive a regular government grants, but are financed with support from community, donations from other sources and school's own resources. Private schools are defined as institutional schools that do not receive regular government grants. This dissertation includes 
both aided and unaided community (public schools) schools under one broad category of public schools.

Public schools are commonly associated with low achievement, poor infrastructure and facilities, low quality teachers and weak management and regulation. Studies have shown that in terms of students' cognitive development, public schools in Nepal have struggled to add value (Caddell, 2006; Carney, 2003). Government plans for education have continuously failed in spite of extensive educational intervention. The schools suffer from inadequate access, low participation, low retention of students (at all levels), and low levels of educational quality. Moreover, inequalities in various regions and social groups are increasing. The school systems have limited managerial capacity and inadequate institutional support and financing. Apart from poor teacher quality, political interference in teacher appointments and transfers have contributed towards the low morale and disenchantment found in the public education system (Carney, 2003).

Private schools in Nepal vary in terms of size, mission and influence. However one can find a number of common factors in such schools. Unlike private schools in the U.S., which are non-profit schools, private schools in Nepal (as in many developing countries) are for-profit schools. Apart from profit, these schools cater towards higher levels of academic achievement preparing for national examinations. In spite of the Education Act, which requires the Nepali language as the medium of instruction, these private schools use English as the primary language of instruction. Most private schools adopt autocratic management systems where community stakeholders are kept away from discussions about how their children's education relates to broader national educational goals (Carney, 2003). Private schools in Nepal, especially those in 
the Kathmandu valley, charge the fees they desire for their educational services. There does not seem to be any strict regulation on fees charged by these private schools in the country.

Besides the ownership distinction, private and public schools in Nepal also vary in several other ways. The first is on how much resources are available and how are they employed in these schools. For example, an analysis of average cost per student between community school and institutional school based on a study of 17 schools of all five regions of the country by Santwona Memorial Academy Educational Research Center (SMAERC, 2008) shows that there is a significant gap in the cost structure between public and the private schools. Their report points out that on average an institutional school spends 215.3 percent higher than community school. According to the study, the average cost per student in public school is Rs.4, 675 while it is Rs.14, 739 in private school. This indicates that private schools spend much more on students' education besides other expenditures made on infrastructure and physical facilities as compared to public schools. The study argues that private schools have managed such facilities better than those of public schools.

The second feature that clearly distinguishes public schools from private schools in Nepal is the quality of teachers and teaching facilities used in schools. In the public school system, although School Teacher Record Office (STRO) is responsible for keeping the record of public school teachers, the monitoring and supervision of teachers is evidenced to be very poor. As a result, teacher absenteeism is a serious concern in public schools. In terms of teaching facilities, although most of the public schools seem to have their own buildings and premises they are left behind in terms of use of modern teaching equipment such as use of science laboratories and computers as compared to private schools (Bhatta, 2005; SMAERC, 2008). 
The third feature relates to the monetary and non-monetary parental contribution and involvement in school matters. In terms of monetary contributions, parental contributions are higher in private schools as they have to incur tuition fees in addition to all the other costs such as costs relating to books, school dress, stationeries and hostel fees where applicable. When it comes to non-monetary contributions, parents whose children go to private schools are usually more active in school matters. The private schools have do conduct parent-teacher meetings frequently, whereas such meetings hardly exist in case of public schools. Parents, in the case of private schools are more involved not only in terms of their child's grade, but also in terms of their performance in class and participation in extra curricular activities.

The fourth feature that distinguishes public and private schools are student's demographic characteristics. Students in private schools are usually from richer and medium class family, and belong to the higher caste. Students in public schools are mostly from medium class or poor families. The majority of the students from the lower class and disadvantaged families go to public schools. In this way, when it comes to the learning aspect, the impact of positive peer effects is greater in the case of private schools than public schools.

Apart from the above mentioned features, there are various immeasurable factors that place students from private schools in a more advantageous position than students from public schools in terms of educational outcomes. Some of them are as follows.

School Management and Climate: Private schools are competitive in nature and hence school management is much orderly and organized. In contrast, studies show that many public schools are not properly managed. For example, although public schools are endowed with bigger pieces of land and buildings in many cases, the lack of use and wastage of resources is rampant in public school (SMAERC, 2008). In private schools, the school runs on its specified schedules 
and the various departments of the school usually have a teacher or person in charge that is responsible for ensuring the smooth functioning of the departmental activities. The teachers and the students follow the rules, and hence there is a proper learning environment in the schools. But, in most of the public schools, as teachers themselves fail to set good examples in following the rules and school schedules, students overlook the set rules and regulations of the school. As a result, the school climate is not very encouraging in public schools. Also, the grade promotion system in private schools is more stringent, whereas it is rather liberal in case of public schools (Bhatta, 2005). As a result, many weaker students in public schools do not make extra effort to improve their academic performance. Likewise, in terms of homework completion for students and course completion for students, private school management is far better as compared to relaxed public school management.

Motivation and team work: Teacher salaries in public schools are based on the type of academic degree the teachers hold, and not on their performance. As a result, in most of the cases, teachers lack motivation and team-spirit to work for the betterment of the school and the students. This is reciprocated to the students as well, and they too lack motivation and the zeal for achieving higher grades. But, in the case of private schools, schools compete to place themselves in top list of private schools in their locality. Although private school teachers are found to be less well off in terms of salary and fringe benefits, the teachers still seem more connected and goal oriented. This could be because of better working conditions and prestige. Further, many private schools do pay their teachers based on their experience and performance. This creates a competitive market for private teachers. At the student level, the level of motivation is different in the two school types. As private schools use English as medium of instruction and promise parents an 
education equivalent to international standards, the goals and aspirations of private school students are much higher as compared to the students from public school (Caddell, 2007). Home and community environment: Home and community environment are another important factors that affect student's academic outcome but are not necessarily measured. For example, private school students come from families with better socioeconomic backgrounds as compared to public school students. Families with better socioeconomic backgrounds have more educated family members, and have a lot of learning opportunities in their social life too. Likewise, community environment matters too. A peaceful community and a community with better facilities that has more schools, more libraries, more coaching centers and more educated neighbors definitely adds a great deal of value in student's learning. Students who go to private schools seem to be exposed to these positive externalities more than students from public schools.

Political influence: Finally, the incidence of political interference is another distinguishing feature between private and public schools in Nepal. Public schools teachers as well as students are more involved in politics than teachers and students from private schools. During the Maoist insurgency from 1996 to 2005, both types of schools were affected in different ways. However, public schools were directly affected to the extent that in some places the whole infrastructure of the schools was destroyed during the 'people's war' and school principals and teachers were badly harassed (see Caddell, 2006; 2007).

These unobservables make a lot of difference and hence need to be noted while estimating and comparing educational outcomes of public and private school students. The findings, as a result of these unmeasured factors are likely to be biased in favor of private school students. Hence, there should be appropriate mechanisms to account for these biases. Though 
this problem is very tricky and cannot always be accounted for fully, this study makes some attempts to account for these factors. This is discussed in more detail in the data description section of Chapter 3 and methodology section of Chapter 4 of this dissertation.

\section{Private Schools: Evolution and Current Issues}

In the post 1990 period, private schooling expanded at a dramatic pace, both in terms of numbers and in relation to the student base it was directed at. The public took it as an opening to a whole new world of educational opportunities. There were many important changes happening in the country during this phase in the education sector. For example, most of the private schools started to adopt the English-medium as the mode of instruction in their schools. This not only made student and teachers involved in private schools feel connected and exposed to the world outside, but also contributed to the differentiation among the private schools themselves. Another striking feature of private schools as observed by many researchers was that the regulation of the market was missing and there was lack of controls on both the number of schools established and the quality of the facilities and tuition they provide (Caddell, 2007; Carney \& Bista, 2009). Since then, there have also been many attempts to integrate private school registration into wider educational planning processes. Unfortunately, this has not been successful so far

Over the last decade, especially during the Maoist insurgency in Nepal, the issue of relations between the state and private schools has been one of the serious political concerns at the national level. As the Maoists place more political pressure for tighter controls in education sector, private school associations were forced to sit in on discussions with the government, the public and directly with the Maoists. This persuaded private schools to remodel their mode of operation, the teaching curriculum and fees they charged. For example, after the indefinite strike 
of 2002 was called off, from the PABSON side, a fee structure for private schools was developed, with schools differentiated in terms of the facilities they provided and were graded AD accordingly. The private schools were also demanded by Maoists to cut their fees by between 10 and 25 percent (Caddell, 2007).

However, as years have rolled by with the Maoists entering the mainstream politics, things have not improved much. There has not been a reduction in the fees in the private schools. Moreover, to the frustration of the public, disruptions in schooling still continue. And, there has been no evident improvement in educational quality in the public schools. As Caddell (2007) puts it, the possibility of a meaningful partnership between the government and private sector still remains unresolved due to the difficulty of engaging with the tensions between the profit and service-oriented motivations for operating private schools in the country. Most of the educational researchers agree that these debates are masked by the vested interests of the private school organizations representing wealthier educational enterprises as opposed to service-oriented NGOs and charity institutions (see Caddell, 2007; Carney \& Bista, 2009).

Table 2.7 gives us the overall picture of SLC students who participated in the SLC exam of 2004. Statistics on this year were especially chosen because the data analysis of this dissertation is based on the SLC exam of 2004. The table gives information on performance in SLC by school type and gender. Out of total students that appeared for the SLC exam in 2004, only 46.2 percent passed, with male and female passing rates of 40.6 and 50.2 percent respectively. The pass rate of private schools was 82.9 percent, where as it was only 36.4 percent for public schools. This clearly shows a huge difference in SLC performance between public and private schools, and between males and females. 
Table 2.7. Performance in SLC Exam -2004 by School-type and Gender

\begin{tabular}{llll}
\hline & Total No of Students & Female & Male \\
\hline Tested & 175418 & 73551 & 101867 \\
Pass & 81008 & 29850 & 51158 \\
Pass (\%) & 46.2 & 40.6 & 50.2 \\
\hline Public & Total & Female & Male \\
\hline Tested & 138636 & 58821 & 79815 \\
Pass & 50511 & 18106 & 32405 \\
Pass (\%) & 36.4 & 30.8 & 40.6 \\
\hline Private & Total & Female & Male \\
\hline Tested & 36782 & 14730 & 22052 \\
Pass & 30497 & 11744 & 18753 \\
Pass (\%) & 82.9 & 79.7 & 85.0 \\
\hline Soure
\end{tabular}

Source (MOES, 2005a)

\section{Teachers Market}

The teacher market in Nepal, like in most of the developing countries of South Asia, is different from that which prevails in developed countries. Teaching is not considered a preferred occupation, both in terms of economic benefit as well as social prestige. Unlike the situation in developed countries (for example, in the U.S), the state does not require teachers to take certification exams to enter the teaching profession. The teachers in the public schools are appointed by the government merely based on the candidate's educational degree. With regards to teachers in the private sector, their appointment is made without any influence of state regulation. As shown in Table 2.8, the percentage of untrained teachers in private schools is much higher than in public schools, especially at the primary and the secondary levels. For example, in 2009, the percentage of untrained teachers at the secondary level in public schools was 4.2 whereas it is 20.1 in the private schools (MOE, 2010). There is a very limited union 
representation of private school teachers, and their positions are not stable due to short term contracts. In most of the cases, private school teachers are paid more than public school teachers. However, in terms of benefits like pensions and job stability, in some cases, public school teachers are considered better-off. In other words, compared to other qualifications, these private school teachers would have earned more in other professions than in the teaching profession. But, since there is a lack of demand for these educated people in other sectors due to low infrastructural development in Nepal, they don't have any other option but to teach even though they are paid less in relation to their higher qualifications. In addition, there is a high level of political interference in the public sector, and hence many teachers join private schools. Moreover, as private schools have better working conditions and are more prestigious than public schools, many teachers like to join private schools compared to public schools even when the pay is lower. As a result of a high inflow of teachers and lower student enrollments in the private schools, the student-teacher ratio is much lower in private schools as compared to public schools. Table 2.8 also shows the student-teacher ratio by school type. Here we can see that at all levels of education; the student-teacher ratio is higher in public schools than in the private schools.

\section{School Leaving Certificate (SLC) Examination}

The School Leaving Certificate (SLC) examination is the most important school-level exam in Nepal and is administered and controlled every year by the Controller of Examinations

Division of the Ministry of Education, Nepal. This exam is equivalent to a $10^{\text {th }}$ grade final exam and is mandatory for all the students in the country who wish to continue their higher education 
$(10+2$ and college). The examination consists of six mandatory subjects (English, Nepali, Compulsory Math and Science, Social Studies, and Health \& Population Studies) and two elective subjects which are chosen by schools. The total score for each of these subjects is 100 while the passing score is 32 . A student has to pass in all of these eight subjects to be considered having 'passed' the SLC examination. This exam is evaluated on a percentage basis ${ }^{11}$. Students who score less than 45 percent are given a 'third division' rating, students with a score in the range of 45 to 60 percentages are given a 'second division' rating, students with scores in the range of 60 to 79 percentages are given a 'first division' rating, and finally students with scores that are 80 percent and above are given a 'distinction' rating.

Besides acting as a gateway for higher education, for many people this examination is also important as a credential for entering the labor market. Therefore, the performance of students in the SLC examination has been a matter of great concern to both students and parents alike. In addition, the SLC examination is also viewed as an indicator of school quality by both the general public and the government (Bhatta, 2005). As a result, these exams have also been influencing the pedagogical approaches and course contents in schools in the country (Singh, 2004). For example, the questions that appear in the SLC test papers tend to guide much of the teaching and classroom practices in many secondary schools. The government also views this exam with utmost importance. Since formal public examinations are aimed at evaluating not just individual achievement but also the performance of individual schools and the school system as a whole, the SLC exams are viewed as the primary measure of success of the government's educational reform efforts (DANIDA, 2003). As a result, education researchers and policy

\footnotetext{
${ }^{11}$ There is no 'grade system' in the SLC examination yet. The grade system is used only in higher secondary and college level, mostly by the private institutions.
} 
makers who are concerned with school reform believe that improving the system of SLC examinations is a critical step in upgrading the quality of education in Nepal.

Table 2.9 presents the number of students who were tested and the percentage who passed the SLC exam from 1990 to 2009. The table shows that the number of students appearing for the SLC exam has been increasing over the years. The unusually large number of SLC candidates in 2000 was due to decision of Office of Controller of Examinations (OCE) to allow all exempted students to participate as regular students during that year. This provision was made to facilitate the transition of the SLC curriculum and grading system from the then-exiting 900 and 700 point systems to the current 800 point system (Bhatta, 2004). In terms of student performance, as seen in figure 2.3, the national trend in SLC student performance has been quite discouraging over the years. The data reveals that although the proportion of students passing the SLC exams has been fluctuating, it is limited to about $30-40$ percent for most of the years from 1990 to 2009. The drop in pass rate of 2001 could be due to the result of the change of SLC format in the year 2000. Other fluctuations could also be attributed by frequent interventions in the education sector due to the Maoist war with the then government of Nepal. After 2006, there has been a little improvement with the pass percentage rising above fifty. This could be more likely due to the end of Maoist guerilla war in 2005. Table, 2.10 gives more detailed information on more recent year (for SLC year 2009). In 2009, 427,051 students sat for the SLC exam and 64.3 percent passed in the regular type. The rate of passing the exam for males and females were 67.6 and 64.6 percent, respectively. The drop out rate was 1.2 percent, with male and female drop out rates of 1.1 and 1.3 percent respectively. The table also shows that 0.7 percent of the results were withheld and 0.1 percent cancelled (MOE, 2010). The drop out rates has been below 2 percent over the years. 
Although the drop out rates are not very high in the Nepalese case, high failure rates on the SLC exams and disparities in performance across school type are a matter of serious concern. Around 40 percent of the students still fail the SLC exam. This matter is discussed widely in the Nepali news media and other public forums, especially before and after the SLC exam every year. The major criticisms of the SLC exam in such forums as pointed by some research studies are related to: i) lack of technical quality; ii) the administration of the exams under varying conditions in different exam centers and in different parts of the country, and iii) systematic grading of the SLC exam (see CERID, 1996; Baily,1998; Bhatta, 2005). According to these studies, as a result of lack of properly trained test developers, the SLC exam test questions are weak in terms of reliability and validity. Further, the studies point out that one of the major factors influencing the SLC results of students is the exam grading process. Many of the examiners are not well trained in grading the exam, and the institutional mechanisms for assuring the quality of grading are not well developed. As a result, the SLC grading is not always fair and reliable (CERID, 1996; Bailey, 1998).

However, from a researcher's point of view, the SLC exam is very crucial as it gives a general picture of student performance at the school level. Moreover, the SLC exam is the only national level exam at the school level. This study capitalizes on this fact and analyzes the SLC data for 2004. The next chapter discusses the data source, data use and variable descriptions. 
Table 2.1. Basic Statistics of Nepal and South Asia

\begin{tabular}{|c|c|c|}
\hline & Nepal & South Asia \\
\hline Area & $\begin{array}{l}\text { 147, } 181 \\
\text { sq. km. }\end{array}$ & $\begin{array}{l}5.1 \text { million } \\
\text { sq. } \mathrm{km} \text {. }\end{array}$ \\
\hline \multicolumn{3}{|l|}{ Demographic Statistics } \\
\hline Population (in million) & 27.5 & 1567.7 \\
\hline Population gr. (annual \%) & 2.25 & 1.5 \\
\hline \multicolumn{3}{|l|}{ Economic Indicator } \\
\hline GDP per capita (in US dollars) & 473 & 3000 \\
\hline GDP gr. (annual \%) & 4.7 & 7.7 \\
\hline$\%$ share of GDP in education & 3.8 & 2.9 \\
\hline Population below poverty line (\%) & 55.1 & 40.9 \\
\hline Gini Index of Income Inequality & 47.3 & 39.3 \\
\hline \multicolumn{3}{|l|}{ Human Development Statistics } \\
\hline Literacy Rate (15 + years $)$ & 55.6 & 61.0 \\
\hline Male & 70.7 & 72.5 \\
\hline Female & 43.3 & 49.5 \\
\hline Life Expectancy at Birth & 64.1 & 64.1 \\
\hline Human Development Index & 0.428 & \\
\hline
\end{tabular}

Source: CBS (2010); UNDP (2010); World Bank (2010)

Notes: (1) GDP per capita is in US $\$$ constant prices in 2000 ; (2) poverty rate is given by $\$ 1.25$ a day (PPP) (\% of population). 
Table 2.2. Total Schools by School-Type, Level and Development Region

\begin{tabular}{|c|c|c|c|c|c|c|c|c|c|c|c|}
\hline \multirow{3}{*}{ Dev. Region } & \multicolumn{4}{|c|}{ Public } & \multicolumn{7}{|c|}{ Private } \\
\hline & $\mathrm{P}$ & $\mathrm{LS}$ & $\mathrm{S}$ & HS & Public & $\mathrm{P}$ & $\mathrm{LS}$ & $\mathrm{S}$ & $\mathrm{HS}$ & Private & Total \\
\hline & $(1-5)$ & $(6-8)$ & $(9-10)$ & $(11-12)$ & Total & $(1-5)$ & $(6-8)$ & $(9-10)$ & $(11-12)$ & Total & \\
\hline Eastern & 5840 & 1801 & 994 & 348 & 8983 & 782 & 395 & 300 & 125 & 1602 & 10585 \\
\hline Central & 7247 & 2307 & 1343 & 517 & 11414 & 2086 & 1495 & 1203 & 399 & 5183 & 16597 \\
\hline KV & 638 & 378 & 255 & 85 & 1356 & 1438 & 1129 & 915 & 280 & 3762 & 5118 \\
\hline Western & 6248 & 1868 & 1136 & 456 & 9708 & 1027 & 620 & 456 & 148 & 2251 & 11959 \\
\hline Mid Western & 4489 & 1317 & 653 & 220 & 6679 & 423 & 239 & 161 & 39 & 862 & 7541 \\
\hline Far Western & 3204 & 1156 & 589 & 226 & 5175 & 309 & 143 & 93 & 34 & 579 & 5754 \\
\hline Total & 27928 & 8449 & 4715 & 1767 & 42859 & 4627 & 2893 & 2213 & 745 & 10478 & 53337 \\
\hline
\end{tabular}

Source: MOE (2010)

Notes: (1) P, LS, S, and HS denote primary, lower-secondary, secondary and higher secondary respectively; (2) KV denotes Kathmandu Valley 
Table 2.3. Percentage of Public and Private School's Enrollment in Total Enrollment by Level and Development Region

\begin{tabular}{lcccccccc}
\hline & \multicolumn{4}{c}{ Public } & \multicolumn{5}{c}{ Private } \\
\hline Dev. Region & $\mathrm{P}$ & LS & $\mathrm{S}$ & HS & P & LS & S & HS \\
\cline { 2 - 8 } & $(1-5)$ & $(6-8)$ & $(9-10)$ & $(11-12)$ & $(1-5)$ & $(6-8)$ & $(9-10)$ & $(11-12)$ \\
\hline Eastern & 90.3 & 91 & 89.2 & 89.6 & 9.7 & 9 & 10.8 & 10.4 \\
Central & 81.4 & 75.1 & 71.9 & 75.1 & 18.6 & 24.9 & 28.1 & 24.9 \\
KV & 30.1 & 36 & 36.6 & 47.3 & 69.9 & 64 & 63.4 & 52.7 \\
Western & 82.7 & 83.3 & 82.4 & 75.6 & 17.3 & 16.7 & 17.6 & 24.4 \\
Mid Western & 92.6 & 93.4 & 92.4 & 92.3 & 7.4 & 6.6 & 7.6 & 7.7 \\
Far Western & 95 & 95 & 94.1 & 96.7 & 5 & 4.8 & 5.9 & 3 \\
Total & 86.8 & 85.2 & 83.1 & 82.6 & 13.2 & 14.8 & 16.9 & 17.4 \\
\hline Source: MOE (2010) & & & & & & & &
\end{tabular}

Notes: (1) P, LS, S, and HS denote primary, lower-secondary, secondary and higher secondary respectively; (2) KV denotes Kathmandu Valley 
Table 2.8. Percentage Trained Teachers and Student-Teacher Ratio in Public and Private Schools

\begin{tabular}{|c|c|c|c|c|c|c|c|c|c|}
\hline \multirow{2}{*}{$\begin{array}{l}\text { Training Status } \\
\text { Public Schools }\end{array}$} & \multicolumn{3}{|c|}{ Primary } & \multicolumn{3}{|c|}{ Lower Secondary } & \multicolumn{3}{|c|}{ Secondary } \\
\hline & & & & & & & & & \\
\hline & $\mathrm{F}$ & M & Total & $\mathrm{F}$ & M & Total & $\mathrm{F}$ & M & Total \\
\hline Trained & 82.5 & 77.1 & 79 & 68 & 56.2 & 58.3 & 84.2 & 84.9 & 84.8 \\
\hline Partial & 10.9 & 13.7 & 12.7 & 13.6 & 18.7 & 17.8 & 10.4 & 11 & 10.9 \\
\hline Untrained & 6.7 & 9.2 & 8.3 & 18.4 & 25.1 & 23.9 & 5.4 & 4.1 & 4.2 \\
\hline $\begin{array}{l}\text { Student- teacher } \\
\text { ratio }\end{array}$ & & & 36.5 & & & 48.9 & & & 36.1 \\
\hline \multicolumn{10}{|l|}{ Private Schools } \\
\hline & $\mathrm{F}$ & M & Total & $\mathrm{F}$ & M & Total & $\mathrm{F}$ & M & Total \\
\hline Trained & 53 & 62.1 & 57 & 68 & 56.2 & 58.3 & 74 & 70.2 & 71.1 \\
\hline Partial & 15 & 19.9 & 17.2 & 13.6 & 18.7 & 17.8 & 10.3 & 8.3 & 8.8 \\
\hline Untrained & 32 & 18 & 25.8 & 18.4 & 25.1 & 23.9 & 15.7 & 21.5 & 20.1 \\
\hline $\begin{array}{l}\text { Student- teacher } \\
\text { ratio }\end{array}$ & & & 17.4 & & & 19.3 & & & 12.3 \\
\hline
\end{tabular}


Table.2.9. Comparative Regular SLC Result (1990 -2009)

\begin{tabular}{ccc}
\hline Year & Appeared & \% pass \\
\hline 1990 & 64166 & 44.13 \\
1991 & 100382 & 48.47 \\
1992 & 94534 & 24.56 \\
1993 & 77455 & 31.49 \\
1994 & 79420 & 31.30 \\
1995 & 79588 & 42.97 \\
1996 & 90458 & 38.30 \\
1997 & 116002 & 36.52 \\
1998 & 113257 & 47.54 \\
1999 & 139202 & 49.20 \\
2000 & 205539 & 45.72 \\
2001 & 132210 & 31.62 \\
2002 & 152334 & 31.22 \\
2003 & 170389 & 32.05 \\
2004 & 175418 & 46.18 \\
2005 & 294216 & 46.50 \\
2006 & 347185 & 58.60 \\
2007 & 367041 & 63.70 \\
2008 & 388522 & 68.50 \\
2009 & 427051 & 64.30 \\
\hline Source: MOES (2005a), MOE $(2010)$
\end{tabular}

Table 2.10. Regular SLC Result 2009

\begin{tabular}{cccccc}
\hline & $\begin{array}{c}\text { Total } \\
\text { Tested }\end{array}$ & $\begin{array}{c}\% \\
\text { passed }\end{array}$ & $\begin{array}{c}\% \\
\text { dropped }\end{array}$ & $\begin{array}{c}\% \\
\text { withheld }\end{array}$ & $\begin{array}{c}\% \\
\text { cancelled }\end{array}$ \\
\hline Total & 385146 & 64.3 & 1.2 & 0.7 & 0.1 \\
Female & 179856 & 60.6 & 1.1 & 0.6 & 0 \\
Male & 205281 & 67.6 & 1.3 & 0.8 & 0.1 \\
\hline
\end{tabular}

Source: MOE (2010)

Note: Withheld and expelled are included in total tested. Absenteeism is not included in total tested. 
Figure 2.1. Map of Nepal

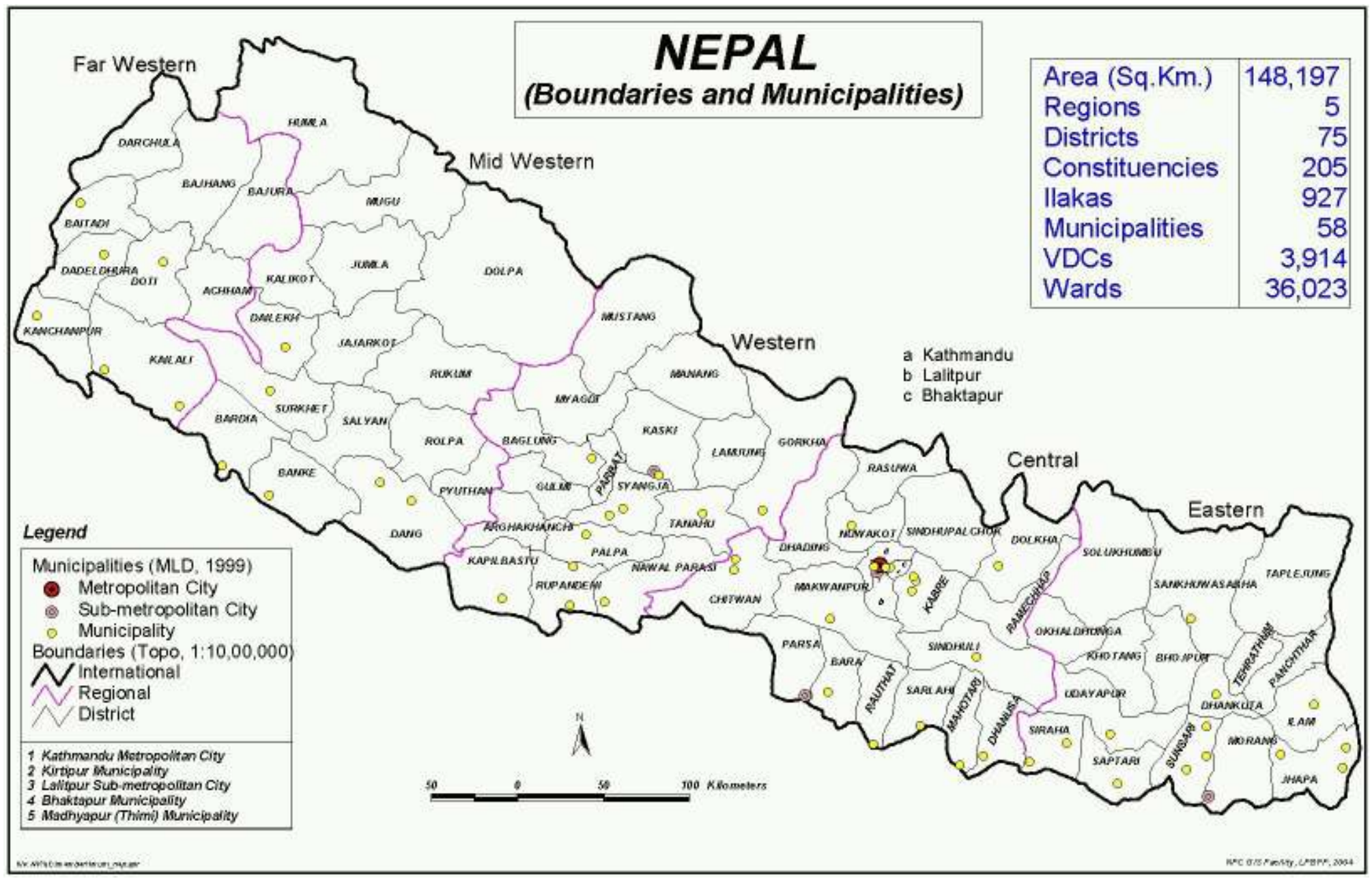

Source : http://www.un.org.np/reports/maps/npcgis/NatBio00004.jpg 
Figure 2.3. Comparative SLC Result: 1990 - 2009

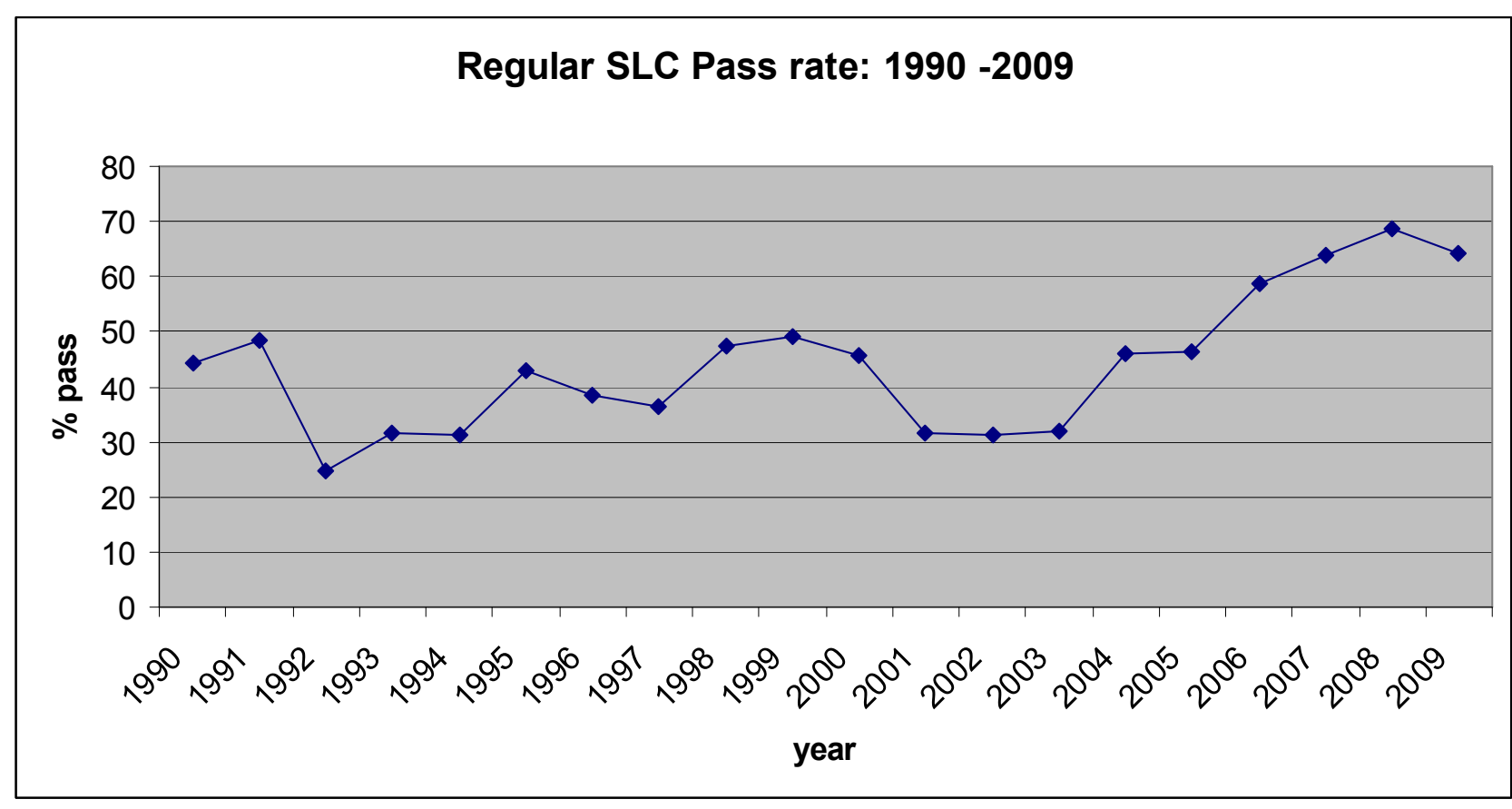

Source: MOES (2005a), MOE (2010) 


\section{Chapter III}

\section{DATA}

\section{The context}

As discussed in the introductory chapter, this dissertation seeks to answer two main research questions:

- Do private school students perform better than their public school counterparts after controlling for student, family, school and teacher characteristics?

- Keeping other things constant, does private school competition have any impact on public school performance in the case of Nepal?

The first research question is dealt with in chapter 4 and the second one is dealt with in chapter 5 . As the data analyses in both chapters 4 and 5 use the same data sets, this chapter is devoted to a description of this common data set. This chapter will thus specifically include sections on the missing data problem and the fixing strategy, discussion on the exploratory data analysis, and a discussion about the study variables plus a detailed summary statistics of the variables used in this study. The models and the related identification problems and strategies are discussed in more detail in the next two chapters in accordance with the key research questions mentioned above. However, to provide a satisfactory context for discussing data for this chapter, a brief introduction to the hypothesis, models and the strategies involved in the data analyses is presented below.

Chapter 4 uses the theory of the educational production function in estimating the effect of school type on student's SLC performance. The approach to this section is to test the 
hypothesis that a student from a private school performs better on the SLC examination than a student from a public school, holding other things constant. Symbolically, the model postulates that the performance of a student $i$, in school $j$ is given by the following reduced form expression:

\section{(3.1) $\quad \mathrm{Y}_{\mathrm{ij}}=\infty_{0}+\infty_{1} \mathrm{~S}_{(\mathrm{i}) \mathrm{j}}+\infty_{2} \mathrm{X}_{\mathrm{ij}}+\mu_{\mathrm{ij}}$}

where $\mathrm{Y}_{\mathrm{ij}}$ is the aggregate SLC Test Score ${ }^{12}$ of student $i$ in school $j, \mathrm{~S}_{(\mathrm{i}) \mathrm{j}}$ is the key independent variable of interest that represents school type ${ }^{13}$ (which is a dummy variable, private if it takes value 1 , and 0 if public), $X_{\mathrm{ij}}$ is a vector of control variables representing student, family, school and teacher characteristics as well as exam context variables, and $\mu_{\mathrm{ij}}$ is a random disturbance with a mean zero and constant variance. The dependent variable in this case is the aggregate SLC score of student, which is a continuous variable. The Ordinary Least Squares (OLS) regression method is used to estimate equation 3.1.

Chapter 4 also involves the application of the probit model of the SLC exam. In equation 3.1, when the dependent variable is changed to a categorical variable equal to one if the student passed the SLC exam and zero otherwise, the model can be stated as:

$$
\mathrm{Y}^{*}{ }_{\mathrm{ij}}=\beta_{0}+\beta_{1} \mathrm{~S}_{(\mathrm{i}) \mathrm{j}}+\beta_{2} \mathrm{X}_{\mathrm{ij}}^{\prime}+v_{\mathrm{ij}}
$$

\footnotetext{
${ }^{12}$ Note that generally the SLC Score is comprised of 8 subjects- 6 compulsory (Math, Science, English, Nepali, Social Studies, Health \& Population studies) and 2 optional subjects. But, this dissertation uses only 6 compulsory subjects. However, I do report results using the aggregate score to compare the data across the models. The score is converted to the scale of 100.

${ }^{13}$ The subscript $i$ in parenthesis denotes that although school type is a school level variable, it is applied for student $i$.
} 
where $\mathrm{Y}^{*}{ }_{\mathrm{ij}}$ is the SLC test outcome of student $i$ in school $j$, and $v_{\mathrm{ij}}$ is a random disturbance with a mean of zero and a constant variance. Since the SLC test outcome variable in this case is a categorical variable, a probit model is used, where a set of explanatory variables, including school type, is postulated to affect the probability that a student passes the SLC exam, as follows:

\section{(3.3) $\quad \operatorname{Pr}\left(\mathrm{Y}^{*}{ }_{\mathrm{ij}}=1 \mid \mathrm{S}_{(\mathrm{i}) \mathrm{j}}, \mathrm{X}_{\mathrm{ij}}\right)=\Phi\left(\beta_{0}+\beta_{1} \mathrm{~S}_{(\mathrm{i}) \mathrm{j}}+\beta_{2} \mathrm{X}_{\mathrm{ij}}^{\prime}+v_{\mathrm{ij}}\right)$}

where $\Phi$ is the standard normal cumulative distribution function.

There is a potential selection-bias problem in this estimation method as private school students are not same as the public school students. This study thus adopts the propensity score matching method (nearest neighbor matching) to address this concern. In addition to these empirical models for analyzing private versus public performance, chapter 4 also includes two supporting probit models: one regarding the language medium of the SLC exam, and the second on private tutoring. Both of these models are similar to the probit model concerning the SLC result in terms of the variable of interest (which is school type) and the covariates controlled for (student, family, school and teacher characteristics).

The approach in chapter 5 is to test the hypothesis that a student of a public school that faces private school competition performs better on the SLC examination than a student from a public school that does not face private school competition, holding other things constant. Symbolically, the model postulates that the performance of a student $i$, in public school $p$ is given by the following reduced form expression:

$$
\mathrm{Y}_{\mathrm{ip}}=\pi_{0}+\pi_{1} \mathrm{C}_{(\mathrm{i}) \mathrm{p}}+\pi_{2} \mathrm{X}_{\mathrm{ip}}^{\prime}+\eta_{\mathrm{ip}}
$$


where $\mathrm{Y}_{\text {ip }}$ is the SLC Test Score ${ }^{14}$ of student $i$ in public school $p, \mathrm{C}_{(\mathrm{i}) \mathrm{p}}$ represents private school competition $^{15}$, given by the number of private schools in the neighborhood of public school $p$, $\mathrm{X}_{\mathrm{ip}}$ is a vector of control variables representing student, family, school, teacher, and community characteristics, and exam context variables, and $\eta_{\text {ip }}$ is a random disturbance with a mean of zero and a constant variance. The dependent variable in this case is the SLC score of public school students, which is a continuous variable. The Ordinary Least Squares (OLS) regression method is used to estimate equation 3.3. This estimation is likely to suffer from the endogeneity problem as private school enrollment is correlated with public school performance. As a way to tackle this problem, this study uses the instrumental variable approach. That is, the presence of a motorable road within an hour's walking distance from the sample school is used as an instrument for the number of private schools in the vicinity of the sample school. A binary measure of private school competition is also constructed and applied to both the OLS and IV methods.

This data set, which is cross-sectional, is one of the first comprehensive data sets collected so far in Nepal in the education sector. This dissertation makes use of this rich data source on the SLC exam. The data set contains information on the student's SLC performance as well as on student, school and teacher characteristics, which are crucial for the types of analyses mentioned above. In addition, it also has information on exam and community context variables, which is essential for the analysis in chapter 5. Therefore, this data set fits well with the data needed to carry out the empirical analyses described in this dissertation to address the study questions.

\footnotetext{
${ }^{14}$ Note that the SLC Score is computed only for compulsory subjects (Math, Science, English, Nepali, Social Studies and Health \& Population studies), and is converted to a scale of 100 (total score =100).

${ }^{15}$ The subscript $i$ within the parenthesis denotes that although private school competition is a school level variable, it is applied to $i$ th student.
} 


\section{Data Source and Sampling Strategy}

The data for this study comes from a nationwide survey of 452 schools and 22,500 students from the School Leaving Certificate (SLC) batches of 2002, 2003, and 2004. This survey was conducted by the SLC study team sponsored by the Ministry of Education and Sports of Nepal. The survey includes 5,625 families, 452 head teachers, and 2500 teachers, with information on each student's SLC performance and the student's personal, school, and family characteristics that could affect the student's educational outcome.

The following descriptions of sampling strategy and missing data information follows Bhatta (2005), which is a SLC study report prepared for the Ministry of Education, Nepal based on MOES (2005b) data. According to this study, a multi-stage, stratified random sampling approach was used to select a nationally representative sample of students from 28 districts representing all the eco-development regions of the country and Kathmandu Valley. This survey was divided into four components: i) Questionnaire design ii) Sample design iii) Field work and iv) Data entry and management. The sample size in this data set is adequately large. For example, the survey covered approximately 450 schools and 22,500 students which is around 10 percent of the secondary schools in the country and 50 students (on average) from each of the sample schools. To improve the representativeness of the sample, SLC results from multiple years $(2002,2003$ and 2004) were included in the sample. Fifty percent of the sample $(11,250$ students) was from the SLC batch of 2004 and an other 50 percent was from SLC batches of 2002 and 2003 batches. The stratification scheme was based on the results of an analysis of school-level SLC performance data that was provided by the Office of the Controller of 
Examinations. The sampling frame consisted of 4709 schools that participated in the 2004 SLC exams. Since the performance and percentage of schools varied considerably across the ecological regions (mountains, hills and the plains), the distribution of the schools across the different ecological and development regions was also analyzed. This ensured a representation of a broad range of schools. Before determining the number of schools that should be selected from each stratum, the sampling frame was modified by dropping schools that were deemed irrelevant from the perspective of the study's focus. A total of 240 schools (around 5 percent) of the 4709 schools with 11,052 students were removed from the original sampling frame.

\section{Information on Missing data}

This data set also suffers from problems as a result of non-observation, which could have occurred due to many factors that arose during the data collection process. For example, many schools in the sample could have been closed or inaccessible during the survey period because of strikes (bandhs) and travel restrictions imposed by the Maoists during that time. Similarly, the whereabouts of many recent SLC students could be unknown because they were either out of the country or were associated with the insurgency. Such students were also removed from the sampling frame. There are various methods of handling non-observations. For this data set, it was handled by the substitution method. In other words, non observation units were substituted with similar units. This was done by considering three categories: school type, SLC class size, and school location. However, in this method, one needs to be aware that if the substitution is not similar, then the sampling method will be biased. 
A total of 240 schools- around 5 percent of 4,709 schools with 11,052 students ${ }^{16}$ were removed from the original sampling frame. Of the 240 schools, seven were located in Bhutanese refugee camps. They were dropped since schools in the refugee camps are not in the government's list of policy priorities. Sixty nine of the schools in the original sampling frame were simply named "private". These schools were also dropped out because the schools with this name actually referred to students taking the SLC exams "as private candidates" through the District Education Office. Finally, schools that had very large (over 200 students) or very small (less than 6 students) SLC classes were also dropped since their performance was unrepresentative of most schools in the sense that they either had very good or very poor SLC results. Altogether 17 very large and 147 very small schools were removed from the list bringing the new sampling frame size to 4469 schools. However, the modified sampling frame seems to be very similar to the original sampling frame in terms of the percentage of private schools, average SLC class size, and pass rate as shown in Table 3.1.

Table 3.1. Original and Modified Sampling Frames

\begin{tabular}{lccc}
\hline Data Source & $\begin{array}{c}\text { \% of private } \\
\text { schools }\end{array}$ & $\begin{array}{c}\text { Average } \\
\text { size }\end{array}$ & $\begin{array}{c}\text { Average performance } \\
\text { (\% pass) }\end{array}$ \\
\hline $\begin{array}{l}\text { Modified Sampling } \\
\text { Frame } \\
\text { Original Sampling }\end{array}$ & 27.2 & 36.8 & 46.8 \\
Frame & 27.3 & 37.3 & 46.2 \\
\hline Source: Bhatta (2005) & & &
\end{tabular}

Fixing missing data problem

${ }^{16}$ This is around six percent of the total number of SLC students in the original sampling frame. 
In this sample there are 19,916 observations. The rate of missing data for some variables turns out to be as high as 50 percent. This is a matter of great concern, as the quality of analysis also depends on the quality of data. As a result, I took several steps to tackle this problem. First, while choosing the variables for my analysis, I used only those variables whose rate of missing data is less than 25 percent. For example, variables such as student's grade $9^{\text {th }}$ score, expenditure per student, percentage of poor in the school and teacher training were some of the variables that had more than 25 percent missing values. Therefore, they were dropped from the study and proxy variables were used in place of them. For example, student's expected division was chosen as proxy for student's precious grade score and school having a science and computer lab was chosen as proxy for expenditure per student. Table 3.2 lists the variables used in this study that have missing values in the range of 5 to 25 percent.

Table 3.2. Variables Between 5 to 25 Percent Missing Values

\begin{tabular}{|c|c|c|c|c|}
\hline Variable & Description of Variable & $\begin{array}{l}\text { Values } \\
\text { Missing }\end{array}$ & $\begin{array}{c}\% \\
\text { Missing }\end{array}$ & $\begin{array}{l}\text { Obs. After } \\
\text { Imputation }\end{array}$ \\
\hline \multicolumn{5}{|c|}{ Dependent Variable } \\
\hline SLC_AGG & SLC Total Score (8 subjects) (Out of 100) & 1073 & 5.4 & 19898 \\
\hline SLC_PASS & 1 if passed in SLC exam, 0 otherwise & 2541 & 12.8 & 19924 \\
\hline \multicolumn{5}{|c|}{ School Characteristics } \\
\hline PRIVATE & $\begin{array}{l}1 \text { if fully private, } 0 \text { if public (partially or fully) } \\
\text { including community managed schools }\end{array}$ & 986 & 5.0 & 19928 \\
\hline PCT_GIRLS & $\begin{array}{l}\text { Percentage of girls in school in higher secondary } \\
\text { grades. }\end{array}$ & 1237 & 6.2 & 19928 \\
\hline \multicolumn{5}{|c|}{ Community Context } \\
\hline NUM_PRIV & $\begin{array}{l}\text { Number of private schools in the vicinity of the } \\
\text { sample school }\end{array}$ & 3406 & 17.1 & 19921 \\
\hline HQRT & $\begin{array}{l}1 \text { if school is located in the district headquarter, } 0 \\
\text { otherwise }\end{array}$ & 1170 & 5.9 & 19928 \\
\hline MO_ROAD & $\begin{array}{l}1 \text { if there is a motorable road within } 1 \mathrm{hr} \text {. walking } \\
\text { distance from the sample school, } 0 \text { otherwise }\end{array}$ & 4072 & 20.4 & 19928 \\
\hline
\end{tabular}


Next, I have used the multiple imputation method to address the missing data problem. Wherever multiple imputation was not applicable (for example in instrumental variable estimation), I used the regression imputation method to first impute the data and then performed the estimations. The idea of multiple imputation is that instead of filling in missing values to create a single imputed dataset, several imputed data sets are created each of which contains different imputed values. The analysis of a statistical model is then conducted on each of the imputed data sets. This is followed by combining the multiple analyses to yield a single set of results. One of the major advantages of the multiple imputation method over single imputation is that it produces standard errors that reflect the degree of uncertainty due to the imputation of missing values. Generally, multiple imputation techniques require that missing observations are missing at random (MAR).

The literature suggests two major approaches to multiple imputation. The first one is based on the joint distribution of all the variables in the imputation model, including the variables to be imputed and the variables to be used only for the purposes of imputing other variables. In this approach, the joint distribution of all variables in the imputation model is assumed to be multivariate normal. The other approach is based on each conditional density of a variable given other variables (see Rubin, 1986, 1996). In this study, I have adopted the second method, termed Imputation by Chained Equations (ICE), by Patrick Royston (Royston, 2004). The major strengths of this approach are that there is no assumption of multivariate joint distribution, and that it is easy to understand. In addition, this approach allows different kinds of weights to be used if they are supported by regression models. Unlike the multivariate normal approach, it may have lower sample size requirements. However, this method is not as 
theoretically sound as the multivariate normal approach, and conditional densities can be incompatible (Allison, 2002).

\section{Exploratory Data Analysis}

We can no longer get along without confirmatory data analysis, but we need not start with it (Tukey, 1977). Taking this as an inspirational point to start, after making a choice of variables based on rate of missing data, this study performed an exploratory data analysis. This was done for three major reasons: to get to know the data, to ensure quality control for mistakes in data entry, and to access missing data. As part of this process, first, descriptive statistics were checked for all the chosen variables to obtain information on the means, medians, variances, ranges, skewness and kurtosis of the data set. In this process itself, values that were clearly in error, such as out-of-range values were evident. For example, some observations for SLC score had values higher than the total score. Such data were removed or replaced with meaningful values. The mean and the standard deviations of the variables used are presented in Table 3.4. Then, a test of normality was performed using histograms as well as box and whisker plots. The histograms were plotted for each of the chosen variables to assist in carrying out a graphical inspection of the data whether or not the data were measured on an interval scale. The box and whisker plots were used to detect any outliers in the data set. In addition, these were also helpful in indicating whether a distribution is skewed. The box plot figures and histograms of the variables chosen for this study are given in the appendix section of this dissertation. Finally, the Shapiro-Wilk test was performed to detect if there were any departures from normality in the dataset. This test calculates a $\mathrm{W}$-statistic that examines whether a random sample comes from a 
normal distribution. Both the graphical method and Shapiro-Wilk test confirmed that the variables chosen for this study in the sample data are normally distributed.

\section{Variable Description}

The dependent variable examined in the OLS model of Chapter 4 is the SLC score of a student. More specifically, this student outcome variable (SLC_SCORE) is a continuous variable that includes the aggregate score of 8 subjects, which are Math, English, Science, Nepali, Social Studies, Health \& Population studies and two optional subjects. For this chapter, except for the first model, all models use SLC score on only six compulsory subjects. Further, the SLC_SCORE variable is converted to a scale of 100 so that it can be interpreted in percentage point terms ${ }^{17}$. For the probit models, the dependent variable used is whether or not the student passed the SLC exam. The variable takes the value equal to one if the student passed the SLC exam, and zero otherwise. The passing score for each subject is 32 out of 100, and a student needs to pass all the subjects to be declared 'passed'. In addition, the study postulates two more probit models: one for language medium of exam and the other, for private tutoring. The medium of the exam variable is coded as one if the SLC exam medium chosen was Nepali, and zero if it was chosen English or mixed ${ }^{18}$. Finally, private tutoring is also a dummy variable which is coded as one if student took private tutoring for the SLC exam and zero otherwise.

The key independent variable to be examined in chapter four is school type (if private). This is a categorical variable equal to one if the school is private and zero if it is public ${ }^{19}$. The observable controls in the econometric analysis are as follows. The first set of controls include

\footnotetext{
${ }^{17}$ To convert a scale with total score 800 to a scale 100 , a given student's score is divided by 8 .

${ }^{18}$ Very few students use 'mixed' medium. For this study, 'mixed medium' is regarded as 'English'.

${ }^{19}$ As discussed in chapter two, note that the community managed schools are also included as public schools for this dissertation.
} 
student's characteristics, which are: age (AGE); gender (FEMALE, female=1); lower caste (L_CASTE, lower caste $=1)$; ethnic groups (ETH_GRPS, ethnic groups $=1$ ); other castes (OTHERS, other caste $=1)$; number of friends passing SLC exam (PEERS); expected division in SLC exam (EXP_DIV); student having taken private tutoring for SLC exam (P_TUTOR) and, number of schools days absent in the school year (SCH_ABS). The mean age of students who appear for the SLC exam appears to be 16 . The older students represent those who either have a record of repeating the grades too often, or those who started their education very late (some even in the adult stage). Hence, one can expect that older the student, the lower is the SLC score. Similarly, in a country like Nepal, the girls are not given as much opportunity as the boys, especially in the rural areas. The girls are expected to take care of the household chores and look after young ones. Hence, as an underprivileged group, females are associated with lower performance on the SLC exam. Next, a review of the data on students belonging to a particular caste/ethnicity is important too. This data set has information on particular student's caste/ethnicity, and for the sake of simplicity in the analysis, the caste/ethnicity is recoded into four categories: higher caste $\left(\mathrm{H} \_\right.$CASTE, if caste $=$Brahmin, Chhetri or Newar) ${ }^{20}$, lower caste (L_CASTE, if caste=dalits), ethnic groups (ETH_GRPS, if caste belongs to any of the ethnic groups), and other caste (OTHERS, other remaining caste/groups). In Nepal, student belonging to the higher caste are considered well off, and students from the lower caste, ethnic groups and other caste are under privileged. The literature suggests that peer effect is another factor that has a substantial impact on student achievement (for example, see Ding \& Lehrer, 2004; Schneeweis \& Winter-Ebmer, 2007). In this dissertation, this aspect of peer-effects is captured by numbers of close friends who passed the SLC exam. Another important variable is whether or not the student

\footnotetext{
${ }^{20}$ Traditionally only Brahmin and Chhetri belong to the higher caste. But, in the present Nepalese society, Newars are considered quite well off in terms of socio-economic status. Therefore, for this study, I have also grouped Newars in the higher caste.
} 
took private tutoring for the SLC exam. Interestingly, both types of students, top performers and lowest performers seem to be more likely as groups to take private tutoring. In this context, the obvious argument is that a student gets to learn more if she takes private tutoring. However, the causality in this case is not so simple and needs to be supported by empirical evidence before one can reach any concrete conclusion. Finally, the variables EXP_DIV (student's expected division in SLC exam) and SCH_ABS (number of school days absent in grade 10) are used as proxy for student's ability and student's motivation, respectively.

A second set of controls include the student's family characteristics. This includes: family size (FAMSIZE); family's annual total expenditure in log terms (LN_FAM_EXP), number of SLC graduates in the family (SLC_GRADS), language spoken at home (LANG, Nepali=1), distance to school from home in minutes (DIST_SCH), and whether or not family possessed a computer (COMPUTER, computer=1). The literature gives a great importance to family's socioeconomic status in influencing a student's educational outcome (see Coleman report, 1966; Hanushek, 1986, 1989). Generally, families with higher socioeconomic status have smaller family size, bigger family expenditure, higher number of SLC graduates in the family, speak Nepali at home and possess a computer at home. The annual family expenditure is given in Nepalese Rupees and includes both educational as well as non educational expenses. Although father's education and mother's education are more widely used as family controls, in this study it was deemed more meaningful to use the number of SLC graduates in the family as an indicator of the educational status of other members of the family have an influence in student's performance. Given Nepal's diverse cultural and linguistic society (with 92 identified languages), it is important to control for the language student's family speaks at home. In general, the family that speaks Nepali has a better socioeconomic status as compared to families 
that speak other indigenous languages. Finally, distance from home to school is an important variable to control for as this factor determines how much time student spends every day commuting to her school.

The third set of control includes school and teacher characteristics. This set includes important variables such as: school size (S_SIZE), whether the school is has a library (LIBRARY, having library=1), whether the school has a science lab and a computer lab (SC_COMP_LAB, having science and computer lab $=1$ ), the number of school days taught in a given school year (SCH_DAYS), the student-teacher ratio (ST_RATIO), teacher qualifications (TCH_QA), teacher experience (TCH_EXP) and teacher experience squared (TCH_EXP_SQ). Due to economies of scale, bigger schools do have better resources, but they could also be less productive in terms of educational outcome. Hence, in addition to school size, I have also included a control on student-teacher ratio in secondary grades as classroom specific characteristics that are important in explaining student achievement (Goldhaber \& Brewer, 1977). Percent of girls in secondary grades is also included to account for gender composition in the classes. The data on per-student expenditure had too many missing observations, so it was excluded from the analysis. Instead, variables: LIBRARY and SC_COMP_LAB representing school having a library and school having a science and computer lab respectively are used as a proxy for school resources Although there is controversy in the advanced countries about the significance of the contribution of school resources towards student achievement, there is almost no doubt about its influence in developing countries (see Heyneman \& Loxley, 1983; Hanushek, 1995; Fuller \& Clark, 1994; Scheerns, 2004). The literature also suggests that the number of teaching hours matters for student's achievement. In this study, this aspect is taken into account by using the number of school days the school was open during the given school year. Finally, 
since teachers are the medium for passing knowledge to students, TCH_QA (teacher qualification) and TCH_EXP (teacher experience) are important variables to control for any analysis involving student performance (see Hanushek, 2010). I have included teacher experience squared as well to capture any non linear behavior of the teacher experience variable as some teachers seemed to have been teaching for a large number of years.

The fourth set of controls include exam context variables. The exam context variables are the language medium for the SLC examination (EX_MED, Nepali=1); if student personally prepared food during exam (FOOD_SELF, food by self=1); whether or not the student was sick during the SLC exam (SICK, sick=1); whether the SLC exam was year 2002 (SLC02, SLC year 2002=1) and whether the SLC exam year was 2003 (SLC03, SLC year 2003=1). In most of the public schools, the medium of instruction is Nepali. This is the reason why low performing students, especially students from lower caste and public schools, are more likely to use Nepali as the language medium for the SLC exam. The medium of instruction is not included in the analysis due to the high correlation of this variable with the medium of exam. The variables representing FOOD_SELF (student personally preparing food during exam) also serves as a proxy of family status and family support the student was getting during the exam period. The SLC exam is taken very seriously so that many students fall sick during the SLC exam. Hence, controlling for whether or not the student is sick during the exam is important in order to capture these effects in the educational production function analysis. Finally, given the number of political changes that occurred in the past decade due to Maoist insurgency, it is useful to include the information on the year of SLC exam. As described earlier in this section, the data comprises 50 percent observations from year 2004 and 25 percent of the observations from years 2002 and 
2003. Hence, I created dummy variables for the year 2002 and 2003 to account for any such changes at the national level during those years as related to the SLC exam.

In chapter 5, the dependent variable used is the SLC score of only public school student (PUB_SCORE). This outcome variable, as before, comprises only the compulsory subjects and is converted in the scale of 100 . In addition, chapter 5 also makes use of community context variables that includes information on the number of private schools in the neighborhood of the school (PRIV_NUM). This variable is the main variable of interest in chapter 5, and is included to serve as the measure of private school competition for this dissertation. The instrument variable used is the presence of a motorable road within an hour's walking distance from the school given by (MO_ROAD, motorable road=1). The idea behind choosing this variable and the validity of this variable will be discussed in more detail in chapter 5 . Another community context variable is the information whether the school is located in the district headquarter (HQRT, school in the district headquarter=1). This variable is used as a proxy for a population density measure.

\section{Summary Statistics}

Table 3.3 presents the summary statistics of SLC performance by gender and school type. As seen in the table, the mean SLC score for the overall students is 47.89 out of 100 . In the sample, 78.57 percent belong to the public schools and 21.43 to private schools. The average score for the private and public school students are 60.97 and 44.34 respectively. The overall pass rate for students is 51.13 percent, while the pass rate for private and public school students are 87.20 percent and 45.12 percent, respectively. The difference in the mean score between private and public school students is 16.63 , and the difference in the pass rate is 42.08 percent. In terms of 
gender composition, the sample consists of 55.23 percent of male students and 44.77 percent of female students. The mean SLC score (aggregate) of male and female students are 49.23 and 46.26 respectively. By gender, the difference in mean score is 2.97 and the difference in the pass percentage is 9.68 .

Table 3.3. Mean score and pass rates in SLC by School-Type and Gender

\begin{tabular}{lcccc}
\hline & \% of students & $\begin{array}{c}\text { Mean } \\
\text { score }\end{array}$ & $\begin{array}{c}\text { Std. } \\
\text { Dev }\end{array}$ & $\begin{array}{c}\text { Pass rate } \\
(\%)\end{array}$ \\
\hline Total & 100 & 47.9 & 12.44 & 51.13 \\
Public & 78.57 & 44.34 & 9.9 & 45.12 \\
Private & 21.43 & 60.97 & 2.08 & 87.2 \\
Difference (Private - Public) & -57.14 & 16.63 & -7.82 & 42.08 \\
Female & 44.77 & 46.26 & 11.93 & 48.72 \\
Male & 55.23 & 49.23 & 12.69 & 58.4 \\
Difference (Male - Female) & 10.46 & 2.97 & 0.76 & 9.68 \\
\hline
\end{tabular}

Source: Author's calculation using MOES (2005b) data.

In addition to the above description, Table 3.4 reports the overall summary statistics for all the variables used in this study. On variables representing student characteristics, on average, 45 percent of the students in the sample are female; the mean age of students appearing in SLC exam is 16.6 years; 66 percent belong to the higher caste (Brahmin, Chhetri or Newar), 17 percent belong to the ethnic groups (Janjatis), two percent belong to the lower caste (Dalits) and 14 percent belong to the other castes. The mean number of close friends who passed SLC exam is three; an average student expected achieving the $2^{\text {nd }}$ division on the SLC exam; on average, 68 percent of the students took private tutoring for SLC exam, and the average number of school days that a student remained absent in grade 10 is six. 
As regards family related variables, the mean family size is six; the mean annual family expenses is N.Rs $65,138.45^{21}$; the mean number of SLC graduates in the family is two; on average, 75 percent of the families spoke Nepali at home; the average distance from home to school is 12.19 minutes and, on average, only 6.87 percent of the families posses a computer in their homes.

Descriptive statistics on school and teacher related variables show that the average school size is 840 ; on average 68.6 percent of the schools have at least a library and 24.8 percent have at least a science and a computer lab; the average student-teacher ratio is 30.58 , the average school days conducted in a school year is 185 days; on average, 44.7 percent of students are girls in the higher secondary grades; an average teacher holds a bachelor's degree and the mean teacher experience is 14.65 years.

Regarding the exam context, on average, 68 percent of the students in the sample used Nepali as the medium of the SLC exam, 21 percent of the students had to prepare food during the SLC exam and 14.65 percent were sick during exam. The average percentage of students who took the exam in 2002 and 2003 was 19 and 25 respectively.

Finally, on a community context variable, the average number of private schools in the neighborhood of a public school under study is four. Around 74 percent of the schools, on average, have a motorable road to an hour's walking distance from the school, and on average, 26.83 percent of the schools are located in the district headquarters.

\section{Correlations}

Tables 3.5 and 3.6 report the correlations between the outcome and independent variables used for chapter 4 and chapter 5 respectively. The table reports only those variables which have

${ }^{21}$ The exchange rate for 1US\$ (for example in April 16, 2011) is equivalent to N.Rs 70.92. 
correlation coefficient of 0.4 or higher. As seen in Table 3.5, the correlations show that for the variable of students being from a public school there is a negative correlation of this variable with the SLC score both in is aggregate form and for compulsory subjects. Also, it is interesting to note that students who are from public schools show a weak negative correction of this variable with the status of passing the SLC exam.

The correlations presented in Table 3.6 are important given the nature of analysis in Chapter 5. As seen in the table, there is no correlation between the outcome variable (SLC_PUB) and the variable representing motorable road from an hour's walking distance from the sample school (MO_ROAD). Also, this variable is correlated, though weakly, with the variable representing private school competition (NUM_PRIV). This information will be recalled while checking the assumptions of the instrument variable in chapter 5.

In summary, the data used for this study is very appropriate. However, there are few limitations of the data. First, there are missing observations. Although the missing values are tackled by using regression and multiple regression methods, the limitations of data imputations cannot be ruled out. This is a cross-sectional data and hence it limits us from estimating value added of student performance over time. Given the strengths and drawbacks of the data set, the next two chapters use this data set and perform analyses on private and private school competition and explore the impact of private school competition on public school performance. 
Table 3.4 Summary Statistics

\begin{tabular}{|c|c|c|c|c|}
\hline Variable & Description of Variable & Obs & Mean & Std. Dev \\
\hline \multicolumn{5}{|c|}{ Dependent Variable } \\
\hline SLC_AGG & SLC Total Score (8 subjects)(Out of 100) & 19898 & 47.88 & 12.44 \\
\hline SLC_COMP & $\begin{array}{l}\text { SLC Score for only } 6 \text { compulsory subjects (Out of } \\
100)\end{array}$ & 19897 & 46.9 & 12.6 \\
\hline SLC_PASS & 1 if passed in SLC exam, 0 otherwise & 19924 & 0.54 & 0.5 \\
\hline SLC_PUB & $\begin{array}{l}\text { SLC Score of public school students (only } \\
\text { compulsory subjects; out of 100) }\end{array}$ & 15643 & 43.25 & 10.16 \\
\hline \multicolumn{5}{|c|}{ Student Characteristics } \\
\hline AGE & Age when student took the most recent SLC exam & 19900 & 16.59 & 1.06 \\
\hline FEMALE & 1 if female, 0 otherwise & 19901 & 0.45 & 0.5 \\
\hline H_CASTE & 1 if Brahmin, Chettri or Newar, 0 otherwise & & & \\
\hline L_CASTE & 1 if lower caste (dalits), 0 otherwise & 19901 & 0.02 & 0.15 \\
\hline ETH_GRPS & 1 if ethnic groups (indigenous), 0 otherwise & 19901 & 0.17 & 0.38 \\
\hline OTHERS & 1 if other caste, 0 otherwise & 19901 & 0.14 & 0.34 \\
\hline PEERS & $\begin{array}{l}\text { Among student's five closest friends, the number } \\
\text { that passed the SLC exams. }\end{array}$ & 19900 & 3.23 & 1.51 \\
\hline SCH_ABS & No. of days absent from school in grade 10. & 19900 & 6.8 & 8.24 \\
\hline \multirow[t]{2}{*}{ EXP_DIV } & Expected Division in SLC exam & 19900 & 3.46 & 0.68 \\
\hline & $\begin{array}{l}1=\text { fail (failed in at least one subject) }, 2=3 \mathrm{rd} \\
\text { division }(32 \% \text { and above) }, 3=2 \mathrm{nd} \text { division }(45 \% \\
\text { and above }), 4=1 \text { st division }(60 \% \text { and above })\end{array}$ & & & \\
\hline P_TUTOR & $1=$ Took private tutoring for SLC exam, 0 otherwise & 19900 & 0.68 & 0.47 \\
\hline \multicolumn{5}{|c|}{ Family Characteristics } \\
\hline FAMSIZE & Number of people who ate in the same kitchen & 19900 & 6.43 & 2.47 \\
\hline FAM_EXP & Yearly family expenditure (NRs.) & 19901 & 65138.4 & 117419 \\
\hline SLC_GRADS & No. of SLC graduates in the family & 19901 & 1.088 & 1.38 \\
\hline LANG & Language spoken at home & 19901 & 0.74 & 0.43 \\
\hline & 1 if Nepali, 0 otherwise & & & \\
\hline DIST_SCH & $\begin{array}{l}\text { Distance of school from home } \\
\text { (Hours taken to commute to school daily). }\end{array}$ & 19900 & 0.2 & 0.5 \\
\hline COMPUTER & 1 if Family has a computer at home, 0 otherwise & 19901 & 0.07 & 0.25 \\
\hline
\end{tabular}




\begin{tabular}{|c|c|c|c|c|}
\hline PRIVATE & $\begin{array}{l}1 \text { if fully private, } 0 \text { if public (partially or fully) } \\
\text { including community managed schools }\end{array}$ & 19928 & 0.21 & 0.41 \\
\hline S_SIZE & $\begin{array}{l}\text { School size (Total number of students in school in } \\
2004 \text {, divided by 100) }\end{array}$ & 19928 & 8.4 & 4.63 \\
\hline PCT_GIRLS & $\begin{array}{l}\text { Percentage of girls in school in higher secondary } \\
\text { grades. }\end{array}$ & 19928 & 44.71 & 12.67 \\
\hline LIBRARY & 1 if school has at least one library, 0 otherwise & 19928 & 0.68 & 0.46 \\
\hline SC_COMP_LAB & $\begin{array}{l}1 \text { if school has at least one science lab and } 1 \\
\text { computer lab, } 0 \text { otherwise }\end{array}$ & 19928 & 0.25 & 0.43 \\
\hline SCH_DAYS & No. of school days taught in the school year & 19928 & 185.62 & 30.57 \\
\hline ST_RATIO & Student teacher ratio in secondary grades & 19928 & 30.58 & 2.34 \\
\hline TCH_QA & $\begin{array}{l}\text { Teacher qualification } \\
1=\text { Intermediate, } 2=\text { Bachelors, } 3=\text { Masters }\end{array}$ & 19928 & 2.19 & 0.62 \\
\hline TCH_EXP & Teacher experience (in years) & 19928 & 14.65 & 8.77 \\
\hline TCH_EXP_SQ & Teacher experience squared & 19928 & 291.56 & 333.32 \\
\hline \multicolumn{5}{|l|}{ Exam Context } \\
\hline EX_MED & 1 if Medium of Examination is Nepali, 0 Otherwise & 19928 & 0.68 & 0.47 \\
\hline FOOD_SELF & $\begin{array}{l}1 \text { if student prepared food by own during exam, } 0 \\
\text { otherwise }\end{array}$ & 19901 & 0.21 & 0.41 \\
\hline SICK & 1 if student was sick during exam, 0 otherwise & 19901 & 0.15 & 0.36 \\
\hline SLC02 & 1 if SLC Year is 2002,0 otherwise & 19928 & 0.19 & 0.39 \\
\hline & 1 if SLC Year 2003, 0 otherwise & 19928 & 0.25 & 0.43 \\
\hline \multicolumn{5}{|l|}{ Community Context } \\
\hline NUM_PRIV & $\begin{array}{l}\text { Number of private schools in the vicinity of the } \\
\text { sample school }\end{array}$ & 19921 & 3.8 & 4.38 \\
\hline HQRT & $\begin{array}{l}1 \text { if school is located in the district headquarter, } 0 \\
\text { otherwise }\end{array}$ & 19928 & 0.27 & 0.44 \\
\hline MO_ROAD & $\begin{array}{l}1 \text { if there is a motorable road within } 1 \mathrm{hr} \text {. walking } \\
\text { distance from the sample school, } 0 \text { otherwise }\end{array}$ & 19928 & 0.74 & 0.44 \\
\hline
\end{tabular}

Source: Author's calculation using MOES (2005b) data. 
Table 3.5. Correlation Coefficient: SLC Outcome and school type

\begin{tabular}{|c|c|c|c|}
\hline & SLC AGG & SLC COMP & SLC PASS \\
\hline SLC_AGG & 1 & & \\
\hline $\mathrm{SLC}_{-}{ }^{-} \mathrm{COMP}$ & 0.94 & 1 & \\
\hline SLC_PASS & 0.65 & 0.67 & 1 \\
\hline PRIVATE & 0.55 & 0.56 & 0.34 \\
\hline
\end{tabular}

Table 3.6. Correlation Table: SLC Score and Private School Competition

\begin{tabular}{llll}
\hline & SLC PUB & NUM PRIV & MO ROAD \\
\hline SLC_PUB & 1 & & \\
NUM_PRIV & 0.10 & 1 & 1 \\
MO_ROAD & 0.08 & 0.34 & 1 \\
\hline \multicolumn{2}{l}{ Source: Author's calculation using MOES (2005b) data. }
\end{tabular}

Source: Author's calculation using MOES (2005b) data. 


\section{Chapter IV}

\section{AN ANALYSIS OF PRIVATE AND PUBLIC SCHOOL PERFORMANCE IN NEPAL}

\section{Introduction}

A comparative study of public and private school performance has been one of the popular topics of research among educational researchers around the world. In the case of developed countries, the evidence is mixed. However, in the case of developing countries, it could be argued that the answer is obvious. The basic understanding is that in most of the developing countries the performance of public schools is consistently below the performance of private schools. Among the many factors that differentiate these two types of schools are factors such as who own the schools, how they are managed, which resources are available and how those resources are used, what are the student's demographic and socioeconomic characteristics who attend such schools, what is the school and community climate in these schools, and so on. Considering all these factors and making it possible to account for these differences will again raise the question: do private school students really perform better than the public school students? This chapter will try to explore this issue in the case of a developing country, Nepal using SLC level data provided by the Ministry of Education of Nepal.

This chapter is organized in the following way. First, a theoretical framework is presented with an introduction to the educational production function and the related literature on this topic. The chapter then reviews some previous studies concerning the evidence surrounding student performance in developed and developing countries. This is followed by a discussion on the relevant literature concerning the evidence related to student performance in Nepal. The 
subject of private tutoring is also dealt with briefly. Finally, the chapter presents the models and methods used for the analysis and discussion on the findings and interpretation of the results.

\section{Theoretical Framework}

This chapter employs an educational production function approach to estimate the impact of school type on student performance. An education production function is defined by a relationship that constitutes all combinations of inputs that produce a given set of outputs. In education, outputs are typically measured by achievement score/graduation rates and inputs usually are school, teacher and student relating factors that influence outcomes. Mathematically, this could be expressed as follows (Harris, 2010):

$$
Y_{i t}=f\left(S_{i t}, S_{i t}-1, \ldots . . F_{i t}, F_{i t}-1, \ldots . . I_{i}, \varepsilon_{i t}\right)
$$

where $\mathrm{Y}_{\mathrm{it}}$ is educational output for individual student $i$ at time $t$; $\mathrm{S}_{\mathrm{it}}$ denotes school inputs for individual student $i$ at time $t ; \mathrm{F}_{\mathrm{it}}$ includes family inputs for individual student $i$ at time $t ; \mathrm{I}_{\mathrm{i}}=$ fixed student contribution (called as innate ability by economists) and $\varepsilon_{\text {it }}$ is a random disturbance term that includes all the unobserved factors in the equation.

\section{Literature Review}

\section{Evidence on Developed Countries}

One of the most famous studies that uses a production function approach is the Coleman report (1966). Coleman and others believed that both school resources as well as the family background contributes significantly to student achievements in a given year. Thus, their 
specification can be written as:

$$
Y_{i j}=\alpha S_{i j}+\beta F_{i j}+\varepsilon_{i j}
$$

where $\mathrm{Y}_{\mathrm{ij}}$ is outcome of student $i$ in school $j, \mathrm{~S}_{\mathrm{ij}}$ is a vector relating to school/teacher inputs and $\mathrm{F}_{\mathrm{ij}}$ is a vector representing the family background of student $i$ in school $j$. The main finding of the Coleman Report (1966) was that school resources account for a very tiny proportion of the variance of student achievements. Although the study was heavily criticized on statistical grounds, this voluminous report spurred an interest on the topic that went far beyond the technicalities embedded on it. The subsequent research in this field was to examine input-output relationships in school by using longitudinal panel information. There is a substantial amount of research in this field of study. Reviews by Hanushek (1989) summarize existing empirical results on the education production function while showing evidence from his vote counting analyses. The main idea of vote counting is that the category with the most results is generally taken to represent the true state of the relation in question. He summarizes 187 empirical specifications that focus on input and output relationships that estimate the education production function in public schools of the United States. His study evaluates the impact of seven measures as inputs of education production function: teacher-pupil ratio, teacher education, teacher experience, teacher salary, expenditures per pupil, administrative inputs, and facilities. He concludes that there is no strong or systematic relationship between school expenditures and student performance. This study was criticized by some, especially on methodological grounds that drew opposite conclusions (see Hedges, Laine, and Greenwald, 1994).

The above research estimates traditional education production functions, such as a Cobb- 
Douglas production function that assumes constant elasticities of substitution and scale.

However, Figlio (1999) using national student-level data to estimate an education production function that does not employ the restrictive assumptions of homotheticity and additivity (trans$\log$ ) and finds statistically significant evidence that school inputs (e.g., teachers' education, teachers' salaries, student-teacher ratios etc.) are associated with student achievements. Based on his evidence, Figlio(1999) argues that traditional education production functions may understate the magnitude of the effects of school factors on student achievements.

The empirical results mentioned above measure students' achievement by test scores as a dependent variable in education production function. However, Card and Krueger (1996) summarize the results of twenty-four estimates of the effect of school expenditures on earnings from eleven different studies. According to them, all the estimates show a positive effect of additional school expenditures on subsequent earnings, graduation rates, and years of educational attainment. In addition, they point out that test scores are not strong predictors of student's success in the labor market. In fact, they find that there is a significant relationship between the quality of educational inputs and earnings.

However, existing databases providing labor market data on young workers (NLS-Y, HSB etc.) have potential problems: many determinants of labor market performance are only revealed with experience. In addition, samples of young workers tend to under-represent individuals of a given age with higher education. For example, the NLS-Y sample used by Betts (1995) to estimate the wage equation used 23 year-old workers on average. The small sample sizes of the datasets make it potentially difficult to avoid self-selection bias.

In light of these data problems, it is interesting to compare the estimated wage equation from the student-level (micro-level) datasets to the estimates in the other literatures. Hanushek, 
Rivkin, and Taylor (1996) argue that many of studies that find positive and significant relationships between school inputs and student achievements use aggregate data that will bias the coefficient estimates upward. They show that when only studies employing student-level data are considered, the evidence supporting a link between measured school inputs and student achievements becomes more tenuous. On the other hand, Ferguson and Ladd (1996) analyzed achievement scores for students in grades four, eight and nine of 131 districts in Alabama and found that empirical results do not change whether using aggregate or disaggregated data.

In any case, according to the evidence from developed countries, research surrounding the estimation of education production functions says that there is no clear, systematic relationship between resources and student outcomes. However, the latest research into the determinants of student achievement strongly indicates that teacher-quality differences are the most significant part of differences across schools (Hanushek, 2010). In the case of developing countries, the targeted outcome in most of the cases is the increase in the enrollment rate. There are others that advocate the learning process. However, there are very few effective studies that evaluate what actually is effective learning. Randomized evaluations are the latest trends in evaluating the effect of various educational interventions (Glewwe \& Lambert, 2010).

The education production function approach is not without issues. The major issues related to estimating educational production functions can be highlighted as follows: Functional form of education production function

The first debate is about the functional form of the educational production function. Normally, the educational production function is assumed to be linear, additive and homothetic.

$$
Y_{t}=g\left(S_{t-1}, F_{t-1}, P_{t-1}, y_{t-1}\right)
$$


where $\mathrm{Y}$ is educational outcome, $\mathrm{S}$, school input variables, $\mathrm{F}$, family variables, $\mathrm{P}$, peer variables, and $\mathrm{g}(\cdot)$ is assumed as homothetic. In other words, the education production relationship is

$$
\mathrm{Y}_{\mathrm{t}}=\mathrm{m}\left(\mathrm{h}\left(\mathrm{S}_{\mathrm{t}-1}, \mathrm{~F}_{\mathrm{t}-1}, \mathrm{P}_{\mathrm{t}-1}, \mathrm{Y}_{\mathrm{t}-1}\right)\right)
$$

where $\mathrm{m}(\cdot)$ is monotonic and $\mathrm{h}(\cdot)$ is homogeneous of degree one. Furthermore, the education production function is also additive, so that:

$$
Y_{t}=m_{1}\left(S_{t-1}\right)+m_{2}\left(F_{t-1}\right)+m_{3}\left(P_{t-1}\right)+m_{4}\left(Y_{t-1}\right)
$$

In more detail, "additivity" means that the educational production function is additive in the inputs of production. Some studies (such as Summers \& Wolfe, 1977) allow the interaction of inputs variables but this relaxation of additive assumption is very rare. In addition, the "homothetic" assumption means that the marginal rate of substitution among inputs of education production depends only on the proportions of the inputs and not on the scale of production. However, if the effects of school inputs on student achievement are sensitive to variation in the scale of education production, these assumptions may not be appropriate and it may reduce precision of estimates (Figlio, 1999). In fact, Figlio (1999) estimates an educational production function that does not hold the assumptions of additivity and homotheticity by using translogarithmic functional form (translog). He finds evidence of a systematic relationship between school inputs and the changes in student performance, although the estimated marginal productivities of school inputs seem rather small (elasticity values of 0.1 and 0.2 ). Figlio 
concludes that traditional specifications of education production function are overly restrictive because they fail to capture potentially nonlinear effects of school resources. Hence his results suggest that traditional education production function may underestimate the effects of school inputs on student achievement. In addition to overly restrictive assumptions of additivity and homotheticity in traditional specifications of education production, Pritchett and Filmer (1999) also criticize the traditional education production function because the assumption that resources are allocated to maximize education output under an optimizing theory is grossly inconsistent with their evidence.

\section{Choice of input/output variables}

When estimating education production function, which input/output variables should be chosen is still controversial. Education may have unmeasured outcomes, such as joy, pleasure, and satisfaction of students and external benefits to societies as a whole. Furthermore, education does not produce a single output but multiple outcomes at the same time. Thus, it is not easy to specify and measure outcomes of schooling. Most studies examining the input-output relationships in school use immediate output measures of schools, such as measured cognitive achievement or continuation to further schooling as a dependent variable of education production function. The use of these measures is justified on the grounds that they relate to important subsequent outcomes for individuals (e.g., Hanushek, 1989; Ferguson \& Ladd, 1996). However, some researchers question educational outcome measured by standardized test scores or other simple measures of student achievement (e.g. Card \& Krueger, 1996).

Burtless (1996) points out that the choice of educational inputs varies from study to study, but these variables are classified as school inputs or non-school inputs. School inputs include teachers' characteristics such as academic backgrounds, experiences, and starting salaries, and 
classroom inputs such as class sizes, facilities, and administrative expenditures. Non-school inputs include family inputs (e.g., parental education, income, and family size), peer inputs (e.g., peer's demographic characteristics), and district or community factors (characteristics of the areas where individuals attended school). On many occasions these educational inputs are unobserved variables that are difficult to measure quantitatively, such as student's and peer's abilities, relationship between students and teachers, and teaching skill differences (Hanushek, 1986). In general, previous researchers have used a proxy that is observable to capture the unobservable, in particular, IQ as a proxy of student's and peer's abilities. However, of course, there are still controversies as to whether IQ is a good measure of ability.

\section{Levels of aggregation}

In previous literature, education production functions have been estimated at various levels of aggregation, such as across individuals, schools and school districts (or a similar geographical classification in other countries). Controversy exists in relation to the level of aggregation of school quality measures. In particular, Hanushek (1997), Hanushek, Rivkin and Taylor $(1995,1996)$ and Betts (1995) suggested that studies that measure school inputs using higher levels of aggregation overstate the positive effect of school inputs. They suggest that the level of aggregation does matter and that as level of aggregation increases, the probability of finding positive and significant results for school influence also increases.

\section{Correcting econometric biases}

Multicollinearity: There are several econometric problems in estimating an education production function. Multicollinearity may appear if two or more independent variables are highly (but not perfectly) correlated. However, since multicollinearlity violates none of the assumptions for establishing the absence of bias in OLS estimation, the problem is not really well-defined 
(Wooldridge, 2009). In practice, in the United States, since school expenditures are funded by property taxes at the local level, it is to be noted that spending per student and family income might be correlated.

Self-selection: One of the econometric issues of the Coleman's report was the self-selection problem. It is pointed out that the Coleman's report examined just a snapshot in time (not a longitudinal picture) and thus its conclusions might reflect what is known as self-selection bias: Blacks and low-income students in racially and economically integrated schools might just be more motivated than those in segregated schools. But numerous subsequent studies sought to correct for this bias, looking longitudinally at the growth in achievement over time, and confirmed that middle-class schools provide a better educational environment than povertyconcentrated schools.

Omitted variable bias: Estimated relationships between school inputs and outputs may reflect the influence of omitted factors, rather than true effect of school resources. In Card and Krueger's (1996) view, the most important omitted variables are likely to be measures of family background and characteristics of the areas where individuals attended schools. Another important omitted variable might be student's abilities (ability bias).

Publication bias: This problem was first addressed by Hedges et al. (1994). It refers to the fact that most of the results usually published by journals are those with statistically significant results, either negative or positive. In such a case, the actual effect is buried due to tendencies to make research reports favorable for purposes of publication (also see Pritchett \& Filmer, 1999). Measurement errors: If input or output variables contain measurement errors, for instance in educational attainment or achievement estimates caused by underreporting/misreporting of the educational level, this may bias the OLS estimations in any direction. In general, earnings- 
education equations usually entail a 10 percent underestimation of rates of return due to measurement error bias (Card, 1999). Krueger and Lindahl (2001) evaluated the attenuation bias due to measurement error by using the reliability ratio.

\section{Evidence on student performance in developing countries}

One of the notable studies that combines data from both developed as well as developing countries is by James (1987) who conducted regression analyses so as to explain variations in size of the private sector across states within several countries: the U.S, Japan, Holland and India. Her results show that excess demand leads to a large private sector at the secondary and university levels in developing countries, while differentiated demand leads to more private education at the primary and secondary levels in advanced industrial countries. On the supply side, the results show that the availability of religious (nonprofit) entrepreneurship plays an important role in both cases. The problem with her study, however, is that her sample size is very small. In addition, the four countries that she has considered differ greatly in terms of stage of development, political system, cultural values and size of private educational sector. Therefore, the external validity of the results from this study is questionable.

A similar attempt of combining data from both developed and developing countries to study the determinants of student performance was done by Heyneman and Loxley (1983). The controversial results from Coleman Report (1966) had suggested that school inputs had a negligible effect on the student performance and that family socio- economic characteristics of students were more important in determining academic achievement. However, Heyneman and Loxley (1983) criticized the report because the U.S. data are not representative of most countries. Rather, they used data from 29 high and low income countries from the Second International 
Mathematics and Science Study (SIMSS) and concluded that the predominant influence on student learning can be attributed to the quality of the schools and teachers to which children are exposed, and that this relationship is stronger in developing countries than developed countries. More studies on developing countries later found a strong relationship between a number of resource variables and student outcomes (Fuller \& Clark, 1994; Hanushek 1995; Scheerns, 2004).

\section{Evidence on student performance in Nepal}

Taking this as our departure point for the case of Nepal, the literature suggests a huge difference between public schools and private schools in Nepal in terms of quality and hence academic achievement (Carney, 2003; Caddell, 2006; Bhatta, 2004; Bhatta, 2005; Carney and Bista, 2009). An example of the striking difference between government and private schools is that in 2004, only 29 percent out of 171,440 government school students passed the School Leaving Certificate Exam, while 80 percent out of 44,863 private school students passed the exam (MOES, 2005a). As a result of poor performance of public schools, the demand for private schools in developing countries is rising rapidly, and private schools are seen to assume huge role in catering to the educational needs of the poor (Tooley \& Dixon, 2005). For example, based on their in-depth study in India, Ghana, Nigeria and Kenya, Tooley and Dixon (2005) point out several reasons to explain the mushrooming of private schools in developing countries. The reasons they claim are: the deterioration of government schools, the lack of government schools, and (in India) the desire of parents for instruction in English. Moreover, the authors argue that the deterioration of government school standards can be attributed to the lack of teacher accountability, strong unions, poor facilities, high pupil-teacher ratios, and poor management. 
But, private schooling as a solution to failing public schools in developing countries is not as straightforward as put by Tooley and Dixon (2005). There are a lot of complexities involved. For example, Colclough (1996) finds that cost recovery policies would be harmful to both efficiency and equity if significant resources were to be generated by these means. So, the case is surely multi-dimensional in the case of developing countries and needs careful study.

In the case of Nepal too, the low performance of public schools amidst extremely disturbing political environment on one hand, and the adverse effect of neoliberalism on the other hand makes the study of public versus private schooling multi-dimensional and hence challenging. So, performing additional comparative studies on public and private schools is very useful. Further, finding the presence of any such linkages and mutual impact between public and private schools is very important for future policy goals. Unfortunately, in Nepal, there are not many studies in this area, however, below is a discussion of some of them known to the author.

A study by The New ERA (1995) used data from 126 schools in 8 districts and found that parental education and student's regularity of school attendance had a positive impact and gender (being female), and time spent household chores had a negative impact on students' academic achievement. Among the school/teacher characteristics, the study found that classroom overcrowding, head teacher competency and teacher qualifications were factors that influenced student performance. Another research study that identified numbers of the potential determinants of student performance is by METCON (1995). The study highlighted that the delay faced by the majority of the students in receiving the full set of textbooks each academic year was one of the most influencing factors in explaining students' achievement. Interestingly, the study points out that 50 percent of the sample students did not have all the textbooks even at the mid point of the academic session. In addition to this, the study suggests that among the other 
factors that influence student's attainment are the distance students travel to school daily, class repetitions, and the loss of school days.

The CERID (2002a), which used multivariate statistical methods, analyzed school conditions and the cost per student to examine the relationship between these factors and the achievement of primary school students at the individual subjects. The study found that both of these factors affected student performance as well as enrolment, promotion and repetition rates for students. However, the study did not control for student's personal characteristics and family background which are very important for accessing student achievement. Hence, although the findings of this study seem quite contextual in the Nepalese context, the results are, no doubt biased. The same institution performed another qualitative study analyzing the impact of the classroom environment. The findings of this study suggested that an inadequate amount of time spent by teachers on classroom instruction, their inability to effectively apply the knowledge gained from teacher training programs, and their emphasis on rote learning were some of the major factors that have a negative impact on student learning (CERID, 2002b).

METCON and ECL (2000) evaluated the Secondary Education Project (SEP) using a qualitative study to examine the potential determinants of student's academic performance. The study, using review of documents, structured interviews and informal discussions with head teachers, teachers, parents and students found that the unavailability of qualified subject teachers, the lack of educational materials, and the shortage of textbooks were some of the important factors for low quality of schooling in rural areas of the country. In addition, the study found a positive impact of teacher training on the teachers as well as students' performance. Moreover, pointing out the large gap in the performance between public and private schools, the study argues that poor physical facilities, shortage of resources, and ineffective management are the 
most important factors marking the stark difference between public and private schools in the nation.

There are basically two major problems related to the studies summarized above. First, all of them focused on the primary level. One cannot generalize the findings to secondary and higher secondary levels because the teaching and learning methods are quite different at the higher levels. Second, these studies do not provide any empirical models and hence are not statistically sound. There are only few others which are relatively better in terms of statistical strength in their analysis. I summarize three such studies identified so far in the Nepalese context.

First, studies by EDSC (1997; 1999; 2001; and 2003) on three national student achievement surveys used multiple regression techniques by utilizing data from nationally representative random samples of students. The EDSC (1997) and EDSC (2001) used the case of grade three students and EDSC (1999) and EDSC (2003) used the case of grade five students to analyze the relationships between subject-wise student achievement and various sets of determinants. The findings from all the above four studies suggested statistically significant relationships between a number of school factors and student performance. Similar to the findings of the METCON and ECL (2000) study, these studies also found that the unavailability of the required textbooks and the distances of the school from the district headquarters were some of the significant factors related to students' performance. Interestingly, the studies point out that the farther the school was located from the district headquarters, the greater was the students' of that school likelihood of having lower test scores. The results of these studies also indicate a positive effect of expenditure per child in explaining student performance. At the student level, the variables that are significant as found by these studies were gender, age, class 
attendance, grade repetitions, and reading habit of students. At the family level, the occupation of the parents was found to be more influencing to their child's achievement. These studies too however are confined to primary school. Also, there is no control of important school factors. Hence, the studies definitely suffer from omitted variable bias.

A second study of more statistical rigor by Subedi (2004) used Hierarchical Linear Modeling (HLM) method to study the impact of class size, the availability of resources and the use of resources by teachers on the average classroom achievement scores in high schools (grades 9 and 10) in Nepal. The target population of this study included all the teachers teaching grades 9 and 10 in high schools (16 public and 14 private schools) of the Lalitpur district, which is in the Kathmandu Valley. The outcome variable for this study was the average classroom achievement score, which was derived from the mean classroom student achievement for individual classroom score in which a specific teacher taught. According to the author, multiple classrooms are nested within a specific teacher and, hence the justification of the use of the HLM method. In the study, classroom level was taken as level 1 and teacher level as level 2. The findings from the study suggest a positive effect of resources and a negative effect of class size on average classroom achievement. The results of the study show that teachers who used the available resources effectively in the classroom were able to increase students' achievement. Further, the results showed a negative effect of class size indicating that a classroom with a large number of students decreases the average level of student achievement. Moreover, the study found significant variations in average classroom achievement and class size effect across the teachers. Although this study made a good attempt to use technique like HLM in the case of Nepalese data, one of the major drawbacks of this study was that the sample size was too small, and the study was limited to only one district, and that too was located in the Kathmandu Valley. 
A study of schools that are within the Kathmandu valley is not at all representative of the schools located in different parts of the country, especially compared to the schools in remote and rural areas of the country. Hence, the external validity of this study is highly questionable.

The third study is by Bhatta (2005). Using a large-scale nationwide survey data set under the sponsorship of Ministry of Education, the study attempted to explore the determinants of student performance on the SLC examination using OLS and logistic regressions. The study found statistically significant differences in student performance across school types (public versus private), genders, ethnicities and school locations. In particular, the study found that after controlling for student, family, school and community characteristics, the SLC scores and pass rates for public schools were relatively low compared to private schools. However, although the study incorporated all the necessary variables, the study still suffers from a selection bias problem. The private school students are significantly different from public school students. The study ignored this serious issue, and hence results are most likely biased.

\section{Evidence on Private Tutoring}

Private tutoring is a supplementary service provided by private agencies and financed by the student/family using the service. It is supplementary because the tutoring service covers the same subjects that have already been or supposed to have been covered in school. There is a huge literature on private tutoring covering both developed as well as developing countries (for example, see Stevenson \& Baker, 1992; Baker, Akiba, LeTendre \& Wiseman, 2001; Assaad \& El-Badawy, 2004; Kim \& Lee, 2004; Baker \& LeTendre, 2005; Dang, 2007; Kim, 2007; Bray, 2009). In general, the literature suggests that the demand for private tutoring could be basically 
motivated by enrichment or remediation. Private tutoring is also called shadow education as these services are assumed to shadow the requirements of the schools that a student goes (Stevenson \& Baker, 1992). According to Bray (1999), shadow education is characterized by the following elements: i) the existence of private tutoring depends on the existence of a formal school education process ii) the size and shape of private tutoring changes with those of the formal school education process iii) public attention focuses mostly on the formal school education process, rather than on its shadow, and iv) the shadow education has less distinctive features than the formal school education process. In most of cases, private tutoring is either offered on a one-to-one basis or provided in small groups or in large classes. Studies around the world show that private tutoring is prevalent in most countries that are diverse in economic, geographic or cultural contexts. In some countries such as Japan, Hong Kong, Singapore, South Korea, Greece and Turkey, the scale of private tutoring is so extensive that it runs parallel to formal schooling (Baker \& LeTendre, 2005). Below, I highlight some selected studies that are relevant to this dissertation.

Using data from the Third International Mathematics and Science Study (TIMSS) for 41 countries and controlling for family income, student, and community characteristics, Baker, Akiba, LeTendre and Wiseman (2001) show that private tutoring is used significantly more often by low math achievers than by high achievers in three-fourths of these countries. In contrast, Kim (2007), using data from South Korea shows that students from the second quintile from the top have a significantly higher probability of participating in private tutoring, and those in the fifth quintile have a lower probability of private tutoring participation.

There are other studies that show that family background variables (such as household wealth, parental education and location of living) influence the use of private tutoring the most 
(Assaad \& El-Badawy, 2004; Dang, 2007; Kim, 2007; Kim \& Lee, 2004; Stevenson \& Baker, 1992). These studies suggest that students from wealthier and more educated households living in urban areas are more likely to use and spend more on private tutoring. However, there could be a different scenario in countries with very poor public education system as in the case of Nepal. For example, Kim and Lee (2004) argue that in the case of a deficient public education system parents tend to resort to private tutoring to compensate for poor quality or lack of education opportunity. In line with this argument, Baker et al. (2001) find that higher public education expenditure as a share of GNP and gross enrollment rates predict lower use of private tutoring. Further, studies also point out that low pay levels and weak monitoring of teachers in the public system could motivate teachers to impose tutoring on students (Buchmann, 1999; Silova \& Bray, 2006). Besides the school quality, studies also suggest that the student's grade level could be an influencing factor in the use of private tutoring. For example, Assaad and ElBadawy (2004) in the case of Egypt, and Dang (2007) in the case of Vietnam find that students in the last year of their current school spend more on private tutoring. In addition, Dang (2007) also finds that private tutoring expenditure is positively related to the share of people with an upper secondary education or higher in the community. Another interesting determinant of use of private tutoring relates to the cultural values (Bray, 1999). For example, Baker and LeTendre (2005) point out that students in countries with an extensive shadow education system often attend private tutoring because their friends do so.

In the context of Nepal, I have not found any significant empirical study regarding private tutoring. However, there are few noteworthy observations regarding private tutoring in Nepal. For example, Carney (2003) argues that the demand for different tiers of education for lower, middle and high income families in education sector is influenced by the interplay of neo- 
liberalism, fiscal constraint and weak public governance. We can thus view the emergence of private tutoring as a by-product of this dynamics in the education market of Nepal. Another supportive observation by Caddell (2007) was made during her field-visits to Nepal's government-funded public schools. She found that public schools offered a private stream for those who could afford, and students were taught in English using English medium textbooks. Moreover, the author found that the students were taught in the same building and by the same teachers as those in the 'non-private' stream. As there are insufficient numbers of studies on private tutoring in the case of Nepal, below I discuss the case of two countries from South Asia, Bangladesh and Sri Lanka that come close to Nepal in terms of size and socioeconomic composition, and hence are relevant in the context of this study. In Bangladesh, a study by Ahmed and Nath (2005) of 8212 households in 10 diverse locations found that an average of 43.2 percent of primary school students receive private tutoring. They found that the proportion receiving private tutoring in the lowest and the highest grade was 33.9 percent and 54.7 percent, respectively. Further, the study showed that boys received more tutoring than girls, with respective averages in the lowest and highest grades of 45.6 percent and 40.7 percent respectively. In Sri Lanka, a study done in 1990 found that the proportions receiving private tutoring in Sri Lanka in year 6 and 11 are 80 percent and 75 percent respectively. In year 13, the proportions were 62 percent for arts students, 67 percent for commerce students, and 92 percent for science students (de Silva, 1994).

Models and Identification Strategy

The Basic Empirical Model 
As discussed above, this dissertation uses the theory of the educational production function in estimating the effect of school type on student's SLC performance. The approach to this section is to test the hypothesis that a student from a private school performs better on the SLC examination than a student from a public school, holding other things constant. Symbolically, the model postulates that the performance of a student $i$, in school $j$ is given by the following reduced form expression:

$$
\mathrm{Y}_{\mathrm{ij}}=\infty_{0}+\infty_{1} \mathrm{~S}_{(\mathrm{i}) \mathrm{j}}+\infty_{2} \mathrm{X}_{\mathrm{ij}}+\mu_{\mathrm{ij}}
$$

where $\mathrm{Y}_{\mathrm{ij}}$ is the aggregate SLC Test Score ${ }^{22}$ of student $i$ in school $j, \mathrm{~S}_{(\mathrm{i}) \mathrm{j}}$ is the key independent variable of interest that represents school type ${ }^{23}$ (which is a dummy variable, private if it takes value 1 , and 0 if public), $X_{\mathrm{ij}}$ is a vector of control variables representing student, family, school and teacher characteristics as well as exam context variables, and $\mu_{\mathrm{ij}}$ is random disturbance with mean zero and constant variance. The dependent variable in this case is the aggregate SLC score of the student, which is a continuous variable. The Ordinary Least Squares (OLS) regression method is used to estimate equation 4.6.

\section{Probit Model for SLC Result}

In equation 4.6, when the dependent variable is changed to a categorical variable equal to one if the student passed the SLC exam and zero otherwise, the model can be stated as follows:

\footnotetext{
${ }^{22}$ Note that generally the SLC Score is comprised of 8 subjects- 6 compulsory (Math, Science, English, Nepali, Social Studies, Health \& Population studies) and 2 optional subjects. But, for this dissertation, only 6 compulsory subjects are used. However, I do report results using the aggregate score to compare across the models. The score is converted to a scale of 100 .

${ }^{23}$ The subscript $i$ in parenthesis denotes that although school type is a school level variable, it is applied for student $i$.
} 


$$
\mathrm{Y}_{\mathrm{ij}}=\beta_{0}+\beta_{1} \mathrm{~S}_{(\mathrm{i}) \mathrm{j}}+\beta_{2} \mathrm{X}_{\mathrm{ij}}^{\prime}+v_{\mathrm{ij}}
$$

where $\mathrm{Y}^{*}{ }_{\mathrm{ij}}$ is SLC test outcome of student $i$ in school $j$, and $v_{\mathrm{ij}}$ is a random disturbance with mean zero and constant variance. Since the SLC test outcome variable in this case is a categorical variable, a probit model is used, where a set of explanatory variables, including school type, is postulated to affect the probability that a student passes the SLC exam, as follows:

$$
\operatorname{Pr}\left(\mathrm{Y}_{\mathrm{ij}}=1 \mid \mathrm{S}_{(\mathrm{i}) \mathrm{j}}, \mathrm{X}_{\mathrm{ij}}\right)=\Phi\left(\beta_{0}+\beta_{1} \mathrm{~S}_{(\mathrm{i}) \mathrm{j}}+\beta_{2} \mathrm{X}_{\mathrm{ij}}^{\prime}+\mathrm{v}_{\mathrm{ij}}\right)
$$

where $\Phi$ is the standard normal cumulative distribution function.

The coefficients of these regressions indicate how a change in each of the explanatory variables is associated with the probability of passing the SLC exams, assuming all the other factors remain constant. In addition to these empirical models for analyzing private versus public performance, I also develop two supporting probit models as follows. The first focuses on the SLC exam, and the second is on private tutoring.

\section{Probit Model for The Medium of Exam}

Since there are two mediums for writing SLC exam (English and Nepali) ${ }^{24}$, I postulate another probit model to explain the medium of exam. In other words, in equation 4.6, I change the dependent variable to medium of exam, which is also a categorical variable that takes the value one if the medium of the SLC exam that student took is Nepali and takes the value zero if the medium is English or mixed (Nepali and English). The model can then be stated as follows:

\footnotetext{
${ }^{24}$ SLC Exam can be given either in Nepali, English or Mixed. For this study, I have considered mixed as English.
} 


$$
\mathrm{M}_{\mathrm{ij}}=\gamma_{0}+\gamma_{1} \mathrm{~S}_{(\mathrm{i}) \mathrm{j}}+\gamma_{2} \mathrm{X}_{\mathrm{ij}}^{\prime}+\varepsilon_{\mathrm{ij}}
$$

where $\mathrm{M}_{\mathrm{ij}}$ is the SLC test outcome of student $i$ in school $j$, and $\varepsilon_{\mathrm{ij}}$ is random disturbance with mean zero and constant variance. Since the medium of the SLC exam variable in this case is a categorical variable, a probit model is used, where a set of explanatory variables, including school type, is postulated to affect the probability that a student passes the SLC exam, as follows:

$$
\operatorname{Pr}\left(\mathrm{M}_{\mathrm{ij}}=1 \mid \mathrm{S}_{(\mathrm{i}) \mathrm{j}}, \mathrm{X}_{\mathrm{ij}}\right)=\phi\left(\gamma_{0}+\gamma_{1} \mathrm{~S}_{(\mathrm{i}) \mathrm{j}}+\gamma_{2} \mathrm{X}_{\mathrm{ij}}^{\prime}+\varepsilon_{\mathrm{ij}}\right)
$$

where $\phi$ is the standard normal cumulative distribution function.

\section{Probit Model for Private Tutoring}

In the Nepalese education system, private education seems to be a dominant factor in explaining student's SLC performance. Hence, I also postulate a probit model to examine the factors that explain a student's behavior about private tutoring. To do this, I change the dependent variable to private tutoring in equation 4.6, which is a categorical variable that takes the value one if student took private tutoring for the SLC exam and takes the value zero if the student did not take private tutoring. The model can then be stated as follows:

(4.11) $\mathrm{T}_{\mathrm{ij}}=\delta_{0}+\delta_{1} \mathrm{~S}_{(\mathrm{i}) \mathrm{j}}+\delta_{2} \mathrm{X}_{\mathrm{ij}}^{\prime}+\mathrm{u}_{\mathrm{ij}}$ 
where $\mathrm{T}_{\mathrm{ij}}$ represent whether or not a student $i$ in school $j$ took private tutoring for the SLC exam, and $\mathrm{u}_{\mathrm{ij}}$ is a random disturbance with a mean of zero and constant variance. Since the private tutoring variable in this case is a categorical variable, I again postulate a probit model, where a set of explanatory variables, including school type, is believed to affect the probability that a student takes private tutoring for the SLC exam, as follows:

$$
\operatorname{Pr}\left(\mathrm{T}_{\mathrm{ij}}=1 \mid \mathrm{S}_{(\mathrm{i}) \mathrm{j}}, \mathrm{X}_{\mathrm{ij}}\right)=\varphi\left(\delta_{0}+\delta_{1} \mathrm{~S}_{(\mathrm{i}) \mathrm{j}}^{\prime}+\delta_{2} \mathrm{X}_{\mathrm{ij}}^{\prime}+\mathrm{u}_{\mathrm{ij}}\right)
$$

where $\varphi$ is the standard normal cumulative distribution function.

\section{Empirical Issue: Self Selection}

The key issue to tackle when estimating the impact of school type on educational outcomes is self-selection bias. Self-selection bias arises because private school students can differ fundamentally from public school students: they self-select. Therefore, one cannot determine what would happen to public school students if they go to private schools, just looking at the student, family and school characteristics (or vice versa).

For example, private school students are generally from wealthier and more educated families who might also be likely to possess more academic skills and learning aptitude, thus performing better in the SLC exam (what is called "positive selection"). However, the selection cannot be observed in advance and contains the error term as unobserved characteristics that are correlated both with the school type and educational outcome.

\section{Propensity Score Matching}


There are techniques to account for the selection bias problem, which is one of the most common in econometric analysis. One of the popular methods used to deal with selection issue is the Heckman-Lee correction. This method, originally developed by Heckman from 1976 to 1979 is a two-step statistical approach that offers a means of correcting for non-randomly selected samples (Heckman, 1979; Lee, 2001). This correction method is easy to implement and has a firm basis in statistical theory. Two of the characteristic features of Heckman's correction method are that it involves a normality assumption and that it provides a test for sample selection bias and formula for bias corrected model (Heckman, 1979). However, if this assumption of normality fails, the estimator is generally inconsistent and can provide misleading inference in small samples. Also, identification in this method will be tenuous unless there are many observations in the tails where there is substantial nonlinearity in the Inverse Mills Ratio (Puhani, 2000). Further, in this method an exclusion restriction is generally required to generate credible estimates: there must be at least one variable which appears with a non-zero coefficient in the selection equation but does not appear in the equation of interest, essentially an instrument. If no such variable is available, it may be difficult to correct for sampling selectivity (Puhani, 2000). If these problems are very evident, semi-parametric and other robust alternatives can be used in such cases. Another correction strategies that address the selection biases in making estimates is the Propensity Score Matching, which was first proposed by Rosenbaum and Rubin (1983). This method employs a predicted probability of group membership, such as a treatment versus control group, based on observed predictors, usually obtained from logistic or probit regressions to create a counterfactual group. It may be used for matching or as covariates alone or with other matching variables or covariates. This method has been increasingly popular in medical trials and in economic policy evaluation studies. The basic objective of this method is to construct a counterfactual, which is the outcome that participants would have experienced, on 
average, had they not participated in the treatment. It then estimates the average treatment effect on treated (ATT). In other words, this method estimates each individual's propensity to receive a binary treatment as a function of observables and matches individuals with similar propensities (Rosenbaum \& Rubin, 1983).

The preference for matching methods over other methods, such as the Heckman-Lee correction method, is that the matching methods have the advantage of making comparisons that are used for statistical identification transparent as they make the fewest parametric assumptions. For example, we don't have to specify the multi-dimensional relationship between the outcome (Y) and the covariates $(\mathrm{X})$ in the propensity score matching method. Although we do have to specify the equation that estimates the propensity scores, this is merely a "means to an end" and, in theory, we can check if it is doing its job with balance diagnostics. Simulation studies demonstrate that treatment effect estimates are fairly robust to misspecification of the propensity scores (see Drake, 1993).

Moreover, matching is most practical in cases where the causative variable is binary, as in the school type in this study. In this study, the propensity score matching enables us to find students who are in private schools and students who are in public schools but received similar "propensity scores" and non-parametrically estimate the effect of school type on educational outcomes. Therefore, this study, using data from MOES (2005b) adopts the propensity score matching to correct for the selection bias problem. This is the first study on private and public school performance in Nepal using the propensity score matching method and hence making this a unique study. 
The propensity score matching, however, is not free of problems and criticisms. For example, as pointed by Shadish, Cook, and Campbell (2002) the requirement of large samples and substantial group is one of the serious problems of this method. The second problem as pointed by the authors relates to unobservable factors. The authors argue that hidden biases may remain because matching only controls for the observed variables to the extent that they are perfectly measured. Likewise, Michalopoulos, Bloom and Hill (2004) argue that although the propensity score matching method can help reduce large biases, significant biases may still remain. This method is also criticized on the grounds that it can be sensitive to choices such as the propensity score specification. After admitting these potential drawbacks of the method well beforehand, I next present a brief review of a few examples of the use of propensity score matching as found in the literature.

After the propensity score matching method was formally introduced by Rosenbaum and Rubin in 1983, LaLonde (1986) attempted to evaluate the performance of observational methods to test the efficacy of a variety of econometric techniques. He started with data from a randomized field experiment (National Supported Work) and constructed an observational study by using the treatment group from this experiment. He then added comparison groups created from contemporaneous survey data from Panel Study of Income Dynamics (PSID) and Current Population survey (CPS). In this way, he showed that observational estimates can be evaluated using the experimental estimate as a reliable benchmark of the "truth". This study was repeated by Dehejia and Wahba (1999) using propensity score approaches. The work by Dehejia and Wahba (1999) was successful overall, but ignited a lot of controversy. Nonetheless, this concept of the "constructed observational study" has since been used more broadly. In this, randomized experiments (where the true treatment effect is "known") are generally used as the starting point, 
but then the control group is replaced by a control group constructed from another survey, another location or cohort in the same experiment, and so on. Then observational methods are used to see how close they can get to the experimental benchmarks. In two such cases (Dehejia \& Wahba, 1999; Hill, Reiter \& Zanutto, 2004) propensity scores were found to replicate experimental estimates well in settings where regression failed. In a few other studies, the results were more mixed. In those cases, they were criticized for not being well-constructed studies making the results difficult to interpret. Hence, there are few such success stories regarding the use of the propensity score matching method. However, as discussed earlier, there are lots of critics of this method, and the method is hotly debated among evaluation researchers. The next discussion relates to the mechanics involved in the propensity score matching method as applied to this dissertation.

Suppose we would like to know the effect of private schooling on student's SLC score. That is, for each student, we imagine that there are two potential outcomes, $Y(0)$ and $Y(1)$, where $\mathrm{Y}(0)=\mathrm{Y}(\mathrm{Z}=0)$ is the outcome if treatment is not received, and $\mathrm{Y}(1)=\mathrm{Y}(\mathrm{Z}=1)$ is the outcome if treatment is received. So, in our case, $\mathrm{Y}(0)$ is the SLC score of the student who goes to public school, and Y(1) is the SLC score of the student who goes to private school. We use these potential outcomes $(\mathrm{Y}(0), \mathrm{Y}(1))$ to define a causal effect for subject $i$ as a comparison of potential outcomes, most often defined as

(4.13) $\tau_{\mathrm{i}}=\mathrm{Y}_{\mathrm{i}}(1)-\mathrm{Y}_{\mathrm{i}}(0)$

In theory, a causal effect can be defined as any function of the potential outcomes such 
(4.14) $g\left(Y_{i}(1)-Y_{i}(0)\right)=1$ if $Y_{i}(1)>Y_{i}(0)$

However, the fundamental problem of causal inference is that we never observe both $\mathrm{Y}_{\mathrm{i}}(0)$ and $\mathrm{Y}_{\mathrm{i}}(1)$.

Suppose we are interested in estimating the effect on the treated,

$\mathrm{E}\left[\left(\mathrm{Y}_{\mathrm{i}}(1)-\mathrm{Y}_{\mathrm{i}}(0) \mid \mathrm{Z}=1\right]=1=\mathrm{E}\left[\left(\mathrm{Y}_{\mathrm{i}}(1) \mid \mathrm{Z}=1-\mathrm{E}\left[\mathrm{Y}_{\mathrm{i}}(0) \mid \mathrm{Z}=1\right]\right.\right.\right.$

Even though we have observational study, if the covariates in $\mathrm{X}$ are the only confounding covariates (ignorability holds) and we stratify on all the covariates X,

$$
\mathrm{E}\left[\left(\mathrm{Y}_{\mathrm{i}}(0) \mid \mathrm{Z}=1, \mathrm{X}\right]=1=\mathrm{E}\left[\left(\mathrm{Y}_{\mathrm{i}}(0) \mid \mathrm{Z}=0, \mathrm{X}\right]\right.\right.
$$

We can unbiasedly estimate

(4.17) $\mathrm{E}\left[\left(\mathrm{Y}_{\mathrm{i}}(0) \mid \mathrm{Z}=1, \mathrm{X}\right]\right.$ with $\overline{\mathrm{Y}}_{\mathrm{Z}=1, \mathrm{X}}$ and

(4.18) $\mathrm{E}\left[\left(\mathrm{Y}_{\mathrm{i}}(0) \mid \mathrm{Z}=1, \mathrm{X}\right]\right.$ with $\overline{\mathrm{Y}}_{\mathrm{Z}=0, \mathrm{X}}$

But, if X includes many covariates this becomes a difficult task to perform. Propensity score matching provides a potential solution in this case. Propensity score theory says that rather than controlling for (stratifying on, regressing on, matching on) all the variables in $\mathrm{X}$, it is 
sufficient to control for just the propensity score, $\mathrm{e}(\mathrm{X})$, which is just a unitary summary of $\mathrm{X}$. In other words, as shown in Rosenbaum and Rubin (1983), full control for the observed covariates can be obtained by controlling solely for a particular function of $X_{i}$ called the propensity score, which is simply the conditional probability of treatment,

(4.19) $\mathrm{e}(\mathrm{X})=\operatorname{Pr}(\mathrm{Z}=1 \mid \mathrm{X}) \quad(=\mathrm{E}[\mathrm{Z} \mid \mathrm{X}])$

We can estimate $\mathrm{e}(\mathrm{X})$ with standard software using logistic or probit regression. Therefore, if ignorability holds, and if we properly control for (e.g. match, stratify, regress) on our estimate of $\mathrm{e}(\mathrm{X})$, we get unbiased treatment effect estimates. Suppose we want to estimate the effect on the treated, as stated in equation (4.15) above. If ignorability holds (i.e., the covariates in $\mathrm{X}$ are the only confounding covariates) and we match on the propensity score, then equation (4.16) can be rewritten as

$\mathrm{E}\left[\left(\mathrm{Y}_{\mathrm{i}}(0) \mid \mathrm{Z}=1, \mathrm{e}(\mathrm{X})\right]=1=\mathrm{E}\left[\left(\mathrm{Y}_{\mathrm{i}}(0) \mid \mathrm{Z}=0, \mathrm{e}(\mathrm{X})\right]\right.\right.$

Now we can unbiasedly estimate

(4.21) $\mathrm{E}\left[\left(\mathrm{Y}_{\mathrm{i}}(0) \mid \mathrm{Z}=1, \mathrm{e}(\mathrm{X})\right]\right.$ with $\overline{\mathrm{Y}}_{\mathrm{Z}=1, \mathrm{e}(\mathrm{X})}$ and

(4.22) $\mathrm{E}\left[\left(\mathrm{Y}_{\mathrm{i}}(0) \mid \mathrm{Z}=1, \mathrm{e}(\mathrm{X})\right]\right.$ with $\overline{\mathrm{Y}}_{\mathrm{Z}=\mathrm{O}, \mathrm{e}(\mathrm{X}) \text {. }}$ 
There are three important issues that arise while implementing matching. The first, is about whether or not to match with replacement. The second is on how many comparison units to match to each treated unit, and finally the choice of the appropriate matching method (Dehijia \& Wahba, 2002). Matching with replacement minimizes the propensity score distance between the matched comparison units and the treatment unit. In this method, each treatment unit can be matched to the nearest comparison unit, even if a comparison unit is matched more than once. Researchers claim that this method helps in reducing the bias. In contrast, in matching without replacement, the control group member once used for matching is removed from the control reservoir and cannot be chosen again. In this case, the researcher will be forced to match treated units to comparison units that are quite different in terms of the estimated propensity score. This is why it is believed to increase bias, however, it could improve the precision of the estimates. In addition, in matching without replacement, the results are potentially sensitive to the order in which the treatment units are matched (Rosenbaum, 1995).

The question of how many comparison units to match with each treatment unit is closely related. By using a single comparison unit for each treatment unit, we ensure the smallest propensity-score distance between the treatment and comparison units. By using more comparison units, one increases the precision of the estimates, but at the cost of increased bias. One method of selecting a set of comparison units is the nearest-neighbor method, which selects the $m$ comparison units whose propensity scores are closest to the treated unit in question. Another method is caliper matching, which uses all of the comparison units within a predefined propensity score radius (or "caliper"). A benefit of caliper matching is that it uses only as many comparison units as are available within the calipers, allowing for the use of extra (fewer) units when good matches are (not) available (see Cochran \& Rubin, 1973). 
The third issue deals with the type of method to select in practice. Generally, we find the following four variants of propensity score matching used by researchers: nearest neighbor matching, radius matching, kernel matching, and interval matching (see Morgan \& Harding, 2006). For example, in kernel-based matching, suppose we associate the outcome $y_{i}$ of treated unit $i$. A matched outcome is given by a kernel-weighted average of the outcome of all nontreated units, where the weight given to non-treated unit $j$ is in proportion to the closeness between $i$ and $j$ (see Heckman, Ichimura \& Todd, 1998) Another matching technique is the Mahalnobis distance matching which is based on Mahalnobis distance that is a useful way of determining similarity of an unknown sample set to a known one. However, the literature on this is not very clear on which of these matching algorithms works best for which analytics. The answer depends crucially on the substantive application (see, Becker \& Ichino, 2002; Becker \& Caliendo, 2007 for more recent discussions on matching algorithms). Nevertheless, in general the choice of method depends on the data in question, and in particular on the degree of overlap between the treatment and comparison groups in terms of the propensity score (Dehejia \& Wahba, 2002). For example, when there is substantial overlap in the distribution of the propensity score between the control and treatment groups, the results from most of the matching algorithms are almost similar. But, when the treatment and controls are very different, finding a satisfactory match by matching without replacement can be very problematic (Dehejia \& Wahba, 2002). The choice of the method also depends on whether a single or multiple treatment framework is used. For example, the Mahalnobis distance matching method is useful in particular for multiple treatment framework (see Rubin, 1980).

This study using data from MOES (2005b) adopts matching with replacement for singlenearest neighbor matching. This is due to the fact that there is minimal overlap between the 
treatment (private school students) and comparison groups (public school students) in Nepal. As discussed earlier, when there is minimal overlap, matching with replacement emerges as a better choice. Also, since the study has one treatment framework, nearest neighbor matching is suitable and not the Mahalnobis distance matching. Therefore, this method uses matching with replacement for nearest neighbor matching.

The idea in the nearest-neighbor matching is that for each control unit a weight is assigned equal to one for the nearest comparison unit in terms of the balancing score, and zero to all the other comparison observations. More specifically, following Becker and Ichino (2002) a nearest neighboring matching estimator is obtained as follows:

Let $\mathrm{T}$ be the set of treated units and $\mathrm{C}$ the set of control units, and let $\mathrm{Y}_{\mathrm{T}}^{\mathrm{i}}$ and $\mathrm{Y}_{\mathrm{C}}^{\mathrm{j}}$ be the observed outcomes of the treated and control units, respectively. $\mathrm{C}(i)$ denotes the set of control units matched to the treated unit $i$ with an estimate value of the propensity score of $\mathrm{p}_{\mathrm{i}}$. Nearestneighbor matching sets:

$$
C(i)=\min _{j}\left\|p_{i}-p_{j}\right\|
$$

It denotes the number of controls matched with observation $i \in \mathrm{T}$ by $\mathrm{N}_{\mathrm{i}}^{\mathrm{C}}$ and defines the weights as

(4.24) $w_{i j}=\frac{1}{N_{i}^{C}}$, if $\mathrm{j} \in \mathrm{C}(\mathrm{i})$ and $\mathrm{w}_{\mathrm{ij}}=0$, otherwise.

Then ATT can be mathematically expressed as follows: 
(4.25) $\tau=\frac{1}{N^{T}} \sum_{i \in T} Y_{i}^{T}-\frac{1}{N^{T}} \sum_{i \in C} w_{j} Y_{j}^{C}$

where the number of units in the treatment group is denoted by $\mathrm{N}^{\mathrm{T}}$ and $\mathrm{w}_{\mathrm{j}}$ are defined as

$$
w_{j}=\Sigma w_{i j}
$$

In this study, the treatment variable is school type (going to private school), and the outcome variable is the SLC score. Matching is done on student characteristics, family background, school and teacher characteristics and exam context variables. Among the student characteristics, the variables included are age, gender, caste/ethnicity, peers, expected division in the SLC exam, use of private tutoring and student absenteeism in grade 10. Among the family characteristics, variables included are family size, number of SLC graduates in the family, language spoken at home, distance to school from home and having computer at home. Among the school and teacher characteristics, variables included are school size, school having a library, school having science and computer labs, number of days taught in school year, percent of girls in higher secondary grades, student-teacher ratio, teacher qualification and teacher experience. Finally, matching is also done on exam context variables such as medium of writing the SLC exam, student preparing food by self during the SLC exam, SLC year 2002 and SLC year 2003.

\section{Chow Test}

For this study, I perform the Chow test to examine whether the parameters (slopes and the intercept) of private school students are different from those of the public school students. 
The Chow test, developed by economist Gregory Chow (Chow, 1960) is a statistical and econometric test of whether the coefficients in two linear regressions on different data sets are equal. In econometrics, the Chow test is most commonly used in time series analysis to test for the presence of a structural break. The Chow test is also often used in program evaluation to determine whether the independent variables have different impacts on different subgroups of the population. Suppose we have the following model which represent the overall pool of data set.

$$
Y_{t}=a+b X_{1 t}+c X_{2 t}+\varepsilon
$$

If we split our data into two groups (the first for public school students and the second for private school students), then we have:

$$
Y_{t}=a_{1}+b_{1} X_{1 t}+c_{1} X_{2 t}+\varepsilon_{1}
$$

(4.29) $Y_{t}=a_{2}+b_{2} X_{1 t}+c_{2} X_{2 t}+\varepsilon_{2}$

The null hypothesis of the Chow test asserts that $a_{1}=a_{2}, b_{1}=b_{2}$, and $c_{1}=c_{2}$.

Let $S_{C}$ be the sum of squared residuals from the combined data, $S_{1}$ be the sum of squared residuals from the first group, and $S_{2}$ be the sum of squared residuals from the second group. $N_{1}$ and $N_{2}$ are the number of observations in each group and $k$ is the total number of parameters (in this case, 3). Then the Chow test statistic is given by the following relation: 
(4.30) $\frac{\left(S_{c}-\left(S_{1}+S_{2}\right)\right) /(k)}{\left(S_{1}+S_{2}\right) /\left(N_{1}+N_{2}-2 k\right)}$

The test statistic follows the F distribution with $k$ and $N_{1}+N_{2}-2 k$ degrees of freedom.

\section{Estimation and Results}

Specification and Diagnostic Analysis

As I use cross-sectional applications for this study, first, I perform a diagnostic analysis to check the six classical linear model assumptions ${ }^{25}$. In the regression model, the error term $\mu$ is the sum of many different unobserved factors, either student and family related or school or other context related, affecting student's educational outcome. Therefore, I use the central limit theorem to conclude that $\mu$ is normally distributed approximately. In order to do this, I plot the histogram of the residuals, and the following figure 4.1 show that the residuals follow an approximate normal distribution.

\footnotetext{
${ }^{25}$ This includes all Guass-Markov assumptions, and also the assumptions of a normally distributed error term.
} 
Figure 4.1. The distribution of residuals of the regression equation in the basic model

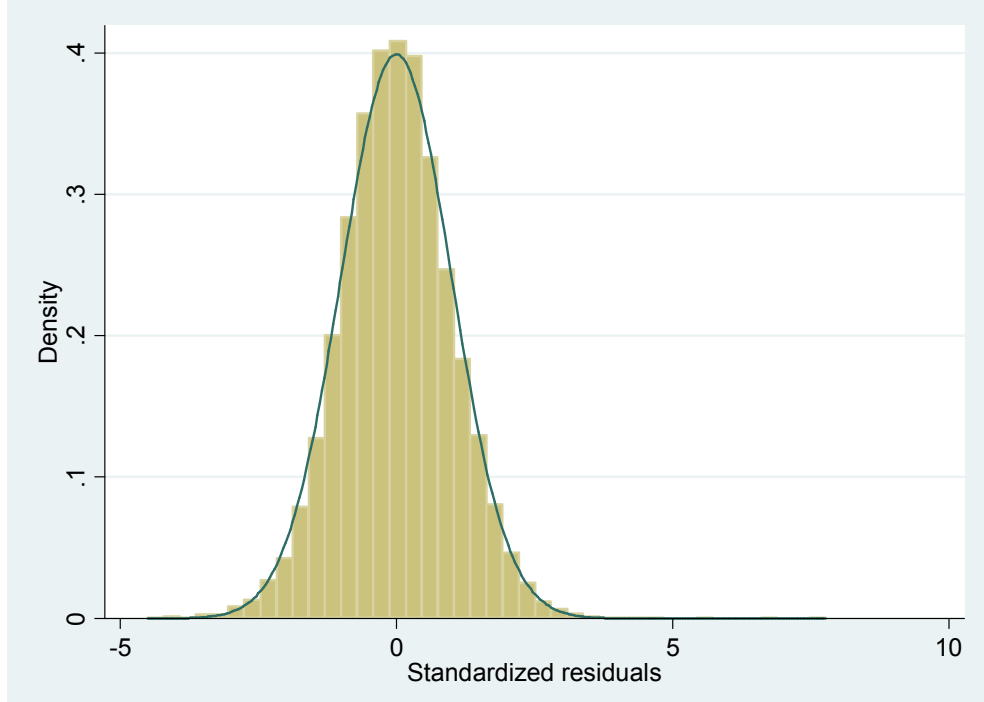

Next, I check if there is heteroskedasticity in the OLS regression. If there is heteroskedasticity, then the OLS estimates are no longer considered BLUE (Best linear Unbiased Estimator). In other words, the presence of heteroskedasticity means that OLS does not provide the estimate with the smallest variance. To check this, I plot residuals against the fitted values and visually inspect for heteroskedasticity. Figure 4.2 shows the plot of the residuals against the fitted values, which shows that the residuals are almost near the zero mean. In addition, the graph also shows that distribution of the residuals do not narrow or widen as most of them are reasonably evenly spread around the mean zero. 
Figure 4.2. Residuals Plotted against the fitted values

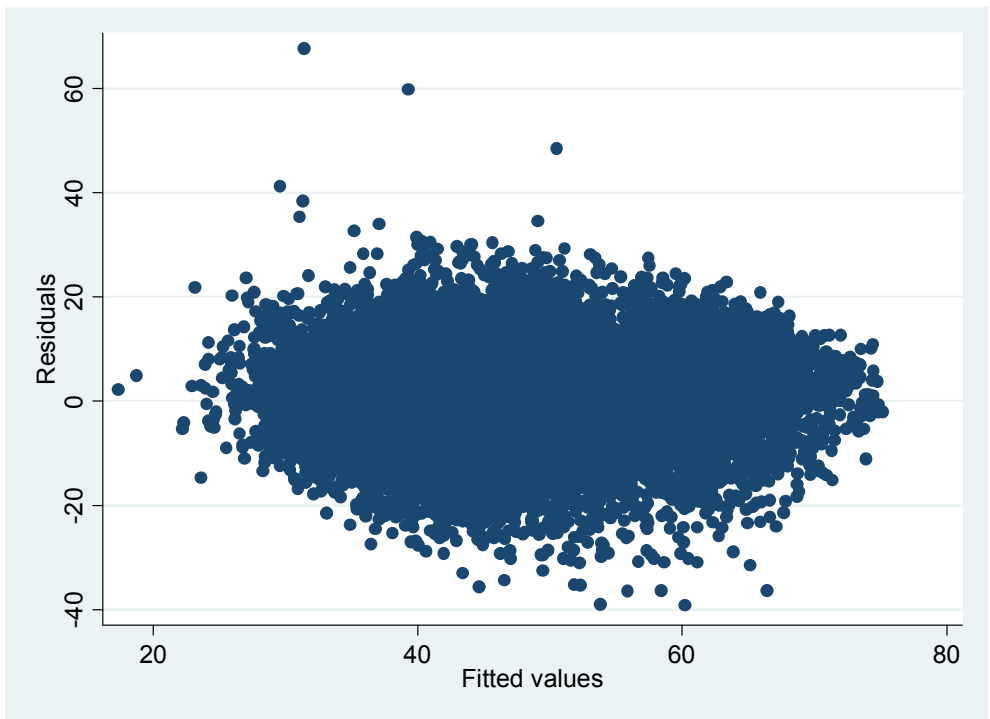

An examination of outliers or extreme values is important for regression analysis. To

check on the outliers, I plot leverage against residual squared. Figure 4.3 shows that there are no points in the right upper side of the graph indicating the presence of no significant outliers in the chosen data set. 
Figure 4.3. Detecting outliers: Leverage vs. normalized residual squared

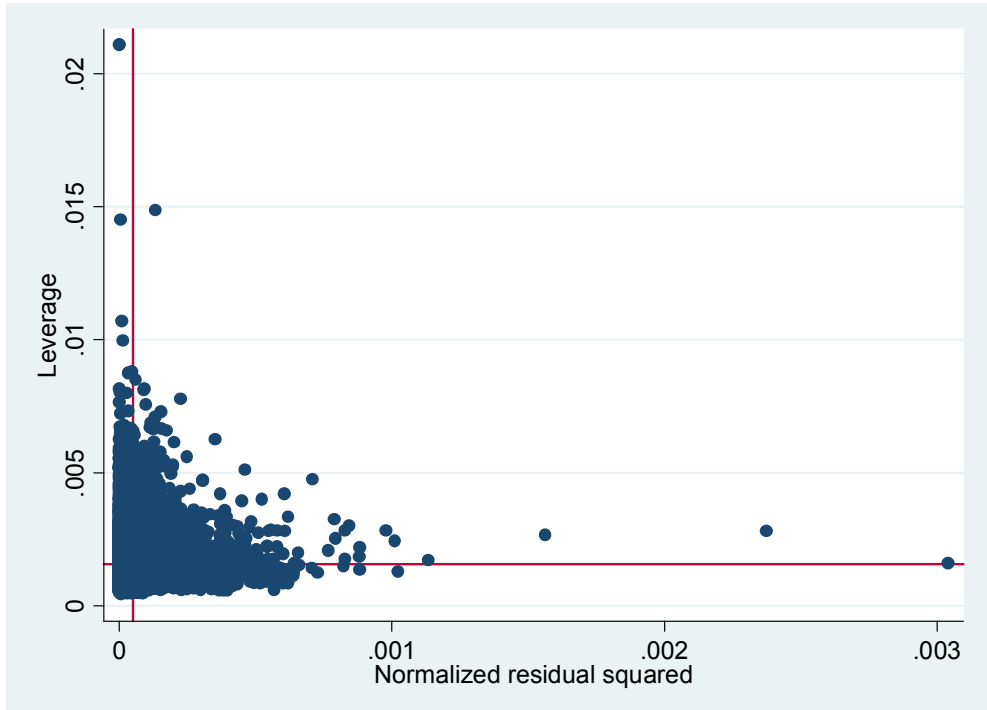

Finally, I examine mulitcollinearity in my regression using the variance inflation index (VIF) that measures the impact of collinearity among the variables in a regression model (see Wooldridge, 2009). The common rule of thumb is that if VIF $>10$, then there is a problem of multicollinearity. The results as shown in table 4.1 show that all the independent variables have VIF that are less than 10. The variable that has the highest VIF is school status with the value of 2.37. Further, I also examine the correlations between the independent variables and find no multicollinearity problem among the independent variables.

\section{Initial Results}

I begin by reporting a simple OLS model that regresses the SLC score (aggregate) with school type (if private) controlling for student, family, school and teacher characteristics, and exam context variables. The summary of the estimates, along with the standard errors are reported in Table 4.2, and the detailed results are presented in Table 4.3. As can be seen in the 
tables, school type (if private) is positive and statistically significant ${ }^{26}$ with a coefficient of 7.47 . This means that holding other things constant, a student going to a private school is associated with 7.47 percentage points increase in the SLC test score. The variables that are significant with positive relationship are the number of friends who passed the SLC exam (peers), expected division in SLC exam, annual family expenses, numbers of SLC graduates in the family, language spoken at home (if Nepali), family having computer at home, school size, school having a science and a computer lab, number of school days in the school year, and percent of girls in higher secondary grades. The variables that are significant with a negative relationship are: age, gender (female), student belonging to the lower caste, the ethnic groups or the other caste, the use of private tutoring, school absenteeism, family size, student-teacher ratio, the medium of the exam ( if Nepali), preparing food during SLC exam, being sick during SLC exam, and SLC year 2003.

Column two reports results from model 2, which is the SLC score using only compulsory subjects (English, Nepali, Mathematics, Science, Social Studies and Health and Population). Removing two optional subjects from the aggregate SLC score reduces the variability in the student performance. Hence, this is believed to be an improvement on the first model that uses all eight subjects for SLC score. The results from this model suggest that school type (private) is positively significant with a coefficient of 7.82. Compared to the model before, in terms of statistical significance and type of relationship with student performance, the result remains almost intact with very slight changes (mostly increases) in the coefficients and standard error of the covariates. The changes are that the percent of girls in higher secondary grades is no longer significant, and SLC year 2002 is now significant with a negative relationship to student performance. It is interesting to note that in both the models the coefficient of private tutoring is

\footnotetext{
${ }^{26}$ Variables that are significant only at $5 \%$ or lower are termed significant in this study.
} 
significant and has a negative sign. Although the standard logic is that private tutoring helps student learn better and hence should have a positive relationship with student performance. However, as also discussed in the literature on private tutoring, most of the students who take private tutoring belong to low performing students from public schools, hence a possible explanation of the negative sign.

The third model is derived from the second model by adding the interaction terms. The interactions are included for the following variables: school type, caste (ethnicity), private tutoring, school size, student-teacher ratio, teacher qualification, teacher experience and the medium of the SLC examination. In this model, school type is positive and statistically significant with coefficient of 9.50. Compared to models 1 and 2, the estimate is much larger. Interestingly, teacher qualification is now significant and positively related to student's SLC performance. Student-teacher ratio, as expected, has a negative sign and is statistically significant. The interaction terms yield few interesting results. For ethnic groups, public school favors, and for other castes the private school is favored in terms of student performance. The interaction of private school with the medium of the exam shows that if students belong to private schools but take their SLC exam in Nepali, their score is lower by around seven percentage points. The private tutoring is not significant in this model. However, if public school students take private tutoring then it adds to their SLC score by 1.74 percentage points. Further, higher teacher qualification seems effective when the student-teacher ratio is lower. Moreover, for private schools, the smaller the school size, the better the student performance.

\section{Chow Test}


As discussed in the methodology section, I perform the Chow test to examine whether the parameters (slopes and the intercept) of private school students are different from those of the public school students. For example, I suspect the impact of school size on student's SLC performance varies across school type. In that case, the slope of school size of public school students will be different from the slopes of private school students. The null hypothesis is that the two types of schools have equal parameters for school size and intercept; deviations of the slope and intercept are not statistically discernible from zero. Computing calculated values of the F test and then comparing these with the tabulated value suggests rejection of the null hypothesis. This indicates that private schools and public schools do not share the same intercept and slope of school size. In other words, private and public schools differ in terms of school size. I conduct Chow test for all the covariates as described in the basic model above, and interestingly the results show that private and public schools differ significantly on all of these factors. 
Table 4.2. Summary of estimates of the effect of school type on student's performance in SLC Exam

\begin{tabular}{|c|c|c|c|c|c|c|c|c|c|}
\hline & $\begin{array}{c}\text { SLC Score } \\
\text { (Aggregate) }\end{array}$ & SLC Scc & mpulsory & ubjects) & & $\begin{array}{c}\text { SLC Result } \\
1=\text { Pass }\end{array}$ & & $\begin{array}{l}\text { Medium of } \\
\text { Exam }\end{array}$ & $\begin{array}{l}\text { Private } \\
\text { Tutoring }\end{array}$ \\
\hline & OLS & OLS & OLS & $\begin{array}{l}\text { PSM in } \\
\text { OLS }\end{array}$ & Probit & Probit & $\begin{array}{l}\text { PSM in } \\
\text { Probit }\end{array}$ & Probit & Probit \\
\hline & 1 & 2 & 3 & 4 & 5 & 6 & 7 & 8 & 9 \\
\hline School Type (private) & $\begin{array}{l}7.47 * * * \\
(0.23)\end{array}$ & $\begin{array}{l}7.82 * * * \\
(0.23)\end{array}$ & $\begin{array}{l}9.50 * * * \\
(0.39)\end{array}$ & $\begin{array}{l}5.33 * * * \\
(1.03)\end{array}$ & $\begin{array}{l}0.202 * * * \\
(0.01)\end{array}$ & $\begin{array}{l}0.302 * * * \\
(0.02)\end{array}$ & $\begin{array}{l}0.079 * * * \\
(0.02)\end{array}$ & $\begin{array}{l}-0.158 * * * \\
(0.05)\end{array}$ & $\begin{array}{l}-0.17 * * * \\
(0.02)\end{array}$ \\
\hline Student Characteristics & $\sqrt{ }$ & $\sqrt{ }$ & $\sqrt{ }$ & $\sqrt{ }$ & $\sqrt{ }$ & $\sqrt{ }$ & $\sqrt{ }$ & $\sqrt{ }$ & $\sqrt{ }$ \\
\hline Family Characteristics & $\sqrt{ }$ & $\sqrt{ }$ & $\sqrt{ }$ & $\sqrt{ }$ & $\sqrt{ }$ & $\sqrt{ }$ & $\sqrt{ }$ & $\sqrt{ }$ & $\sqrt{ }$ \\
\hline $\begin{array}{l}\text { School \& Teacher } \\
\text { Characteristics }\end{array}$ & $\sqrt{ }$ & $\sqrt{ }$ & $\sqrt{ }$ & $\sqrt{ }$ & $\sqrt{ }$ & $\sqrt{ }$ & $\sqrt{ }$ & $\sqrt{ }$ & $\sqrt{ }$ \\
\hline $\begin{array}{l}\text { Exam and National } \\
\text { Context }\end{array}$ & $\sqrt{ }$ & $\sqrt{ }$ & $\sqrt{ }$ & $\sqrt{ }$ & $\sqrt{ }$ & $\sqrt{ }$ & $\sqrt{ }$ & $\sqrt{ }$ & $\sqrt{ }$ \\
\hline Interaction terms & & & $\sqrt{ }$ & & & $\sqrt{ }$ & & $\sqrt{ }$ & $\sqrt{ }$ \\
\hline $\mathrm{R}^{2} /$ PseudoR $^{2}$ & 0.512 & 0.524 & 0.537 & 0.500 & 0.220 & 0.225 & 0.308 & 0.298 & 0.055 \\
\hline Number of observations & 19897 & 19897 & 19897 & 5104 & 19896 & 19896 & 5113 & 18961 & 18961 \\
\hline
\end{tabular}

Notes: (1) In case of OLS models, the estimates represent the OLS coefficients, and in case of probit models, the estimates represent the marginal effect which is for discrete change of dummy variable from 0 to 1 ; (2) robust standard errors are in parenthesis; (3)* denotes statistically significant at $10 \%$, ** statistically significant at $5 \%$, and $* * *$ statistically significant at $1 \%$. 


\section{Blinder- Oaxaca Decomposition}

One of several techniques used to study labor market outcomes by groups (for example, by sex, race, education) is the Blinder-Oaxaca Decomposition method (Blinder, 1973; Oaxaca, 1973). In this approach, mean differences in log wages is decomposed based on regression models in a counterfactual manner. This procedure divides the wage differential between two groups into a part that is "explained" by group differences in productivity characteristic (such as education, work experience or training) and a residual part that cannot be measured, hence that cannot be accounted for by such differences in wage determinants. This "unexplained" part is taken as a measure for discrimination, but it also subsumes the effects of group differences in unobserved predictors. Though most applications of this method can be found in the labor market and discrimination literature ${ }^{27}$, the technique has also been used in other areas. For example, the technique was used by O' Donnell, van Doorslaer, Wagstaff and Lindelow (2008) to study health inequities by poverty status. In a general sense, this method has been used to study group differences in any (continuous and unbounded) outcome variable (Jann, 2008).

I employ this technique to study the differences in student performance in SLC examination by school type (whether student belonged to private school or public school). Group 1 in my analysis consists of public school students and group 2 belongs to private school students. The covariates used in regression for this decomposition are the usual student, family, school, teacher and exam context variables. Table 4.5 summarizes the result from BlinderOaxaca decomposition. The first section of the table relates to decomposition outputs that reports the mean predictions by school type and their difference. According to the results, for this sample data, the mean of the SLC score ${ }^{28}$ is 60.30 for private schools and 43.25 for public

\footnotetext{
${ }^{27}$ For example, see meta studies such as Stanley and Jarrell (1998); Weichelbaumer and Winter-Ebmer (2005)

${ }^{28}$ Note that the total SLC score for this study is 100 .
} 
schools. The gap between private and public schools in terms of the SLC score is 17.05. In the second section of the table, the SLC score is divided into three parts. The first part reveals that the mean increase in public school students would be 13.12 if they had the same characteristics as private school students. In other words, this suggests to us that the differences in the endowments account for almost two thirds of the performance gap between private and public school students. The second part reflects the change in public school students' performance when applying the private school students' coefficients to the public school students' characteristics. If this is done, public school students will be able to gain 9.61 percent more score points. The third part is the interaction term that measures the simultaneous effect of differences in endowments and coefficients, which is 5.68 percentage points.

\section{Table 4.5. Estimates from Oaxaca-Blinder Decomposition}

\begin{tabular}{lcc}
\hline & Coefficient & $\begin{array}{c}\text { Robust } \\
\text { Std. Error }\end{array}$ \\
\hline $\begin{array}{l}\text { Differential } \\
\text { Public }\end{array}$ & $43.25 * * *$ & 0.08 \\
Private & $60.30 * * *$ & 0.18 \\
Difference & $-17.05 * * *$ & 0.19 \\
Decomposition & & \\
Endowments & $-13.12 * * *$ & 0.45 \\
Coefficients & $-9.61 * * *$ & 0.27 \\
Interaction & $5.68 * * *$ & 0.48 \\
Explained & $-9.23 * * *$ & 0.22 \\
Unexplained & $-7.82 * * *$ & 0.26 \\
\hline
\end{tabular}

Source: Author's calculation using MOES (2005b) data.

Notes: $*$ denotes statistically significant at $10 \%,{ }^{* *}$ statistically significant at $5 \%$, and $* * *$ statistically significant at $1 \%$.

Results from Propensity Score Matching

Although the OLS results are consistent with findings from previous studies (for e.g., Bhatta, 2005), it must be noted that this is an estimate unadjusted for the selectivity as discussed 
in the methodology chapter. Therefore, I apply the propensity score matching to account for selectivity bias. By employing this method, I attempt to estimate average the treatment effects on the treated group (ATT). In other words, I am trying to create a counterfactual to reduce the selection bias in the estimation of treatment effects with observational datasets. The treatment variable is 'private schooling' and the outcome is student's SLC score. The ATT is estimated within the common support region and the standard errors are calculated by bootstrapping with 1000 replications. Balancing propensity scores are estimated in OLS regression by using the same set of observable covariates (student, family, school and teacher characteristics, and exam context) as those used in the previous OLS model. However, as seen in tables 4.2 and 4.3 , the use of propensity score matching reduces the sample size from 19,897 to around 5,100. This is due to the fact that the public school students are very different from the private school students. We see very few cases where public school students share resemble private school students in terms of the characteristics mentioned above. Therefore, when matched on student, family, school and teacher characteristics, the best we could get were only 5,100 such cases. This is a significant drop in the sample size and is not an encouraging situation. However, the good thing is that we are better able to match the distribution of the propensity scores of the treated units at least among these 5,100 cases.

As shown in table 4.6, the ATT of nearest-neighbor matching is 3.96 percent with 2.69 standard errors (confidence interval of -1.306 and 9.236), and is statistically significant at the 5 percent level. In other words, the mean score of the controls after matching increases from 43.25 to 56.34. Comparing this with the results from the Blinder-Oaxaca decomposition results as shown in Table 4.5, we can see that the mean difference in SLC score reduces from 17.05 to 3.96 after using the propensity score matching technique. 
Table 4.6. Average Treatment Effect on the Treated Estimated by Nearest Neighbor Matching

\begin{tabular}{ccc}
\hline & SLC Score (OLS) & SLC Result (Probit) \\
\hline \multirow{3}{*}{ ATT } & 1 & 2 \\
& $3.96^{* *}$ & 0.077 \\
& $(-2.96)$ & $(-0.05)$ \\
& {$[-1.31,9.24]$} & {$[-0.02,0.17]$} \\
\hline
\end{tabular}

Source: Author's calculations

Notes: (1) Robust standard errors of the difference between a treatment and a control group which are calculated by bootstrap techniques with 1000 replications are in parenthesis; (2)The confidence interval associated with the standard errors are in brackets; (3)* denotes statistically significant at $10 \%,{ }^{* *}$ statistically significant at $5 \%$, and $* * *$ statistically significant at $1 \%$.

Table 4.3, Column 4 reports the OLS estimates after matching. This estimate is 5.33 with a standard error of 1.03, which is slightly lower than the previous models. Many of the variables that are significant in Model 2 are not significant in this model. For example, regarding variables with positive relationship, annual family expenses, language spoken at home, family having a computer at home and school having a science and a computer lab are no longer significant in this model. Regarding variables with negative association with student performance, lower caste, private tutoring, family size, and distance to school from home are no longer significant.

\section{Results from Probit Models}

Table 4.4 reports marginal probabilities evaluated at the sample mean along with standard errors from the probit model, where the dependent variable is whether the student passed the SLC exam or not. As before, the variable of interest is school type (if private), and the model is controlled for student characteristics, family characteristics, school and teacher characteristics and exam context variables. The estimates show that school type (private) is positive and 
statistically significant with a marginal effect of 0.20 and a standard error of 0.20 . This means that students who are in private schools are 20 percent more likely to pass the SLC exam than students from public schools. Looking at the marginal effects of variables other than school type, I find that most have the expected signs. For example, variables representing peers, expected division, annual family expenses, number of SLC graduates in the family, school size and school having a science and a computer lab have a positive sign and are statistically significant. On the other hand, variables such as age, gender ( if female), belonging to ethnic groups and other castes, private tutoring, being absent from school, family size, student-teacher ratio, the medium of exam (if Nepali), preparing food during exam and being sick during the exam are negative and statistically significant. Compared with the OLS results, I find that most of the variables are consistent in terms of statistical significance in explaining student's SLC performance.

Next, I introduce interaction terms to this probit model, estimates of which are reported in Column 2 of Table 4.4. The interactions are included for the following variables: school type, caste (ethnicity), private tuition, school size, student-teacher ratio, teacher qualification, teacher experience and the medium of SLC examination. The estimates show that school type (if private) is positive and statistically significant with marginal effect size of 0.302 and a standard error of 0.02 . After the use of the interaction terms, the probability of a private school passing the SLC exam has increased by another 10 percent. The interaction terms also show interesting results in terms of caste/ethnicity of the student. For example, the effect of private school student is lower for students belonging to a lower caste. Teacher experience also seems to have a negative impact for lower caste students. As seen in earlier models, even students from private schools seem to score lower on the SLC exam if the medium of the exam is Nepali. The impact of private tutoring on student score is positive, but when it comes to private school students and a 
higher student teacher ratio, the impact seems to have a negative relationship. This makes good sense because most of the students who take private tutoring seem to be low performing students in classes that have higher student-teacher ratio. Also, the private school effect is lower for those schools with a larger school size.

Finally, as in the OLS case, I also apply the propensity score matching method to the above probit model to estimate the effect of the treatment on the treated (ATT). As before, the treatment variable is 'private schooling' and now the outcome is student's SLC result (if passed). The ATT is estimated within the common support region and the standard errors are calculated by bootstrapping with 1000 replications. However, this time balancing the propensity scores are estimated in the probit regression by using the same set of observable covariates as in the previous models. As reported in Column 2 of table 4.6, the ATT of nearest-neighbor matching is 0.77 with 0.05 standard errors (confidence interval of $-0.019 \& 0.173$ ), which is, however, not statistically significant. Column 7 of Table 4.4 reports the marginal effect of school type after matching is done. The estimate now is 0.079 with standard error of 0.02 . This means, that the students from private schools are now only 7.9 percent more likely to pass the SLC examination than their public school counterparts, keeping other things constant. This shows that even after adjusting for selection bias, the effect of school type on student's SLC performance is substantial. However, the estimate is much lower than that obtained from the OLS regression. Looking at variables other than school type, it is interesting to note that only in this model are teacher variables significant. Both teacher qualification and teacher experience have statistically significant and positive association with student performance. Also, teacher experience squared is negatively significant which means that a longer teacher experience has a negative impact on 
student performance in the SLC exam. Further, as expected, the results show that the marginal effects in most of the covariates are slightly increased with robust standard errors.

Column 8 of Table 4.4 reports estimates from another probit model, where the dependent variable is the language medium of the SLC exam. The variable takes the value 1 if the medium of the SLC exam that the student took is Nepali and takes the value 0 if the medium is English or mixed (Nepali and English). The variable of interest is school type, and the control variables are student, family, school and teacher characteristics, and exam context variables. The estimation results show that school type (private) is negative and statistically significant. The marginal effect of the school type variable is -0.158 with a standard error of 0.05 . This shows that the students in private schools are 15.8 percent less likely to use Nepali as their language medium of examination than students from public schools. In addition, the results also show that those students who speak Nepali at home are likely to use Nepali as their language medium for the SLC examination.

Results from the interaction terms show that although private school students have a negative relationship with the medium of the exam, students from other castes seem to use the Nepali medium even if they are in private schools. The teacher experience is positively related to the medium of the exam. However, for the lower castes, the ethnic groups and the other castes, for schools with higher student-teacher ratio, and for larger schools, teacher experience is negatively related to the medium of exam. Students taking private tutoring and with higher student-teacher ratio are more likely to use Nepali as the medium of exam. The interaction results further show that students exposed to higher teacher qualification but with larger studentteacher ratio are likely to use Nepali as the medium of the exam. However, private school students being taught with higher qualified teachers are more likely to use English or mixed 
language as medium of exam. Also, public schools larger school sizes are more likely to use Nepali as their language medium for the exam.

Finally, Column 9 of Table 4.4, reports estimates from the probit regression that models private tutoring for the SLC exam. The dependent variable is private tutoring that takes the value one if the student took private tutoring for the SLC exam and zero otherwise. As before, the variable of interest is school type, with a similar set of control variables. The results indicate that school type (private) is negative and significant. The estimate of the marginal effect is -0.170 with a standard error of 0.02 . This means that students from private schools are 17.0 percent less likely to take private tutoring for the SLC exam as compared to the students from public schools, keeping other things constant.

The significant interaction terms show that among the private school students, students belonging to the ethnic groups and the other caste are more likely to take private tutoring. Teacher experience seems to have a negative relationship with student taking private tutoring if students belong to the other castes, private schools and in bigger schools. Students in classes with a higher student-teacher ratio are more likely to take private tutoring. However, if students are exposed to teachers with higher qualifications, they seem to be less likely to take private tutoring. Finally, those students who use Nepali as the medium for the exam are more likely to take private tutoring. And, this effect seems to be more pronounced for private students who use Nepali as the language medium for the SLC exam. This analysis shows that students in public schools are most likely to use private tutoring. The results show that students belonging to ethnic groups are more inclined not to take private tutoring. The medium of the exam seems to play a significant role in explaining which students take private tutoring. Those students who use Nepali as the language medium for the SLC exam also seem to be associated positively with 
private tutoring. At the same time the results show that families with more SLC graduates and with good family resources are also likely to send their children for private tutoring. Further students from schools having library, science and computer labs are also likely to go for private tutoring. Hence, there seem to be two groups of students who are more likely to go to private tutoring. The first group belongs to the low performing students from public schools, and the second group belongs to students from the well-to-do families who aspire to perform better than the average. However, the percentage from the first group is suspected to be far bigger than the second group, and is an interesting topic for further research. Also, the findings seem to be consistent with the literature of private tutoring in developing countries that the demand for private tutoring is motivated either by enrichment or remediation. In the case of Nepal, the findings point out that demand for private tutoring is induced more by remediation than enrichment.

\section{Conclusions}

In this chapter, I analyze the private and public school performance in Nepal using various empirical models, the summary of which is presented in table 4.2. First, I use the Ordinary Least Squares regression method to model private school and public school performance. I performed diagnostic checks and show that the data fulfills Gauss-Markov assumptions for linear regression. Next, I add interaction terms and observe that the relationship of the variables is explained more fully. For example, the school and teacher related variables become more meaningful in explaining their relationship to student's SLC performance when interacted with caste/ethnicity, school type and student-teacher ratio. The estimated coefficient of 
school type on student's SLC score from this model is 9.50. This finding suggests that school type matters significantly in student's SLC performance in Nepal.

Next, the Chow test is performed on the pooled data and then separately for private and public school students. The tests on each of the covariates controlled in the regression and logistic models suggest that they vary significantly by school type. In addition, a Blinder-Oaxaca decomposition approach that is performed for private and public school students indicates that there is a gap of 17.42 percentage points in SLC score between private and public school students. Moreover, according to the results from the decomposition, public school students would have their SLC score increase by 9.17 percentage points if they were provided the same endowments as private school students.

In order to tackle the selection bias problem above estimations, I use the propensity score matching technique where the treatment is the student going to private school and the outcome is student's SLC performance. The propensity score model reduces the coefficient of school type to 5.33 and makes the standard errors more robust. Next, I use probit regression to study the impact of school type on student's SLC performance. The results from both the baseline and the model with interactions are mostly consistent with the OLS results in determining the impact of school type on school performance as well as the impact of other covariates on student's SLC score. The marginal effects from the probit model suggest that public school students are 30.2 percent more likely to pass the SLC exam than the public school students. After adding the interactions to this model, the relationship between the covariates becomes more meaningful. I also use the propensity score matching method to the probit model where the treatment is student going to private school and the outcome this time being SLC result (whether student passed in SLC 
exam). The marginal effect of school type reduces to 7.89 , and standard errors are much more robust by the use of the matching technique.

In addition to modeling student's SLC results, I also perform probit models for the medium of the exam and the status of private tutoring. Both the models bear interesting results. The findings suggest that public school students are more likely to use Nepali as the medium of the SLC exam, and also more likely to use private tutoring compared to the students from private schools. In the conclusion, although the study finds that private school students perform better than the public school students; the study likes to point out the importance of unobserved factors in making the interpretations. For example, private schools have more resources and students in those schools are from families with higher socio-economic status. Therefore, private school students are exposed to better peer effects. Thus, it is very likely that these differences account for the overall differential in achievement between public and private schools rather than the sponsorship. The next chapter explores the impact of private school competition on public school performance. 
Table 4.1 Variance Inflation Factor

\begin{tabular}{ll}
\hline Variable & VIF \\
\hline PRIVATE & 2.37 \\
EX_MEDIUM & 1.55 \\
SC_COMP_LAB & 1.44 \\
PEERS & 1.37 \\
ST_RATIO & 1.37 \\
SLC_GRADS & 1.34 \\
LIBRARY & 1.27 \\
S_SIZE & 1.21 \\
OTHERS & 1.21 \\
TEACHER_EXP & 1.20 \\
PCT_GIRLS & 1.19 \\
COMPUTER & 1.19 \\
LANG & 1.18 \\
EXP_DIV & 1.17 \\
FAMSIZE & 1.16 \\
SCH_DAYS & 1.15 \\
ETHNIC_GRPS & 1.13 \\
LN_FAM_EXP & 1.11 \\
SLC02 & 1.10 \\
AGE & 1.10 \\
SLC03 & 1.10 \\
FEMALE & 1.08 \\
P_TUTORING & 1.06 \\
DIST_SCH & 1.06 \\
SCH_ABS & 1.05 \\
TEACHER_QA & 1.05 \\
LOWER_CASTE & 1.03 \\
\hline SOE_A__Cal_t
\end{tabular}

Source: Author's Calculation

Note: The VIF is an indicator used to check the severity of multicollinearity in regression analysis and measures how much the variance of an estimated regression coefficient is increased because of collinearity. The formula for obtaining the VIF is given by $1 /\left(1-R_{j}^{2}\right)$ where $R_{j}^{2}$ is the $R$-squared for $j^{\text {th }}$ covariance on other covariates. Generally, if the VIF is higher than 10 , then there is an indication of multicollinearity. 
Table 4.3. OLS Estimates of the Effect of School Type on Student's Performance in SLC Exam

\begin{tabular}{|c|c|c|c|c|}
\hline & \multirow{2}{*}{$\begin{array}{l}\text { SLC } \\
\text { Aggregate } \\
\text { Score } \\
1\end{array}$} & \multicolumn{3}{|c|}{ SLC Compulsory subjects } \\
\hline & & 2 & 3 & 4 \\
\hline Constant & $\begin{array}{c}43.89 * * * \\
(30.68)\end{array}$ & $\begin{array}{c}43.73 * * * \\
(1.43)\end{array}$ & $\begin{array}{c}41.01 * * * \\
(1.46)\end{array}$ & $\begin{array}{c}71.46^{* * *} \\
(11.81)\end{array}$ \\
\hline School Type (Private School) & $\begin{array}{c}7.47 * * * \\
(0.23)\end{array}$ & $\begin{array}{c}7.82 * * * \\
(0.23)\end{array}$ & $\begin{array}{c}9.50 * * * \\
(0.39)\end{array}$ & $\begin{array}{c}5.33 * * * \\
(1.03)\end{array}$ \\
\hline \multicolumn{5}{|l|}{ Student Characteristics } \\
\hline Age & $\begin{array}{c}-1.04 * * * \\
(0.06)\end{array}$ & $\begin{array}{c}-1.13 * * * \\
(0.06)\end{array}$ & $\begin{array}{c}-1.13 * * * \\
(0.06)\end{array}$ & $\begin{array}{c}-2.96 * * * \\
(0.53)\end{array}$ \\
\hline Gender (female) & $\begin{array}{c}-2.34 * * * \\
(0.13)\end{array}$ & $\begin{array}{c}-2.48 * * * \\
(0.13)\end{array}$ & $\begin{array}{c}-2.45 * * * \\
(0.13)\end{array}$ & $\begin{array}{c}-3.32 * * * \\
(0.87)\end{array}$ \\
\hline Lower caste & $\begin{array}{c}-1.05^{* *} \\
(0.40)\end{array}$ & $\begin{array}{c}-0.91 * * \\
(0.41)\end{array}$ & $\begin{array}{c}-0.96 * * \\
(0.40)\end{array}$ & $\begin{array}{l}-2.75 \\
(2.72)\end{array}$ \\
\hline Ethnic group & $\begin{array}{c}-1.56^{* * *} \\
(0.17)\end{array}$ & $\begin{array}{c}-1.27 * * * \\
(0.17)\end{array}$ & $\begin{array}{c}-1.17 * * * \\
(0.18)\end{array}$ & $\begin{array}{c}-1.75 * * \\
(0.78)\end{array}$ \\
\hline Other caste & $\begin{array}{c}-3.15 * * * \\
(0.20)\end{array}$ & $\begin{array}{c}-3.27 * * * \\
(0.20)\end{array}$ & $\begin{array}{c}-3.40 * * * \\
(0.22)\end{array}$ & $\begin{array}{c}-3.99 * * * \\
(0.84)\end{array}$ \\
\hline Peers & $\begin{array}{c}1.62 * * * \\
(0.05)\end{array}$ & $\begin{array}{c}1.68 * * * \\
(0.05)\end{array}$ & $\begin{array}{c}1.61 * * * \\
(0.05)\end{array}$ & $\begin{array}{c}2.21 * * * \\
(0.37)\end{array}$ \\
\hline Expected Division in SLC exam & $\begin{array}{c}3.13 * * * \\
(0.10)\end{array}$ & $\begin{array}{c}3.11 * * * \\
(0.10)\end{array}$ & $\begin{array}{c}3.02 * * * \\
(0.10)\end{array}$ & $\begin{array}{c}4.31 * * * \\
(0.66)\end{array}$ \\
\hline $\begin{array}{l}\text { Took private tutoring before SLC } \\
\text { exam }\end{array}$ & $\begin{array}{c}-0.99 * * * \\
(0.14)\end{array}$ & $\begin{array}{c}-0.87 * * * \\
(0.14)\end{array}$ & $\begin{array}{l}-0.24 \\
(0.15)\end{array}$ & $\begin{array}{c}1.40 \\
(1.04)\end{array}$ \\
\hline No. of school days absent in gr. 10 & $\begin{array}{c}-0.07 * * * \\
(0.008)\end{array}$ & $\begin{array}{c}-0.08 * * * \\
(0.008)\end{array}$ & $\begin{array}{l}-0.07 * * * \\
(0.007)\end{array}$ & $\begin{array}{c}-0.12 * * * \\
(0.04)\end{array}$ \\
\hline Family Characteristics & & & & \\
\hline Family size & $\begin{array}{c}-0.27 * * * \\
(0.03)\end{array}$ & $\begin{array}{c}-0.28 * * * \\
(0.03)\end{array}$ & $\begin{array}{c}-0.26 * * * \\
(0.03)\end{array}$ & $\begin{array}{l}-0.24 \\
(0.14)\end{array}$ \\
\hline Log of Family expenses & $\begin{array}{l}0.30 * * * \\
(0.07)\end{array}$ & $\begin{array}{l}0.36 * * * \\
(0.07)\end{array}$ & $\begin{array}{l}0.32 * * * \\
(0.07)\end{array}$ & $\begin{array}{l}-0.63 \\
(0.39)\end{array}$ \\
\hline No. of SLC graduates in the family & $\begin{array}{l}0.86 * * * \\
(0.05)\end{array}$ & $\begin{array}{l}0.93 * * * \\
(0.05)\end{array}$ & $\begin{array}{l}0.88 * * * \\
(0.05)\end{array}$ & $\begin{array}{l}1.13 * * * \\
(0.30)\end{array}$ \\
\hline Language spoken at home & $\begin{array}{l}0.65 * * * \\
(0.15)\end{array}$ & $\begin{array}{l}0.76^{* * * *} \\
(0.15)\end{array}$ & $\begin{array}{l}0.73 * * * \\
(0.15)\end{array}$ & $\begin{array}{c}0.98 \\
(0.85)\end{array}$ \\
\hline Distance to school from home & $\begin{array}{l}-0.09 \\
(0.12)\end{array}$ & $\begin{array}{l}0.27 * * \\
(0.13)\end{array}$ & $\begin{array}{c}-0.32 * * \\
(0.13)\end{array}$ & $\begin{array}{l}-1.20^{*} \\
(0.70)\end{array}$ \\
\hline There is a computer at home & $\begin{array}{l}1.63 * * * \\
(0.26)\end{array}$ & $\begin{array}{l}1.29 * * * \\
(0.26)\end{array}$ & $\begin{array}{l}0.49 * \\
(0.27)\end{array}$ & $\begin{array}{l}-2.28 \\
(1.44)\end{array}$ \\
\hline School \& Teacher Characteristics & & & & \\
\hline School size & $\begin{array}{l}0.24 * * * \\
(0.01)\end{array}$ & $\begin{array}{l}0.21 * * * \\
(0.01)\end{array}$ & $\begin{array}{l}0.10^{* * *} \\
(0.01)\end{array}$ & $\begin{array}{l}0.27 * * \\
(0.09)\end{array}$ \\
\hline School has a library & $\begin{array}{l}0.68 * * * \\
(0.15)\end{array}$ & $\begin{array}{l}0.50 * * * \\
(0.15)\end{array}$ & $\begin{array}{l}0.65 * * * \\
(0.15)\end{array}$ & $\begin{array}{l}1.82 * * \\
(0.90)\end{array}$ \\
\hline School has a science \& computer lab & $\begin{array}{l}2.01 * * * \\
(0.17)\end{array}$ & $\begin{array}{l}2.07 * * * \\
(0.17)\end{array}$ & $\begin{array}{l}1.72 * * * \\
(0.17)\end{array}$ & $\begin{array}{l}1.43 \\
(0.97)\end{array}$ \\
\hline $\begin{array}{l}\text { No. of school days taught in school } \\
\text { year }\end{array}$ & $\begin{array}{l}0.01 * * * \\
(0.002)\end{array}$ & $\begin{array}{l}0.01 * * * \\
(0.002)\end{array}$ & $\begin{array}{l}0.01 * * * \\
(0.002)\end{array}$ & $\begin{array}{l}0.05 * * * \\
(0.01)\end{array}$ \\
\hline Percent of girls in higher secondary & -0.005 & 0.006 & $0.02 * * *$ & 0.03 \\
\hline
\end{tabular}




\begin{tabular}{|c|c|c|c|c|}
\hline \multirow{2}{*}{$\begin{array}{l}\text { grades } \\
\text { Student-teacher ratio }\end{array}$} & $(0.005)$ & $(0.005)$ & $(0.005)$ & $(0.03)$ \\
\hline & $\begin{array}{c}-0.17 * * * \\
(0.03)\end{array}$ & $\begin{array}{c}-0.19 * * * \\
(0.03)\end{array}$ & $0.34 * * *$ & $\begin{array}{c}-1.84 * * * \\
(0.42)\end{array}$ \\
\hline Teacher qualification & $\begin{array}{c}0.05 \\
(0.10)\end{array}$ & $\begin{array}{c}0.12 \\
(0.10)\end{array}$ & $\begin{array}{c}0.96^{* * * *} \\
(0.19)\end{array}$ & $\begin{array}{l}1.11^{*} \\
(0.65)\end{array}$ \\
\hline Teacher experience & $\begin{array}{l}-0.01 \\
(0.02)\end{array}$ & $\begin{array}{l}-0.02 \\
(0.02)\end{array}$ & $\begin{array}{l}-0.01 \\
(0.02)\end{array}$ & $\begin{array}{l}-1.26^{*} \\
(0.13)\end{array}$ \\
\hline Teacher experience squared & $\begin{array}{l}-0.0005 \\
(0.0006)\end{array}$ & $\begin{array}{l}-0.0003 \\
(0.0006)\end{array}$ & $\begin{array}{l}-0.0004 \\
(0.0006)\end{array}$ & $\begin{array}{l}0.006^{*} \\
(0.004)\end{array}$ \\
\hline \multicolumn{5}{|l|}{ Exam Context } \\
\hline The medium of SLC exam is Nepali & $\begin{array}{l}-1.56^{* * *} \\
(0.16)\end{array}$ & $\begin{array}{l}-1.46^{* * *} \\
(0.16)\end{array}$ & $\begin{array}{l}-0.003 \\
(0.18)\end{array}$ & $\begin{array}{c}-3.73 * * * \\
(0.76)\end{array}$ \\
\hline Prepared food by own during exam & $\begin{array}{l}-1.22 * * * \\
(0.16)\end{array}$ & $\begin{array}{l}-1.33 * * * \\
(0.16)\end{array}$ & $\begin{array}{c}-1.35 * * * \\
(0.15)\end{array}$ & $\begin{array}{l}-0.58 \\
(0.93)\end{array}$ \\
\hline Sick during exam & $\begin{array}{l}-0.72 * * * \\
(0.17)\end{array}$ & $\begin{array}{c}-0.78 * * * \\
(0.17)\end{array}$ & $\begin{array}{c}-0.66 * * * \\
(0.17)\end{array}$ & $\begin{array}{l}-3.65^{* *} \\
(1.63)\end{array}$ \\
\hline SLC Year 2002 & $\begin{array}{c}-0.27 * * \\
(0.16)\end{array}$ & $\begin{array}{c}-0.77 * * * \\
(0.16)\end{array}$ & $\begin{array}{c}-0.73 * * * \\
(0.16)\end{array}$ & $\begin{array}{c}1.39 \\
(1.43)\end{array}$ \\
\hline SLC Year 2003 & $\begin{array}{l}-0.45^{* *} \\
(0.15)\end{array}$ & $\begin{array}{c}-0.89 * * * \\
(0.15)\end{array}$ & $\begin{array}{c}-0.88^{* * * *} \\
(0.14)\end{array}$ & $\begin{array}{l}-2.45^{* *} \\
(0.93)\end{array}$ \\
\hline \multicolumn{5}{|l|}{ Interaction terms } \\
\hline Ethnic groups $*$ Private school & & & $\begin{array}{c}-1.04 * * \\
(0.43)\end{array}$ & \\
\hline Other caste* Private school & & & $\begin{array}{l}1.24 * * \\
(0.45)\end{array}$ & \\
\hline Private school* Medium of Exam & & & $\begin{array}{c}-7.17 * * * \\
(0.41)\end{array}$ & \\
\hline Private School*Private Tutoring & & & $\begin{array}{c}-1.75 * * * \\
(0.31)\end{array}$ & \\
\hline Private School* School size & & & $\begin{array}{c}0.27 * * * \\
(0.03)\end{array}$ & \\
\hline $\begin{array}{l}\text { Student teacher ratio*Teacher } \\
\text { qualification }\end{array}$ & & & $\begin{array}{c}-0.23 * * * \\
(0.044)\end{array}$ & \\
\hline $\mathrm{R}^{2}$ & 0.5128 & 0.5244 & 0.5367 & 0.5001 \\
\hline Number of observations & 19897 & 19897 & 19897 & 5104 \\
\hline
\end{tabular}

Notes: (1) robust standard errors are in parenthesis; (2)* denotes statistically significant at $10 \%$, ** statistically significant at $5 \%$, and $* * *$ statistically significant at $1 \%$. 
Table 4.4. Probit Estimates of the Effect of School Type on Student's SLC Result

\begin{tabular}{|c|c|c|c|c|c|}
\hline & \multicolumn{3}{|c|}{ SLC Result } & \multirow{2}{*}{$\begin{array}{c}\text { Medium of } \\
\text { Exam } \\
8\end{array}$} & \multirow{2}{*}{$\begin{array}{c}\begin{array}{c}\text { Private } \\
\text { Tutoring }\end{array} \\
9 \\
\end{array}$} \\
\hline & 5 & 6 & 7 & & \\
\hline School Type (Private School) & $\begin{array}{c}0.20 * * * \\
(0.01)\end{array}$ & $\begin{array}{c}0.30 * * * \\
(0.02)\end{array}$ & $\begin{array}{c}0.08 * * * \\
(0.02)\end{array}$ & $\begin{array}{c}-0.16^{* * *} \\
(0.05)\end{array}$ & $\begin{array}{c}-0.17 * * * \\
(0.02)\end{array}$ \\
\hline \multicolumn{6}{|l|}{ Student Characteristics } \\
\hline Age & $\begin{array}{c}-0.03 * * * \\
(0.004)\end{array}$ & $\begin{array}{c}-0.03 * * * \\
(0.004)\end{array}$ & $\begin{array}{l}-0.01 \\
(0.01)\end{array}$ & $\begin{array}{c}0.005 \\
(0.004)\end{array}$ & $\begin{array}{c}0.004 \\
(0.003)\end{array}$ \\
\hline Gender (female) & $\begin{array}{c}-0.10 * * * \\
(0.008)\end{array}$ & $\begin{array}{c}-0.10 * * * \\
(0.008)\end{array}$ & $\begin{array}{c}-0.07 * * \\
(0.02)\end{array}$ & $\begin{array}{l}-0.003 \\
(0.008)\end{array}$ & $\begin{array}{l}0.05 * * * \\
(0.007)\end{array}$ \\
\hline Lower caste & $\begin{array}{c}0.0007 \\
(0.02)\end{array}$ & $\begin{array}{c}0.13 * * \\
(0.04)\end{array}$ & $\begin{array}{l}-0.10 \\
(0.07)\end{array}$ & $\begin{array}{c}0.01 \\
(0.02)\end{array}$ & $\begin{array}{l}-0.01 \\
(0.02)\end{array}$ \\
\hline Ethnic group & $\begin{array}{c}-0.04 * * * \\
(0.01)\end{array}$ & $\begin{array}{c}-0.04 * * * \\
(0.01)\end{array}$ & $\begin{array}{c}-0.08 * * \\
(0.03)\end{array}$ & $\begin{array}{c}-0.03 * * \\
(0.01)\end{array}$ & $\begin{array}{c}-0.03 * * \\
(0.01)\end{array}$ \\
\hline Other caste & $\begin{array}{c}-0.09 * * * \\
(0.01)\end{array}$ & $\begin{array}{c}-0.09 * * * \\
(0.01)\end{array}$ & $\begin{array}{c}-0.10 * * * \\
(0.03)\end{array}$ & $\begin{array}{c}0.02 \\
(0.02)\end{array}$ & $\begin{array}{c}0.06 * * \\
(0.02)\end{array}$ \\
\hline Peers & $\begin{array}{c}0.07 * * * \\
(0.003)\end{array}$ & $\begin{array}{l}0.06 * * * \\
(0.003)\end{array}$ & $\begin{array}{l}0.04 * * * \\
(0.007)\end{array}$ & $\begin{array}{c}-0.03 * * * \\
(0.003)\end{array}$ & $\begin{array}{c}-0.005 * * \\
(0.003)\end{array}$ \\
\hline Expected Division in SLC exam & $\begin{array}{l}0.15 * * * \\
(0.006)\end{array}$ & $\begin{array}{l}0.14 * * * \\
(0.006)\end{array}$ & $\begin{array}{c}0.10 * * * \\
(0.02)\end{array}$ & $\begin{array}{c}-0.03 * * * \\
(0.006)\end{array}$ & $\begin{array}{l}0.01 * * \\
(0.005)\end{array}$ \\
\hline $\begin{array}{l}\text { Took private tutoring before SLC } \\
\text { exam }\end{array}$ & $\begin{array}{c}-0.03 * * * \\
(0.009)\end{array}$ & $\begin{array}{l}0.04 * * \\
(0.01)\end{array}$ & $\begin{array}{c}0.02 \\
(0.02)\end{array}$ & $\begin{array}{c}0.12 * * * \\
(0.15)\end{array}$ & \\
\hline No. of school days absent in gr. 10 & $\begin{array}{c}-0.003 * * * \\
(0.0005)\end{array}$ & $\begin{array}{c}-0.003 * * * \\
(0.0005)\end{array}$ & $\begin{array}{c}-0.0008 \\
(0.001)\end{array}$ & $\begin{array}{l}-0.0002 \\
(0.0005)\end{array}$ & $\begin{array}{r}-0.001 * * * \\
(0.0004)\end{array}$ \\
\hline Family Characteristics & & & & & \\
\hline Family size & $\begin{array}{c}-0.009 * * * \\
(0.002)\end{array}$ & $\begin{array}{c}-0.008 * * * \\
(0.002)\end{array}$ & $\begin{array}{l}-0.003 \\
(0.003)\end{array}$ & $\begin{array}{l}0.007 * * * \\
(0.002)\end{array}$ & $\begin{array}{l}-0.002 \\
(0.001)\end{array}$ \\
\hline Family expenses & $\begin{array}{c}0.02 * * * \\
(0.004)\end{array}$ & $\begin{array}{l}0.01 * * \\
(0.005)\end{array}$ & $\begin{array}{c}0.007 \\
(0.008)\end{array}$ & $\begin{array}{c}-0.02 * * * \\
(0.004)\end{array}$ & $\begin{array}{l}0.03 * * * \\
(0.004)\end{array}$ \\
\hline No. of SLC graduates in the family & $\begin{array}{l}0.04 * * * \\
(0.003)\end{array}$ & $\begin{array}{l}0.04 * * * \\
(0.003)\end{array}$ & $\begin{array}{c}0.007 \\
(0.006)\end{array}$ & $\begin{array}{c}-0.009^{* *} \\
(0.003)\end{array}$ & $\begin{array}{l}0.01 * * * \\
(0.003)\end{array}$ \\
\hline Language spoken at home & $\begin{array}{c}0.01 \\
(0.010)\end{array}$ & $\begin{array}{c}0.01 \\
(0.01)\end{array}$ & $\begin{array}{l}0.009 \\
(0.02)\end{array}$ & $\begin{array}{l}0.02 * \\
(0.01)\end{array}$ & $\begin{array}{l}-0.006 \\
(0.008)\end{array}$ \\
\hline Distance to school from home & $\begin{array}{l}-0.009 \\
(0.008)\end{array}$ & $\begin{array}{l}-0.008 \\
(0.008)\end{array}$ & $\begin{array}{c}-0.008 \\
(0.02)\end{array}$ & $\begin{array}{l}-0.006 \\
(0.008)\end{array}$ & $\begin{array}{l}-0.05^{* * *} \\
(0.007)\end{array}$ \\
\hline There is a computer at home & $\begin{array}{l}0.04 * \\
(0.02)\end{array}$ & $\begin{array}{c}0.02 \\
(0.02)\end{array}$ & $\begin{array}{l}0.006 \\
(0.03)\end{array}$ & $\begin{aligned}-0.13 * * * \\
(0.02)\end{aligned}$ & $\begin{array}{l}0.006 \\
(0.01)\end{array}$ \\
\hline School \& Teacher Characteristics & & & & & \\
\hline School size & $\begin{array}{l}0.005 * * * \\
(0.001)\end{array}$ & $\begin{array}{l}0.003 * * \\
(0.001)\end{array}$ & $\begin{array}{l}-0.0009 \\
(0.002)\end{array}$ & $\begin{array}{l}0.01 * * * \\
(0.002)\end{array}$ & $\begin{array}{l}-0.002 \\
(0.003)\end{array}$ \\
\hline School has a library & $\begin{array}{l}-0.004 \\
(0.009)\end{array}$ & $\begin{array}{l}-0.001 \\
(0.009)\end{array}$ & $\begin{array}{l}0.06^{*} \\
(0.03)\end{array}$ & $\begin{array}{c}-0.03 * * * \\
(0.009)\end{array}$ & $\begin{array}{c}-0.03 * * * \\
(0.008)\end{array}$ \\
\hline $\begin{array}{l}\text { School has a science \& computer } \\
\text { lab }\end{array}$ & $\begin{array}{l}0.10 * * * \\
(0.01)\end{array}$ & $\begin{array}{l}0.09 * * * \\
(0.01)\end{array}$ & $\begin{array}{c}0.03 \\
(0.02)\end{array}$ & $\begin{array}{c}-0.12 * * * \\
(0.01)\end{array}$ & $\begin{aligned}- & 0.04 * * * \\
& (0.01)\end{aligned}$ \\
\hline $\begin{array}{l}\text { No. of school days taught in school } \\
\text { year }\end{array}$ & $\begin{array}{l}0.0002 \\
(0.0001)\end{array}$ & $\begin{array}{l}0.0002 * \\
(0.0001)\end{array}$ & $\begin{array}{l}0.0006 * * \\
(0.0003)\end{array}$ & $\begin{array}{l}0.0004 * * * \\
(0.0001)\end{array}$ & $\begin{array}{l}-0.0001 \\
(0.0001)\end{array}$ \\
\hline $\begin{array}{l}\text { Percent of girls in higher } \\
\text { secondary grades }\end{array}$ & $\begin{array}{c}-0.00005 \\
(0.0003)\end{array}$ & $\begin{array}{l}0.0003 \\
(0.0003)\end{array}$ & $\begin{array}{l}-0.0004 \\
(0.0006)\end{array}$ & $\begin{array}{l}0.001 * * * \\
(0.0003)\end{array}$ & $\begin{array}{l}0.0005^{*} \\
(0.0003)\end{array}$ \\
\hline Student-teacher ratio & $\begin{array}{l}-0.005 * * \\
(0.002)\end{array}$ & $\begin{array}{l}0.005 \\
(0.003)\end{array}$ & $\begin{array}{c}-0.03 * * * \\
(0.006)\end{array}$ & $0.01 * *$ & $0.02 * * *$ \\
\hline Teacher qualification & $\begin{array}{r}-0.0001 \\
(0.006)\end{array}$ & $\begin{array}{l}-0.002 \\
(0.006)\end{array}$ & $\begin{array}{c}0.04 * * \\
(0.01)\end{array}$ & $\begin{array}{l}0.007 \\
(0.01)\end{array}$ & $\begin{array}{c}0.01 \\
(0.01)\end{array}$ \\
\hline
\end{tabular}




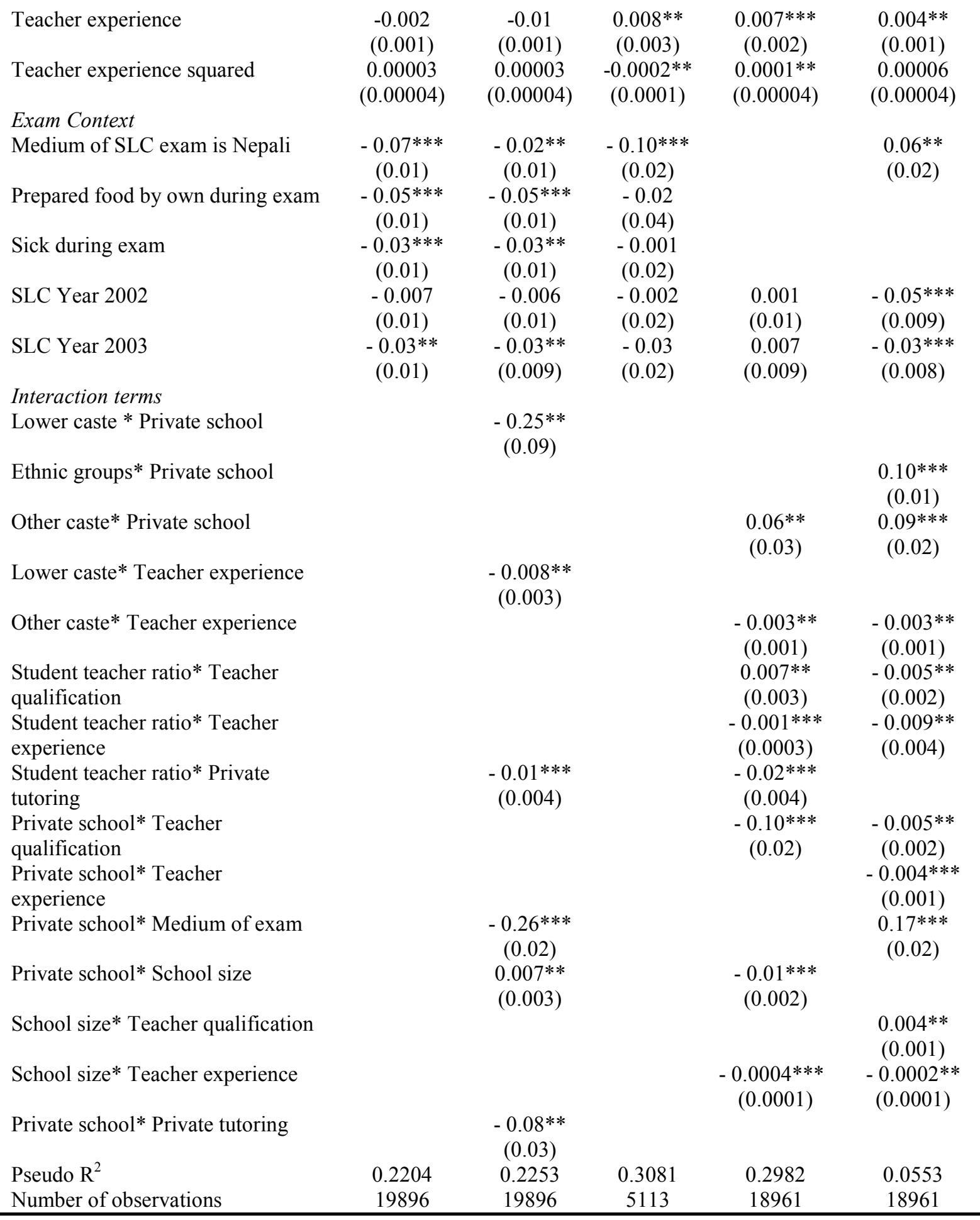

Notes: (1) robust standard errors are in parenthesis; $(2)^{*}$ denotes statistically significant at $10 \%, * *$ statistically significant at $5 \%$, and $* * *$ statistically significant at $1 \%$. 


\section{Chapter V}

\section{THE IMPACT OF PRIVATE SCHOOL COMPETITION ON PUBLIC SCHOOLS}

\section{Introduction}

The idea of competition in economics has been discussed since the time of Adam Smith. In this regard, the concept of competition as discussed by Adam Smith in The Wealth of Nations (1776), was later applied by various economists in the context of the idea of allocating productive resources to their most highly-valued uses and encouraging efficiency. Later, microeconomics theory distinguished between perfect competition and imperfect competition, concluding that no system of resource allocation is more efficient than perfect competition. Competition, according to the theory, causes commercial firms to develop new products, services and technologies, which give consumers a greater selection and better products. The greater selection of products typically lowers the prices for the products, compared to what the price would be if there was no competition (monopoly) or little competition (oligopoly) ${ }^{29}$ (see Pindyk \& Rubinfeld, 2009). Competition plays a significant role in many areas, not only in business and economics, but also in areas such as law, politics, literature, sports, and so on. This dissertation, and specifically this chapter, deals with competition in the education field within the private sector. The purpose of this chapter is to explore the second research question of this dissertation: keeping other things constant, does private school competition have any impact on public school performance in the case of Nepal?

\footnotetext{
${ }^{29}$ A Monopoly arises in the case when a market has a single seller (producer), and an oligopoly occurs in the case when a market has few sellers (producers). For example, see Pindyk and Rubinfeld (2009) for a discussion on markets in microeconomic theory.
} 
This chapter is organized in the following way. Following the discussion on the theoretical framework, the background on education market and competition is presented. The chapter then reviews some previous studies concerning the evidence surrounding private school competition in developed countries. Finally, the chapter presents the models and methods used for the analysis and discussion on the findings and interpretation of the results.

\section{Theoretical Framework}

In the same spirit of chapter 4, this chapter also employs the method of the education production function to the present analyses. However, this time I estimate the effect of private school competition on public school performance. The dependent variable is the SLC score of the public school student. As in the earlier chapter, the SLC score includes only six compulsory subjects and is converted into the scale of 100 . The variable of interest is private school competition, which is given by the number of private schools in the vicinity of the sample school. The controls include the same set of variables as used in chapter four, which are student, family, school and teacher characteristics, and exam context variables.

\section{Background on Education Market and Competition}

Before describing the literature that deals with the evidence related to competition and its impact on educational outcomes, it appears more meaningful to first discuss the theoretical concepts of 'educational markets' and 'competition'. An education market is said to exist when parents have a feasible choice set of alternative provisions. The choice set has three domains 
where parents may choose i) between public and private schools, ii) among public school districts, and iii) among public schools within a given district (Levin \& Belfield, 2002). However, the identification of a feasible set in this context is not simplistic, and since the costs involved with regard to parents choice differ across the variants, private and public schools may not represent a 'single market' (Levin \& Belfield, 2002; Couch \& Shughart, 1995).

James (1987) puts forth a theory that explains the size of the private sector in education as depending on three variables: i) excess demand, stemming from a political coalition, which limits government production below full enrollment levels; ii) differentiated demand, arising from deep-seated religious or linguistic diversity, in the face of a relatively uniform government product; and iii) the supply of nonprofit entrepreneurship, often religious, to start the private schools. Levin $(1991,1998,1999,2002)$ sets out a framework for evaluating market reforms based on four criteria and three policy instruments. According to him, the four criteria are i) freedom of choice; ii) productive efficiency; iii) equity; and iv) social cohesion, and the set of three policy instruments are i) finance, ii) regulation, and iii) support services. All educational arrangements, including the market approaches, face a conflicting set of goals, and they involve trade offs among these goals (Levin \& Belfield, 2003). Their study argues that any movement in the educational market (for example between public and private) faces this trade-off, and it points out the 'voucher program' as a way to introduce markets into the education system.

With regards to competition, discussing three aspects of an organization or state: exit, voice and loyalty, Hirschman (1970) attributes this economic or market mechanism as an exit mechanism. According to Hirschman (1970), those producers who are not able to survive this market competition automatically exit the market leaving behind only the efficient performers ${ }^{30}$.

\footnotetext{
${ }^{30}$ According to Hirshman (1970), the other feature that signals to management its success or failure is the "voice of its clientele. In this discussion on public versus private education, the emergence of another type of school called
} 
On the concept of competition as a construct, Levin and Belfield (2002) refer both to the existence of multiple education suppliers within the choice set, and to how these suppliers behave strategically. However, this competition could be either demand-induced or supplydriven. In the literature we can find many ways in which competition is measured. One of the ways is the use of the Herfindahl Index (HI) which is the sum of the squares of per-unit enrollments over total enrollments typically relating to public school choices, either inter-district or intra-district (Borland \& Howson, 1992). A second way to measure competition is the private schooling enrollment share. This share may represent competition, but may also be determined by other factors, such as regional religiosity, or community wealth levels (Belfield \& Levin, 2002). However, according to Hoxby (1994), neither measure of competition is able to capture how or whether schools or districts compete because schools and districts also have the tendency to show monopolistic and oligopolistic behavior.

The next question is what kind of impact does competition have on the educational outcomes. Levin and Belfield (2002) believe that market competition improves both technical and allocative efficiency in the use of resources. According to the authors, due to competition suppliers must strive to be efficient, and demanders will have more choices. However, it is less clear whether this can be generalized across all markets and countries. The next section discusses the evidence we have so far from the previous literature.

\section{Literature Review}

“community managed schools" can be seen as a 'voice' that is taking public schools in a newer direction. In this study, I have included community managed schooling within the public schooling system. 
In his seminal work, Friedman (1962) in "Capitalism and Freedom" advocates the introduction of the market mechanism into public education. In connection with the system of providing educational vouchers for both public as well as private schools, Friedman says that the competition between private and public schools would make the education systems more effective. The argument has been a topic of debate for a long time. For example, Levin (1968) argues that the replacement of the publicly operated schools by a market of private onessupported by government vouchers would generate mixed results. He explains that on the one hand, some parents would have greater choices among schools and some schools would have to be productive in order to survive in the competitive framework. On the other hand, he argues that the market approach to schooling would do poorly in fulfilling certain social functions such as its tendency to increase racial and social stratification of students among schools.

Empirical results on this hypothesis are mixed. To start with, let us take the case of how charter schools influence the performance of public schools. Charter advocates argue that charter schools are more innovative and more responsive to students than public schools. In addition, they claim that charter schools, apart from improving educational outcomes of charter students, also improve student outcomes at neighboring public schools through increased competition. Bettinger (1999) uses data from Michigan's standardized testing program and estimates the effect of charter schools on both students attending them and students at neighboring public schools. The paper exploits the factor of exogenous variation created by Michigan's charter law that allows state universities to approve charter schools to identify the effects of charter schools on public schools. The study uses the proximity of a public school to one of these state universities as an instrument for the likelihood that one or more charter schools were established nearby. The results, using both the OLS and instrumental variables approaches show that charter 
schools have little or no effect on student achievement in neighboring public schools. However, there is a serious concern that the instrument he has chosen (proximity of public school to one of the authorizing state universities) is very likely to be correlated with the error term, which in turn will cause results to be biased. Additionally, the results in this study were estimated in the midst of the rapid growth of charter schools in the U.S (short run), and this might differ with the long run equilibrium of charter schools.

Coming to the more specific issue, there are many studies that have conducted a literature review on the effect of private school competition on public school performance. Rouse and McLaughlin (1998) provide a review of the literature on the effects of school competition on performance of public schools and show that the evidence is mixed. Similarly, Levin and Belfield (2002) carry an impressive review of 42 studies on the effects of greater market competition on academic outcomes. They show that over one -third of the studies report a statistically significant positive association between increased competition and higher public school achievement. The study also points out that very few studies show more competition having a negative impact on public school achievement, and there are few studies with no effect at all. In summarizing the evidence of competition on educational outcome, I have borrowed the same approach as Levin and Belfield (2002), where I group the literature according to the measure of competition used in various studies.

\section{Evidence Using Herfindahl Index}

As discussed earlier, one of the ways to measure competition is by using the Herfindahl Index (HI). Using this measure, most empirical articles report only weak or null effects on academic outcomes (Borland \& Howson, 1992, 1995; Hanushek \& Rivkin, 2001; Marlow, 
2000). One of the frequently citied studies is by Henry and Gordon (2003) who also adopt the Herfindahl index as a measure of competition. Using longitudinal data from a probability sample of children who participated in Pre-K during the 1996-1997 school year, the study estimates the effects of naturally occurring variations in institutional structures on students' outcomes after four years of schooling. Their results show that competition results in lower retention rates, and improves third grade reading and math test scores, but does not significantly affect teachers' readiness during elementary school. However, this study seems to suffer from missing data since 33 percent of the children lacked data on their test scores. Also, the results are likely to be biased because of the use of test scores of the on-grade children.

Greene and Kang (2004) employ two measures relating to the degree of competition: the percent of private school enrollments in a county where the public school district is located, and the Herfindahl index of school district concentration. The study uses a data set on an upstate New York school district to test whether competition from private schools and competition within the public school sector positively affect public school output and again whether different types of expenditures affect output differently. In general, the study finds significant positive effects of private competition for some measures of school output, but little if any on measures such as the percent of students receiving high quality statewide Regents diplomas. The study, however, seems to suffer from measurement error because some variables measured at the county level are mismatched to the dependent school output variables that are measured at the district level. Also, the use of aggregated data has a high likelihood of inflating the coefficients through omitted variable bias.

There are other studies that use HI for categorization of markets. For example, studies that categorize markets into high or low levels of competition mostly find positive and more 
significant results (Borland \& Howson, 1993; Zanzig, 1997) except for Figlio and Stone (1999) who find no clear positive effects across the US. Finally, there are other studies that use interaction of HI with other process measures. For example, Hanushek and Rivkin (2001) interact their HI scores with the percentage of different teachers across 1,140 schools and 832 districts in Texas. Their results show that more competition leads to a smaller between cohort variance in school average value-added test scores.

\section{Evidence using Private School Enrollment}

\section{a) Using district/country/school level data}

Many studies have used private schools enrollments as a measure of competition and across districts and counties. These studies have shown mixed results for the effect of private school competition on public school outcomes. Couch, Shughart, and Williams (1993) present empirical estimates that indicate that public schools in North Carolina counties with higher levels of private school enrollment also had higher grades on the End of Term Test for Algebra I. Their results are based on OLS estimates that treat private school enrollment as an exogenous variable. But, there is a high chance of endogeneity between private school enrollment and public school performance, and hence the OLS results can be highly biased. Newmark (1995) replicates the work of Couch et al. (1993) and also estimates equations using alternative standardized exams, various measures of private school competition, and various combinations of control variables. Newmark's findings show that Couch et al. (1993)'s results are not robust and demonstrate that the estimated effect of private school competition is not significant. Geller, Sjoquist, and Walker (2001) investigate whether increased private school competition results in enhanced performance of public schools using a pooled data set from the Georgia school systems between 1980 and 
1990 for third and tenth grade for reading and math test scores. They address the endogeneity between private school enrollment and public school performance by using lagged private school enrollment as the instrument for private school competition. Their results suggest very little evidence that current levels of private school competition increase public school performance in Georgia. Simon and Lovrich (1996), using data on districts in Washington state find neutral effects, and Sander (1999), using school level data finds no significant effect on Math scores within the State of Illinois. On the other hand, there are studies which show counter results. For example, studies of Smith and Meier (1995) and Maranto, Milliman and Stevens (2000) show that competition has an adverse effect on public school performance.

\section{b) Using Student level data}

McMillan (1998) uses NELS data and finds weak negative effects on public school $8^{\text {th }}$ grade scores. Arum (1996) using High School and Beyond data, finds a positive effect for individuals' $12^{\text {th }}$ grade test scores. Hoxby (1994) uses the instrumental variables (IV) approach in a nationwide study to show that public schools perform better in areas where they face more competition from private schools. She uses density of Roman Catholics as an instrument for private schools, and finds that public high schools' outcomes are better in areas with more competition. Jepsen (1999) using NELS and NLS72 data finds that the effect of competition is mostly insignificant for standardized mathematics scores.

\section{Evidence Using Other Measures of Competition}

There are studies that use proxy measures for competition typically for different levels of choice and are somewhat related to Herfindahl index values. For example, Marlow (1997) uses number of districts/schools per 1000 students, and finds a strongly positive statistical effect on 
Math SAT and $8^{\text {th }}$ grade scores, but weaker effects on Verbal SAT scores across the 50 states. Blair and Staley (1995) use the number of neighboring districts and find no effect on districtlevel achievement test scores in Ohio. Geller, Sjoquist and Walker (2001), using the same proxy measure find no positive effects on academic scores in Georgia. Husted and Kenny (2000) use a proxy for government (monopoly) intervention and show mixed results. Hammons (2001) uses two measures of choice: i) proportion of town-tuitioned students and ii) distance to all tuition towns within a seven mile radius and finds a positive effect. On the other hand Hoxby (2000) uses the share of a district's enrollment in a particular metropolitan area as a measure of school choice with an instrumental variable based on the natural boundaries to the formation of school districts. In this study, the author finds a positive effect of competition on academic scores.

Overall, the evidence from the literature suggests that the effect of competition on public school performance is mixed. Some studies suggest positive effects of private school competition and others find no effect. But, more find large effects. Many studies account for the endogenity between private school enrollment and public school performance using the instrumental variable method. Even after dealing with this identification problem, the evidence is mixed, and hence the issue demands more rigorous studies. From a critical viewpoint, there are chances of having the mis-measurement of variables representing competition and, hence, results might be misleading. Also, these studies which use instrumental variables, rely on the quality of the instrument used. Furthermore, many of the above studies also suffer from omitted variable bias where the key variables are omitted from the model especially due to data unavailability or missing data problems. In addition, some of the above studies are also crippled due to publication bias, where only studies that find statistically significant effects are submitted and recommended for publication. As Levin and Belfield (2002) point out, publication bias is of 
serious concern in areas of research where there are a large number of small-sample studies; where fewer randomized trials are conducted; and where research is ideologically motivated. Finally, these studies might not have good external validity. For example, Hoxby's (1994) primary explanatory variable is the percentage of the local population that is Roman Catholic. So her results may not generalize to all private schools. Besides, most of the studies discussed so far are based on the U.S educational system, and generalization to developing countries might not hold true. We need to gather more empirical evidence from both developing as well as developed countries, especially more from the former.

\section{Evidence on Nepal}

In the case of Nepal, I have not found any study related to private school competition. A study that comes close is by Bhatta (2005), where he attempts to explore the determinants of student performance in the SLC examination using OLS and logistic regressions. Although the main results of the study suggest statistically significant differences in student performance across school types (public versus private), genders, ethnicities and school locations, the findings also indicate that the number of private schools in the vicinity of the sample school has a negative effect on student SLC score. However, this is statistically significant only at the10 percent level. Further, like many studies of this kind, the paper is very likely to suffer from an endogenity problem which is not accounted for in the study. For example, as highlighted in an earlier section there is a high chance of a correlation between the number of private schools in the vicinity and private schools enrollment. Besides this, to the best of my knowledge, there is no study on this area using data from Nepal. 


\section{Models and Identification Strategies}

As shown in the literature review section above, there are many studies of private school competition on public school performance in developed countries. However, there is little evidence on less developed countries such as Nepal. This dissertation attempts to provide empirical evidence of the impact of private school competition on pubic school performance in the case of Nepal.

\section{The Basic Empirical Model}

The approach to this section is to test the hypothesis that a student of a public school that faces private school competition performs better on the SLC examination than a student from a public school that does not face private school competition, holding other things constant. Symbolically, the model postulates that the performance of a student $i$, in public school $p$ is given by the following reduced form expression:

$$
Y_{\text {ip }}=\pi_{0}+\pi_{1} C_{(i) p}+\pi_{2} X_{i p}^{\prime}+\eta_{i p}
$$

where $\mathrm{Y}_{\text {ip }}$ is the SLC Test Score ${ }^{31}$ of student $i$ in public school $p, \mathrm{C}_{(\mathrm{i}) \mathrm{p}}$ represents private school competition $^{32}$, given by the number of private schools in the neighborhood of public school $p$, $\mathrm{X}_{\mathrm{ip}}$ is a vector of control variables representing student, family, school, teacher, and community

\footnotetext{
${ }^{31}$ Note that the SLC Score is computed only for compulsory subjects (Math, Science, English, Nepali, Social Studies and Health \& Population studies), and is converted to a scale of 100 (total score $=100$ ).

${ }^{32}$ The subscript $i$ within the parenthesis denotes that although private school competition is a school level variable, it is applied to $i$ th student.
} 
characteristics, and exam context variables, and $\eta_{\text {ip }}$ is random disturbance with mean zero and constant variance.

The dependent variable in this case is the SLC score of public school students, which is a continuous variable. The Ordinary Least Squares (OLS) regression method is used to estimate equation 5.1 .

\section{Identification Problems \& Strategy}

With regards to the correlation between competition measure and educational outcome, there are two major estimation problems (Dee, 1998). First is the problem of simultaneity. In our context, the demand for private school will increase when public schools do not perform well. This creates a negative relationship between public school quality and private school enrollment. The second problem is related to omitted variable bias. This means, when factors that confound the relationship between public school quality and private school supply are omitted from the analysis, the results will be biased. Besides these two major problems, there could be other biases while estimating this relationship (Levin \& Belfield, 2002). For example, when private school students sort more able students (cream skimming), performance of public schools might fall. This will then result to the omitted variable bias. In another case, resource- omission bias may come into play when the higher demand for private schooling reduces taxpayer support for pubic schooling. Finally, when local socio-economic characteristics such as community income and educational levels influence the demand for private schooling, then could lead to socioeconomicomission bias.

In equation 5.1, the identification problem exists due to endogeneity between private school enrollment and public school performance (Geller et al., 2001). In addition, both the 
competition effect, as discussed before, and a "cream skimming" effect might be operating simultaneously. In order to address this endogeneity problem, the literature suggests the use of the instrumental variable approach. In such a case, if the measure of competition is private school enrollment, then the supply is identified through a source of variation that is held to be uncorrelated with schooling quality (Levin \& Belfield, 2002).

Identification strategies based on instrumental variables can be thought of as a scheme for using exogenous filed variation to approximate randomized trials, and are hence used to remove any such bias. This is possible if the researcher has access to an instrumental variable $Z$, which is correlated with private school competition (C), but is otherwise independent of the SLC performance of public school student $(\mathrm{S})$. The identifying assumption in this case is that the instrumental variable, $Z$, is independent of educational outcomes, which means that $Z$ is uncorrelated with $\eta(\operatorname{Cov}(Z, \eta)=0)$, and $Z$ is correlated with $C(\operatorname{Cov}(Z, C) \neq 0)$. These assumptions serve to indentify the parameter $\pi_{1}$. Identification of $\pi_{1}$ in this context means that I can write $\pi_{1}$ in terms of population covariances. The covariance between $\mathrm{Z}$ and $\mathrm{S}$ is:

$$
\operatorname{Cov}(Z, S)=\pi_{1} \operatorname{Cov}(Z, C)+\operatorname{Cov}(Z, \eta)
$$

Since by assumption, $\operatorname{Cov}(Z, \eta)=0, \& \operatorname{Cov}(Z, C) \neq 0$, I can solve for the IV estimate of $\pi_{1}$ as

$$
\pi_{1}=\operatorname{Cov}(Z, S) / \operatorname{Cov}(Z, C)
$$


Equation (5.2) is typically estimated using 2SLS by substituting the fitted value from a first-stage regression on $C_{p}$ on $X_{i p}$ and $Z_{p}$, which is also called the reduced form equation. The 2 SLS equations can be stated as follows:

$2^{\text {nd }}$ stage:

$$
Y_{i p}=\rho_{0}+\rho_{1} Z_{(i) p}^{\prime}+\rho_{2} X^{\prime}{ }_{i p}+\eta_{i p}
$$

$1^{\text {st }}$ stage:

$$
C_{(i) p}=\hat{\lambda}_{0}+\lambda_{1} Z_{(i) p}^{\prime}+\lambda_{2} \hat{X}_{i p}^{\prime}+\hat{\xi}_{p}
$$

where, $\mathrm{Z}$ is an instrument for private school competition, $\xi_{\mathrm{p}}$ is a random error term associated with the reduced form equation, and ${ }^{\wedge}$ represent predicted values.

The most serious challenge of the IV strategy is the validity of the instrument because the choice of instrument for private school competition is critical for properly identifying any existing bias. Again, the major assumptions of this method are that a) instrumental variable $(Z)$ should have no partial effect on student's SLC score $(S)$ and, b) the instrumental variable should not be correlated with the unobserved factors that affect student's SLC score. These assumptions of instrument validity can be tested. A simple way to check is to look for an association between $Z$ and other variables that should not be affected by private school competition $(C)$. Another useful check is to look for an association between the instrument(s) and educational outcomes in samples where there is no reason for such a relationship.

Instruments that we find in the literature relating to private school competition are lagged private school enrollment to instrument for concurrent year's percentage of students in private 
schools (Geller et al., 2001), and the density of Roman Catholics as the instrument for private schools (Hoxby, 1994), and so on. In this study I use the presence of a motorable road to a walking distance from the sample school as an instrument for number of private schools in the neighborhood. The idea behind this instrument is that having a motorable road provides a high chance of having more private schools in that locality, but it does not have any direct relation to the student's test score. In other words, my claim is that presence of a motorable road is correlated with private school competition and not correlated with the SLC score of the public school student.

\section{Estimation and Results}

\section{Specification and Diagnostic Analysis}

Similar to the diagnostic analysis performed in chapter four, I check the six classical linear model assumptions ${ }^{33}$ for ordinary least square models relating the impact of private school competition on public school competition. First, I check if the error term, $\eta$ follows an approximate normal distribution. The plot of the histogram of the residuals as shown in figure 5.1 suggests that residuals follow an approximate normal distribution.

\footnotetext{
${ }^{33}$ This includes all Guass-Markov assumptions, and also the assumptions of a normally distributed error term.
} 
Figure 5.1. The Distribution of Residuals of the OLS Regression Equation

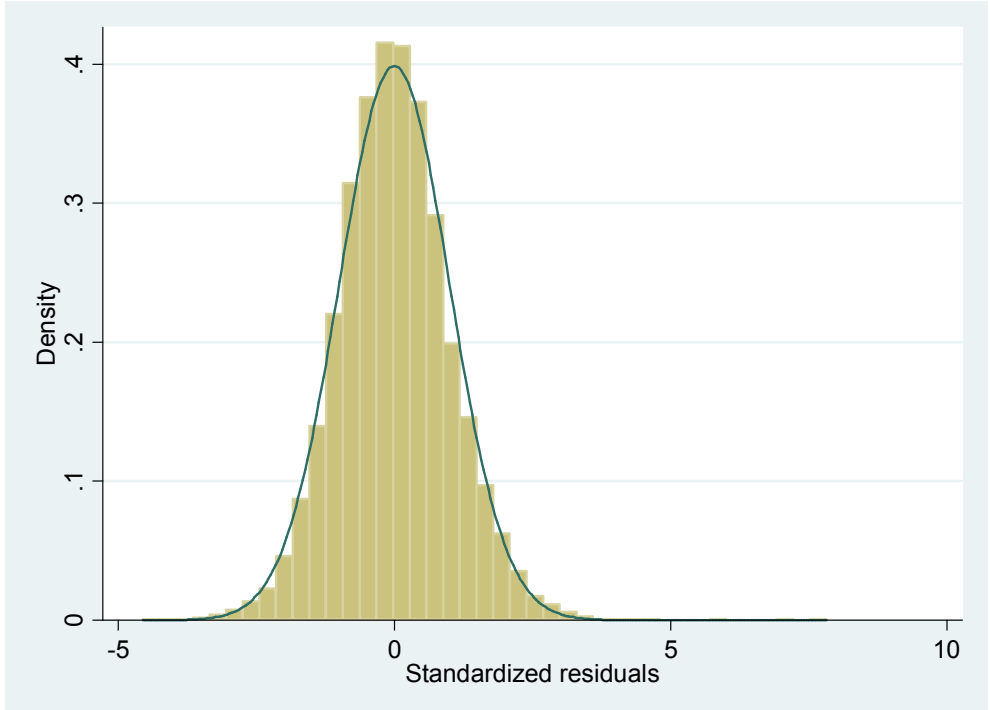

Next, I check if there is heteroskedasticity in the OLS regression. I check this by plotting residuals against the fitted values and visually inspecting for heteroskedasticity. Figure 5.2 shows that the residuals are almost near the zero mean. The graph also shows that the distribution of the residuals do not narrow or widen as most of them are reasonably evenly spread around the mean zero. Hence, there is no evidence of heteroskedasticity in the chosen dataset. 
Figure 5.2. Residuals Plotted against the fitted values

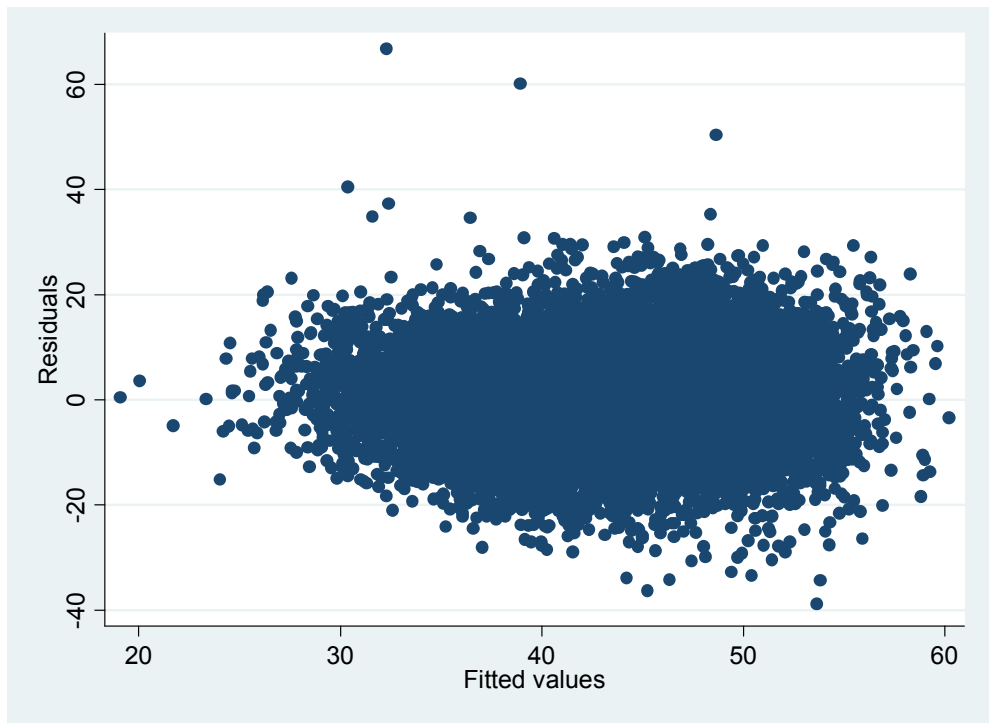

Next, I examine outliers or extreme values by plotting leverage against residual squared.

Figure 5.3 shows that there are no points on the right upper side of the graph indicating no significant outlier evident in the chosen variable set.

Figure 5.3. Detecting Outliers: Leverage vs. Normalized Residual Squared

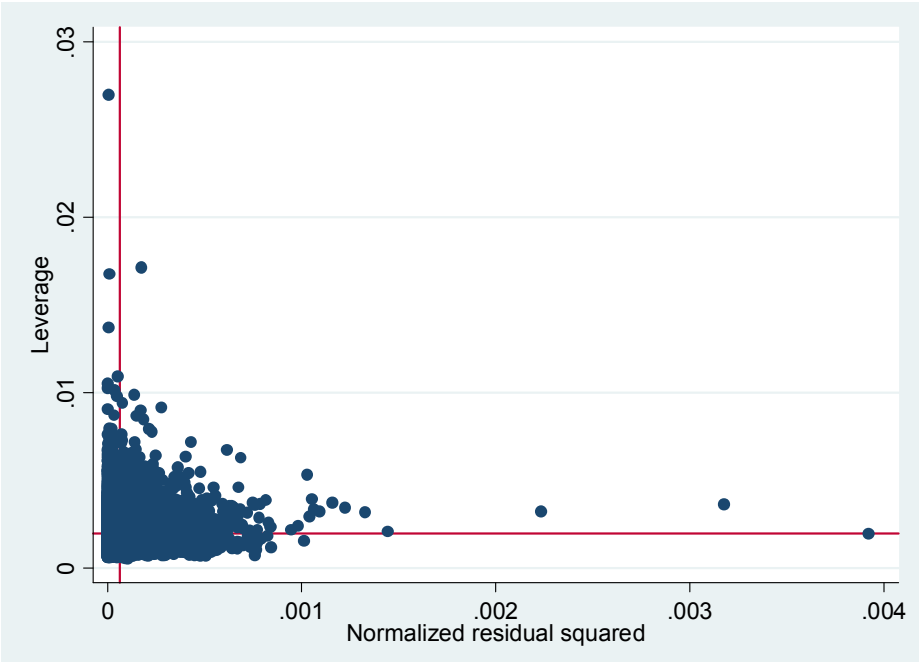


Finally, I examine multicollinearity in my regression using the variance inflation index (VIF) that measures the impact of collinearity among the variables in a regression model. The VIF values as presented in table 5.1 show that all the independent variables have VIF values that are less than 1.43, suggesting no case of multicollinearlity among the independent variables. Further, examining the correlations between the independent variables confirms the absence of multicollinearity in the regression analysis.

\section{Validity Check for Instrument Variable}

As mentioned in the methodology section, I use an instrumental variable to correct for the endogeneity problem in estimating the impact of private school competition on public school performance. The instrument that I choose is the presence of a motorable road within an hour's walking distance from the sample school. The idea is that having a motorable road increases the chances of private school competition in the area, but has no direct impact on the public school student's SLC performance. But, one can always argue that if there is a motorable road near the school, the student will have access to better educational facilities, and that more educated parents might choose the area for their residence, thereby contributing to student's outcome. Therefore, it is necessary to control for some measure of population density in order to capture the effect of urbanism. Due to data limitations, I use the information that describe whether the school is located in the district headquarters as a proxy for a measure of population density. The choice of this variable relies on the idea that more people tend to live and crowd in district headquarters than other parts of the district.

The validity of the chosen instrumental variable depends on it having a high correlation with the number of private schools in the neighborhood of the school (measure of private school 
competition for this study), and a smaller or zero correlation with the SLC performance of public school student. As shown in Table 5.2, the first- stage equations shows that the coefficient of motorable road is positive and significant at the 1 percent with a coefficient of 3.13 and a standard error of 0.07. Even after adding the covariates in this equation, the variable is significant at the 1 percent level. This confirms that there is a statistically significant correlation between the instrument variable (motorable road) and private school competition. Next, I check the correlation between the instrument and the outcome variable ( the SLC score) and find that there is almost a zero correlation between them (0.08). This fulfills both conditions as discussed above for using the presence of a motorable road as a valid instrument for private school competition.

Table 5.2. First-stage equation of 2SLS

\begin{tabular}{lll}
\hline & $\begin{array}{l}\text { Without } \\
\text { covariates }\end{array}$ & $\begin{array}{l}\text { With } \\
\text { covariates }\end{array}$ \\
\hline Motorable road & $3.13 * * *$ & $1.40^{* * *}$ \\
& $(0.07)$ & $(0.05)$ \\
$\mathrm{R}^{2}$ & 0.0975 & 0.2398 \\
Obs & 19921 & 19900 \\
F statistic & 2152.5 & 235.14 \\
\hline
\end{tabular}

Notes: (1) The dependent variable is private school competition, given by the number of private schools in the vicinity of the sample school; (2) robust standard errors are in parenthesis; (3)* denotes statistically significant at $10 \%, * *$ statistically significant at $5 \%$, and $* * *$ statistically significant at $1 \%$.

With the above mentioned instrumental variable, this dissertation employs the 2SLS (Two Stage Least Squares) method to obtain the IV estimators. The study performs a Hausman test (general as well as the Wu version) to check the superiority of using a 2SLS over an OLS method. The null hypothesis is that the OLS estimator is consistent. If the null hypothesis is 
accepted, it indicates that OLS method is better than the 2SLS method. The Wu version makes use of the original OLS version where it adds the OLS predicted values of all the (suspected) endogenous variables. In the case of this study, it is the predicted value of private school competition. Therefore, the $\mathrm{Wu}$ version of the Hausman test is the standard significance test for the coefficients on these added variables (see Greene, 2008). The two Hausman tests give identical information. The general version is in chi-square form, and equals 6.91 with p-value of 0.008. The $\mathrm{Wu}$ version gives a t-statistics, $\mathrm{t}=2.67$, which is approximately the square root of 6.91. They have the same p-value of 0.008 , indicating rejection of the consistency of the OLS, and hence providing support for using the 2SLS over the OLS method.

\section{Power Check of the instrument}

To test the power of the instrument variable, I first set the hypothesis that the coefficient of motorable road variable is zero. Then, I perform F-test for the $1^{\text {st }}$ stage equation. The calculated value of F statistic for the first stage without covariates for 19921 observations and 1 degree of freedom is 2152.54. With covariates, F statistic for the first stage for 19900 observations and 31 degrees of freedom is 235.14 . In both the cases, the calculated value is much higher than the tabulated value (6.61) at 1 percent critical value. Hence, I reject the hypothesis and conclude that motorable road is significant in predicting private school competition, hence confirming the presence of the power of the instrument used.

\section{Empirical Results}

Continuous Measure of Private School Competition 
The measure of private school competition in this study is the number of private schools in the vicinity of the school. Although the focus of this chapter is on public school students, I begin by reporting the OLS estimates of the effect of private school competition on private school student's SLC score controlling for student, family, school, teacher and community characteristics, and exam context variables. The results as presented in column 1 and 2 of Table 5.4 show that private school competition is not significant in explaining private school performance in both the models, with and without the interaction terms.

Table 5.3 gives the summary, and Table 5.4 (columns 3 through 7) gives the detailed estimates of the effect of private school competition on public school performance, To start with, Column 3 of Table 5.3 gives the OLS estimates of the effect of private school competition on public school student's SLC performance. The results show that private school competition is not significant with a coefficient of 0.01 and a standard error of 0.03 . Regarding variables other than private school competition, variables those are significant with a positive relationship are: peers, expected division, annual family expenditure, number of SLC graduates in the family, language spoken at home (if Nepali), having a computer at home, school size, school having a library, school having a science and a computer lab, numbers of school days in the school year, and percent of girls in higher secondary grades. On the other hand, variables that are significant and show a negative relationship are: age, gender (if female), student belonging to lower caste, ethnic groups and other castes, number of days absent in grade 10, family size, student-teacher ratio, student preparing food during the SLC exam, student being sick during the SLC exam, and the SLC years 2002 and 2003. 
Table 5. 3. Estimates of Private School Competition on Public School Student's SLC score

\begin{tabular}{|c|c|c|c|c|c|}
\hline & \multicolumn{5}{|c|}{ Measure of Competition } \\
\hline & \multicolumn{3}{|c|}{$\begin{array}{c}\text { Continuous } \\
\text { (Number of Private Schools) }\end{array}$} & \multicolumn{2}{|c|}{$\begin{array}{l}\text { Binary Measure } \\
1=\text { Competition }\end{array}$} \\
\hline & OLS & OLS & IV & OLS & IV \\
\hline & 1 & 2 & 3 & 4 & 5 \\
\hline Private School & 0.01 & 0.01 & $0.82 * *$ & -0.09 & $2.18^{* *}$ \\
\hline Competition & $(0.03)$ & $(0.03)$ & $(0.38)$ & $(0.16)$ & $(0.83)$ \\
\hline Student Characteristics & $\sqrt{ }$ & $\sqrt{ }$ & $\sqrt{ }$ & $\sqrt{ }$ & $\sqrt{ }$ \\
\hline Family Characteristics & $\sqrt{ }$ & $\sqrt{ }$ & $\sqrt{ }$ & $\sqrt{ }$ & $\sqrt{ }$ \\
\hline $\begin{array}{l}\text { School \& Teacher } \\
\text { Characteristics }\end{array}$ & $\sqrt{ }$ & $\sqrt{ }$ & $\sqrt{ }$ & $\sqrt{ }$ & $\sqrt{ }$ \\
\hline $\begin{array}{l}\text { Community and Exam } \\
\text { Context }\end{array}$ & $\sqrt{ }$ & $\sqrt{ }$ & $\sqrt{ }$ & $\sqrt{ }$ & $\sqrt{ }$ \\
\hline Interaction terms & & $\sqrt{ }$ & $\sqrt{ }$ & & \\
\hline $\mathrm{R}^{2}$ & 0.299 & 0.304 & 0.258 & 0.298 & 0.289 \\
\hline Number of observations & 15643 & 15643 & 15643 & 15643 & 15643 \\
\hline
\end{tabular}

Notes: (1) The dependent variable is the SLC score of the pubic school student, which is converted to the scale of 100. (2) The continuous measure of competition is given by the number of private schools in the neighborhood of the school, and for binary measure of competition, it is coded as 1 if there is more than one private school in the vicinity of the school, and 0 otherwise; (3) robust standard errors are in parenthesis; (4)* denotes statistically significant at $10 \%, * *$ statistically significant at $5 \%$, and $* * *$ statistically significant at $1 \%$.

Column 4 of Table 5.4 presents the estimates when the interactions between the covariates are included in the previous model. The results show that private school competition is still not significant, with coefficient of 0.13 and a standard error of 0.03 . The statistically significant interactions are among caste/ethnicity, student-teacher ratio and school size with teacher qualification; and between the school's location (district headquarter and school size). Higher teacher qualification seems to have a negative relationship with public school student's performance if the student is from an other caste and when the student-teacher ratio is higher in public school, whereas, higher teacher qualification has a positive impact on student's performance if the school size if larger. Unlike the earlier model, whether or not the school is located in the district headquarter seems to matter. For example, a school being in the district 
headquarter has a positive impact on public school student's performance. On the other hand, even if the school is located in the district headquarter, but has a larger size, this has a negative impact on student performance.

In column 5 of Table 5.4, estimates from the instrumental variable regression method are reported. The outcome variable is the SLC score of a public school student, the treatment variable is private school competition, and controls include a similar set of covariates as in the previous models. As discussed earlier in this chapter, the instrument for private school competition is the presence of a motorable road to an hour's walking distance from the school. The IV method shows interesting results as presented in Column 5. The estimate of private school competition is now positive and statistically significant with a coefficient of 0.81 and standard error of 0.38 . Variables other than private school competition show expected signs while explaining their relationship with public school student's performance. For example, variables that are significant with positive relationships are: peers, expected division, annual family expenditure, number of SLC graduates in the family, language spoken at home (if Nepali), school having a library, school having a science lab and a computer lab, number of school days at school, and percent of girls in higher secondary grades. And, variables that are significant with negative relationship are: age, gender (if female), student belonging to lower caste, ethnic groups and other caste, number of days absent from school, family size, student preparing food during SLC exam, student being sick during exam, and SLC years 2002 and 2003. The results also show that teacher qualification by itself is not significant in determining student performance. However, the interaction between teacher qualification and student-teacher ratio indicates that higher teacher qualification with lower student-teacher ratio has a positive impact on student performance. 
Binary Measure of Private School Competition

Note that I have been using private school competition as a continuous variable in earlier models, which is given by the number of private schools in the vicinity of the public school under study. I also construct another measure of competition that is binary in nature. If there is more than one private school in the vicinity of the school, then private school competition is coded as one; otherwise it is coded as zero. Column 6 of Table 5.3 shows the results from the OLS regression using private school competition in binary form. The variable of interest, as before, is private school competition and the regression controls for the same set of covariates as in the preceding models. The OLS results show that private school competition is not statistically significant in determining public school student's SLC exam outcome with a coefficient of 0.09 and a standard error of 0.16 .

Next, I use the instrumental variables method using the same instrument (motorable road) for private school competition. The only difference this time is that the treatment variable is dichotomous (whether or not the school faces private school competition). The results, as presented in column 7 , show that private school competition is statistically significant in explaining public school student's SLC score. The coefficient has drastically improved to 2.18 with standard error of 0.83 . In other words, if a school faces private school competition, then, findings of this study suggest that the SLC score of a student in that school increases by 2.18 percentage points.

\section{Conclusions}


In this chapter, the effect of private school competition on public school performance is analyzed. The measure of private school competition in this study is given by the number of private schools in the vicinity of the school under study. First, I estimate the effect of private school competition on private school performance. The results (both baseline and with interactions) suggest that private school competition is not statistically significant in explaining the performance of private schools for this study. Next, I construct a model on public schools where the dependent variable is the SLC score of public school students. The results from the OLS models suggest that the private school competition is not significant in explaining public school performance, the coefficient of private school competition merely being 0.12 . In addition, the OLS results seem to give biased results because public school performance is believed to be correlated to private school enrollment, what we call the endogeneity problem. As an identification strategy to tackle this problem, I use presence of a motorable road within an hour's walking distance to the school as an instrument for private school competition. The assumptions of the instrument variable seem to be valid for the instrument chosen. Also, to make the instrument meaningful and to capture any other effect of urban concentration, I control for a measure of population density. For this, I use the information concerning whether the school area is in the district headquarters as a proxy for a measure of population density. I also perform the Hausman's test and find that the 2SLS model is better than the OLS. The IV method gives interesting results as the coefficient of private school competition (2.04) becomes significant (even at the 1 percent level of significance). Finally, I use a binary measure of competition where I code competition to take the value one if there is more than one private school in the vicinity of the public school, and zero otherwise. The OLS results using this measure indicate that private school competition is not statistically significant in explaining public school performance. 
However, the IV method shows that the coefficient of private school competition is 2.45 , and is statistically significant at the 5 percent level. Using two measures of competition reaffirms the consistency of the statistically significant OLS estimates, and statistically significant IV estimate of private school competition. Therefore results from the IV methods suggest that private school competition does have a positive impact, though not large, on the public student's performance in the case of Nepal. 
Table 5.1. Variance Inflation Factor

\begin{tabular}{ll}
\hline Variable & VIF \\
\hline PRIVATE_NUM & 1.62 \\
S_SIZE & 1.49 \\
HQRT & 1.42 \\
LANG & 1.29 \\
OTHERS & 1.27 \\
LIBRARY & 1.25 \\
SLC_GRADS & 1.23 \\
SC_COMP_LAB & 1.23 \\
ETHNIC_GRPS & 1.19 \\
PCT_GIRLS & 1.19 \\
PEERS & 1.17 \\
ST_RATIO & 1.17 \\
FAMSIZE & 1.14 \\
TEACHER_EXP & 1.13 \\
TEACHER_QA & 1.11 \\
SLC02 & 1.10 \\
EXP_DIV & 1.09 \\
SLC03 & 1.09 \\
FEMALE & 1.09 \\
AGE & 1.07 \\
DIST_SCH & 1.06 \\
LN_FAM_EXP & 1.05 \\
SCH_ABS & 1.04 \\
SCH_DAYS & 1.04 \\
LOWER_CASTE & 1.03 \\
P_TUTORING & 1.03 \\
COMPUTER & 1.02 \\
EX_MEDIUM & 1.02 \\
\hline Sol_An_'_Caly
\end{tabular}

Source: Author's Calculation

Note: The VIF is an indicator for checking the severity of multicollinearity in regression analysis and measures how much the variance of an estimated regression coefficient is increased because of collinearity. The formula for obtaining VIF is given by $1 /\left(1-R_{j}^{2}\right)$ where $R_{j}^{2}$ is the R-squared for $j^{\text {th }}$ covariance on other covariates. Generally, if the VIF is higher than 10 , then there is an indication of multicollinearity. 
Table 5.4. Estimates of Effect of Private School Competition on Student's SLC Performance by School Type

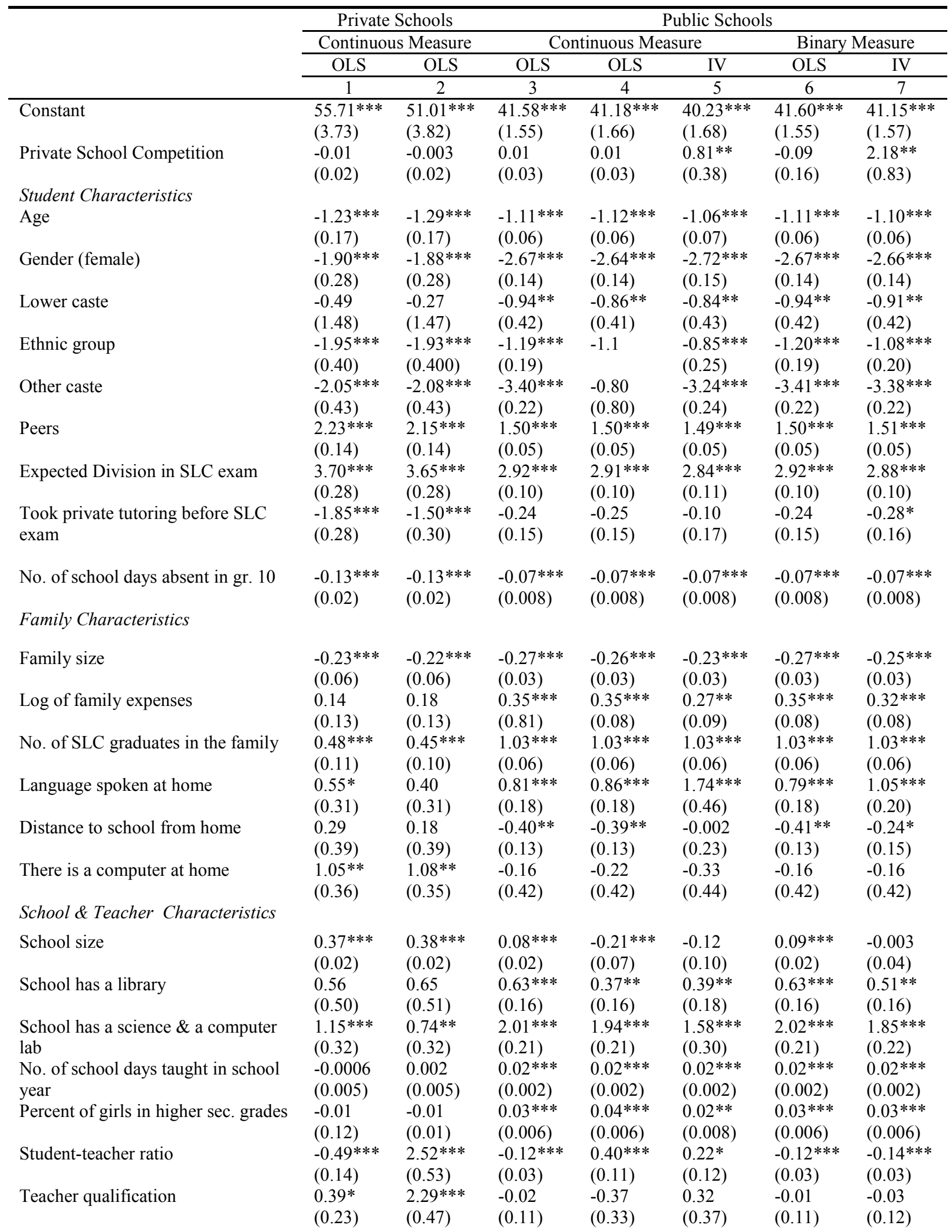




\begin{tabular}{|c|c|c|c|c|c|c|c|}
\hline Teacher experience & $\begin{array}{l}-0.07 \\
(0.06)\end{array}$ & $\begin{array}{l}-0.06 \\
(0.06)\end{array}$ & $\begin{array}{l}0.006 \\
(0.03)\end{array}$ & $\begin{array}{l}0.005 \\
(0.03)\end{array}$ & $\begin{array}{l}0.03 \\
(0.03)\end{array}$ & $\begin{array}{l}0.005 \\
(0.03)\end{array}$ & $\begin{array}{l}0.03 \\
(0.03)\end{array}$ \\
\hline Teacher experience squared & & $\begin{array}{l}0.0005 \\
(0.002)\end{array}$ & $\begin{array}{l}-0.0009 \\
(0.0007)\end{array}$ & $\begin{array}{l}-0.001 \\
(0.0007)\end{array}$ & $\begin{array}{l}-0.001 * \\
(0.0008)\end{array}$ & $\begin{array}{l}-0.0009 \\
(0.0007)\end{array}$ & $\begin{array}{l}-0.001^{*} \\
(0.0007)\end{array}$ \\
\hline \multicolumn{8}{|l|}{ Exam Context } \\
\hline The medium of SLC exam is Nepali & $\begin{array}{l}-6.13 * * * \\
(0.45)\end{array}$ & $\begin{array}{l}-0.32 \\
(0.87)\end{array}$ & $\begin{array}{l}-0.02 \\
(0.18)\end{array}$ & $\begin{array}{l}-0.009 \\
(0.18)\end{array}$ & $\begin{array}{l}-0.08 \\
(0.18)\end{array}$ & $\begin{array}{l}-0.02 \\
(0.18)\end{array}$ & $\begin{array}{l}-0.08 \\
(0.18)\end{array}$ \\
\hline Prepared food by own during exam & $\begin{array}{l}-0.98^{*} \\
(0.58)\end{array}$ & $\begin{array}{l}-0.59 \\
(0.058)\end{array}$ & $\begin{array}{l}-1.34 * * * \\
(0.16)\end{array}$ & $\begin{array}{l}-1.22 * * * \\
(0.16)\end{array}$ & $\begin{array}{l}-1.26^{* * *} \\
(0.17)\end{array}$ & $\begin{array}{l}-1.34 * * * \\
(0.16)\end{array}$ & $\begin{array}{l}-1.26^{* * *} \\
(0.17)\end{array}$ \\
\hline Sick during exam & $\begin{array}{l}-0.03 \\
(0.42)\end{array}$ & $\begin{array}{l}-0.02 \\
(0.42)\end{array}$ & $\begin{array}{l}-0.80 \text { *** } \\
(0.19)\end{array}$ & $\begin{array}{l}-1.78 * * * \\
(0.19)\end{array}$ & $\begin{array}{l}-0.79 * * * \\
(0.19)\end{array}$ & $\begin{array}{l}-0.80 * * * \\
(0.19)\end{array}$ & $\begin{array}{l}-0.73 * * * \\
(0.19)\end{array}$ \\
\hline SLC Year 2002 & $\begin{array}{l}-0.26 \\
(0.35)\end{array}$ & $\begin{array}{l}-0.23 \\
(0.35)\end{array}$ & $\begin{array}{l}-0.92 * * * \\
(0.18)\end{array}$ & $\begin{array}{l}-0.91 * * * \\
(0.18)\end{array}$ & $\begin{array}{l}-0.88 * * * \\
(0.19)\end{array}$ & $\begin{array}{l}-0.92 * * * \\
(0.18)\end{array}$ & $\begin{array}{l}-0.93 * * * \\
(0.18)\end{array}$ \\
\hline SLC Year 2003 & $\begin{array}{l}-0.62 * * \\
(0.32)\end{array}$ & $\begin{array}{l}-0.60^{*} \\
(0.31)\end{array}$ & $\begin{array}{l}-0.97 * * * \\
(0.17)\end{array}$ & $\begin{array}{l}-0.99 * * * \\
(0.16)\end{array}$ & $\begin{array}{l}-0.93 * * * \\
(0.17\end{array}$ & $\begin{array}{l}-0.97 * * * \\
(0.17)\end{array}$ & $\begin{array}{l}-0.96 * * * \\
(0.17)\end{array}$ \\
\hline School is in the district Headquarter & $\begin{array}{l}0.66^{* *} \\
(0.30)\end{array}$ & $\begin{array}{l}0.42 \\
(0.30)\end{array}$ & $\begin{array}{l}0.25 \\
(0.20)\end{array}$ & $\begin{array}{l}3.96 * * * \\
(0.42)\end{array}$ & $\begin{array}{l}-2.07^{*} \\
(1.13)\end{array}$ & $\begin{array}{l}0.30 \\
(0.19)\end{array}$ & $\begin{array}{l}-0.18 \\
(0.26)\end{array}$ \\
\hline Interaction terms & & & & & & & \\
\hline EX_MED *P_TUTOR & & $\begin{array}{l}-2.58 * * * \\
(0.79)\end{array}$ & & & & & \\
\hline ST_RATIO*TCH_QA & & $\begin{array}{l}-1.12 * * * \\
(0.24)\end{array}$ & & $\begin{array}{l}-0.27 * * * \\
(0.05)\end{array}$ & $\begin{array}{l}-0.15^{* *} \\
(0.06)\end{array}$ & & \\
\hline ST_RATIO *EX_MED & & $\begin{array}{l}-2.15^{* * *} \\
(0.31)\end{array}$ & & & & & \\
\hline OTHERS *TCH_QA & & & & $\begin{array}{l}-1.09 * * \\
(0.35)\end{array}$ & & & \\
\hline S_SIZE* TCH_QA & & & & $\begin{array}{l}0.18 * * * \\
(0.03)\end{array}$ & & & \\
\hline HQRT*S_SIZE & & & & $\begin{array}{l}-0.40 * * * \\
(0.04)\end{array}$ & & & \\
\hline $\mathrm{R}^{2}$ & 0.4387 & 0.4487 & 0.2978 & 0.3037 & 0.2580 & 0.2978 & 0.2885 \\
\hline Number of observations & 4254 & 4254 & 15643 & 15643 & 15643 & 15643 & 15643 \\
\hline
\end{tabular}

Notes: (1) The dependent variable is the SLC score of the pubic school student, which is converted on the scale of 100. (2) The continuous measure of competition is given by the number of private schools in the neighborhood of the school, and for the binary measure of competition, it is coded as 1 if there is more than one private school in the vicinity of the school, and 0 , otherwise; (3) robust standard errors are in parenthesis; (4)* denotes statistically significant at $10 \%, * *$ statistically significant at $5 \%$, and $* * *$ statistically significant at $1 \%$. 


\section{Chapter VI \\ CONCLUSIONS}

\section{Summary of Findings}

This dissertation seeks to answer two research questions using data from the Ministry of Education, Nepal (MOES, 2005b). The first question is whether public school students perform better than private school students, controlling for student, family, school, teacher and exam context variables. Chapter 4 of this dissertation addresses the first question using the Ordinary Least Squares regression method to model private school and public school performance. The findings show that school type (private) is positive and statistically significant in explaining student's SLC performance. For example, the estimated coefficients of school type on student's SLC score obtained from final OLS model is 9.50. This indicates that a student from a private school has 9.50 points higher score in her SLC exam as compared to a student from public school, keeping other things constant. Next, the Chow test is performed on the pooled data, and then separately for private and public school students. The tests on each of the covariates controlled in the regression and logistic models suggest that they vary significantly by school type. In addition, the Blinder-Oaxaca decomposition performed for private school and public school students indicate a gap of 17.42 points in SLC score between private and public school students. According to the results from the decomposition, there would be an increase of 9.17 points in the SLC score of public school students if they were provided the same endowments as private school students.

The OLS results are likely to be plagued by the selection-bias problem. In order to tackle this issue, the study uses the propensity score matching technique, where the treatment is going 
to private school and the outcome is student's SLC performance. The average treatment effect on the treated (ATT) derived from propensity score matching is 3.96 with a bootstrapped standard error of 2.68. Also, as a result of taking into account the presence of selection bias, the coefficient of school type after propensity score matching is only 5.33 .

Seeking the answer to the first research question, the study also uses a probit regression to examine the impact of school type on student's SLC performance. The results from the probit estimations are mostly similar to the OLS results in determining the impact of school type as well as other covariates in explaining the student performance. The marginal effects from the probit model suggest that public school students are 30.2 percent more likely to pass the SLC exam than the public school students. As in the case of the OLS, the propensity score matching method is also applied to the probit model; this time the outcome variable being categorical ( 1 if the student passed the SLC exam). After performing the matching, the marginal effect of school type reduces to 7.89. Finally, besides using the probit model with SLC as the dependent variable, the study also applies probit models for the language medium of the exam and private tutoring. Interestingly, the results suggest that public school students are more likely to use Nepali as the language medium for the SLC exam and take private tutoring compared to students from private schools.

Chapter 5 of the dissertation deals with the second research question, and attempts to explore the impact of private school competition on public school performance. The measure of private school competition is given by the number of private schools in the vicinity of the sample school. The results from the OLS regressions show that private school competition is not statistically significant in explaining public school performance. Moreover, the OLS results seem to give biased results due to the endogeneity between private school enrollment and public 
school performance. This study uses the presence of a motorable road within an hour's walking distance to the school as an instrument for number of private schools (private school competition) to account for this problem. To ensure the validity of the instrument, the study also controls for the information if the school area is located in the district headquarters as a proxy for a measure of population density. Further, Hausman's test performed for the instrument confirms that the 2SLS model is better than the OLS model. Interestingly, the findings from the IV method show that the coefficient of private school competition is 2.04 and this is statistically significant even at the 1 percent level of significance. Finally, binary measure of competition is also constructed where competition is coded taking the value one if there is more than one private school in the vicinity of the public school, and zero otherwise. As in the continuous measure, the private school competition variable is not statistically significant in OLS but is significant in the IV method. For example, the coefficient of private school competition using the IV method is 2.18 with standard error value of 0.83 . Therefore, the final results from the IV method suggest some evidence of a positive impact of private school competition on the public student's performance for the case of Nepal.

\section{Discussion}

The study of private versus public schooling is of great interest at the present time. The topic is more interesting in the case of developing countries where the demand for a better education system is rising day by day. In such a situation, a study on linkages between private and public education becomes crucial to both education researchers and policy makers. In addition, as the wave of privatization of education in developing countries is taking huge strides, this study is of even more importance. This study is one of the first empirical studies on the 
impact of private school competition on public school performance in a developing country setup.

One of the major strengths of this study is the use of data on the SLC (School Leaving Certificate) examination from the Ministry of Education which is one of the most comprehensive data sets collected so far in Nepal relating to the SLC examinations. The SLC examinations are, by far, the most important school-level exams for the majority of Nepalese. Hence, the use of data incorporating the SLC variables and outcomes is very appropriate for this study. In addition, this study adopts the propensity score matching and the instrumental variable method as an identification strategy to address the selection bias/endogeneity problem. Therefore, this makes the study richer as compared to those that do not account for these serious problems, and hence contributes to the literature of private versus public schooling in developing countries.

With regards to limitations, the first concerns the unobservable factors that the data does not capture. There could be factors that cannot be measured but enter the equations in both the analyses. In that case, the study will also be likely to suffer from the omitted variable bias. The second concern relates to the missing data problem, with the rate of missing data being quite high for some variables. In this study, only those variables with a rate of missing rate of below 25 percent are considered. In addition, the study adopts regression and multiple imputation method to address the missing data problem. In spite of these steps, the drawbacks of using data imputation are always there. In addition, the data is cross-sectional, and therefore I am not able to measure the value-added in students' performance over a period of time. Furthermore, nationally representative school surveys generally involve multistage, stratified random sampling designs. The data resulting from such surveys have complex hierarchical structures which might lead to biased results. This study does not take account of this as well. The third limitation 
concerns the measure of competition. For example, this dissertation uses the number of private schools in the vicinity of the sample school as the measure of private school competition. This might not be an ideal measure of competition. A better measure of competition would rather be the Herfindahl index as discussed in the literature review section of chapter 5. However, given Nepal's poorly organized education system, it is difficult to identify market share of educational units in the district or zonal level. As a result, this study makes no attempt to construct a Herfindahl index. The fourth limitation relates to the analysis of private school competition on the public school performance. The present analysis is at the overall level, and includes both urban and rural districts of the country. However, it is very likely that many districts, especially in the rural areas of Nepal, could have very few private schools or no private school at all. In such a case, it is ideal to make the analysis based on only the urban districts of the country. Finally, the limitation could be related to the methodology as well. In estimating the effect of private school competition on public school performance, this study uses the presence of a motorable road within an hour's walking distance from the sample school as an instrument for the number of private schools in the neighborhood. Here, I am assuming that the presence of a motorable road is not correlated with the error term. But, one must admit that this is a strong assumption, and that finding a pure instrument is very rare.

\section{Policy Implications}

This study, using the SLC data from Nepal and using the latest empirical techniques presents two major findings. First, analysis performed in Chapter 4 shows that controlling for all observed characteristics in student, family, teacher and school levels, students from private 
schools perform better than students from public schools. However, it is important to take account of the fact that private schools have more resources and certainly have students from families with higher socio-economic status for peer effects. These are omitted variables or nonobservables. Thus, it is very likely that these differences account for the overall differential in achievement between public and private schools rather than the sponsorship. Secondly, analysis conducted in Chapter 5 shows that private school competition in Nepal has a positive impact on public school performance. Although the impact found is not so large, the analyses using the instrumental variable method for both continuous and binary measure of competition consistently show a positive impact of private school competition for the case of Nepal. Hence, this study finds some evidence that private school competition seems to work for Nepal. Again, due to unobserved factors in the estimation process, a definite conclusion cannot be reached at.

Table 6.1 presents a summary of variables that are statistically significant in explaining student's SLC performance in most of the models analyzed in chapter 4 and 5. Among student related variables, those that can be influenced by policy intervention are gender and caste/ethnicity. Taking the case of gender, the lower performance of girls could be directly related to the gender discrimination prevalent in the Nepalese society. This gender discrimination is more rampant in rural areas of the country, and can exist at all levels: home, school and community. Likewise, people from the lower caste and ethnic groups are under-privileged in the society. Students from the lower caste and ethnic groups do not get as many educational opportunities as the higher caste students get due to the discriminatory treatment they generally receive in the society. Hence, findings from this study suggests that the government needs to come up with targeted policies and goals to help female students and students from 
disadvantaged castes in order to bridge the huge gap in their performance level compared to the other groups.

Among the family related variables, there is not much room for policy intervention. However, family expenditures for children's education is an influencing factor in student's academic performance. Policies that help in giving subsidies or financial assistance to low income families for educational expenses could be very effective in helping the poor students perform better.

Among the school variables, variables found to be statistically significant and subject to policy intervention are school type and school resources, such as school having a science lab and computer labs. These variables also serve as proxy for per-student expenditures, and evidence from the international literature implies that school resources do matter in student achievement. Moreover, a country's social and economic development depends greatly on the educational levels of its citizens (see Krueger \& Lindahl, 2001). Hence, no matter how constrained the national budget is, the government of Nepal should make sure it allocates enough funds to the education sector that is especially targeted towards improving the public education system. 
Table 6.1 Variables that are consistently significant in explaining student's SLC performance

\begin{tabular}{|l|l|l|l|}
\hline Student & Family & $\begin{array}{l}\text { School \& } \\
\text { Teacher }\end{array}$ & Exam Context \\
\hline Age (-) & $\begin{array}{l}\text { Family size } \\
(-)\end{array}$ & $\begin{array}{l}\text { School } \\
\text { type/private } \\
(+)\end{array}$ & $\begin{array}{l}\text { Medium of } \\
\text { exam /Nepali } \\
(-)\end{array}$ \\
\hline $\begin{array}{l}\text { Gender(female) } \\
(-)\end{array}$ & $\begin{array}{l}\text { No. of SLC } \\
\text { graduates in } \\
\text { the family } \\
(+)\end{array}$ & $\begin{array}{l}\text { Science \& } \\
\text { Computer lab } \\
(+)\end{array}$ & $\begin{array}{l}\text { Preparing } \\
\text { food during } \\
\text { exam (-) }\end{array}$ \\
\hline $\begin{array}{l}\text { Ethnic } \\
\text { groups/other } \\
\text { castes (-) }\end{array}$ & $\begin{array}{l}\text { Language } \\
\text { spoken at } \\
\text { home (+) }\end{array}$ & $\begin{array}{l}\text { Private School } \\
\text { Competition } \\
(+)\end{array}$ & $\begin{array}{l}\text { Sick during } \\
\text { exam (-) }\end{array}$ \\
\hline Peers (+) & $\begin{array}{l}\text { Annual } \\
\text { family } \\
\text { expenses (+) }\end{array}$ & & $\begin{array}{l}\text { SLC year } \\
\text { 2003 (-) }\end{array}$ \\
\hline $\begin{array}{l}\text { Expected } \\
\text { division in SLC } \\
\text { exam (+) }\end{array}$ & & & \\
\hline
\end{tabular}

Note: The signs in the parenthesis denote the type of relationship of the variable with student's performance in SLC exam.

The analysis of chapter 5 provides us with one of the major findings of this study, which relates to the impact of private school competition on public school performance. In fact, not everyone views private school competition as a good thing. However, using comprehensive data and the latest methodology, this study shows that private school competition is associated with increased public school performance in the case Nepal. In spite of the possibility of unobservable factors in the estimation methods and other limitations of this study, the findings of this study are useful and quite thought provoking. The explanation of this finding on competition can be rooted on two main aspects. First, private schools might be more competitive and efficient. As discussed in chapter 2 of this dissertation, this could be due to various reasons such as better administration and management, better teacher quality, better school climate and better 
motivated students in private schools as compared to public schools. As a result of competition itself, it could be that private schools are getting better. Moreover, following Hirschman's (1970) idea of 'exit', competition could also be forcing the inefficient private schools to exit, and as a result making the educational market more efficient. Further, following Friedman's (1962) idea that presence of competition raises the overall educational productivity, it could be that even the public schools are evolving to be better performers in the market. We could take this as a 'spillover effect' too. The second effect is related to the sorting mechanism. Private schools, endowed with better resources and better promises are capable of attracting higher achieving students from the pubic schools. As a result of this cream skimming and selection of good students, their performance is very likely to be better. In practice, both of these effects could be functioning simultaneously, thereby raising private school performance to a higher level. The study of private school competition demands more empirical evidence to reach any particular conclusion. However, the analyses of this study lead the author to conclude that private school competition work's in the Nepalese context.

As a policy recommendation, this study thus suggests that the government should consider using a policy of private school incentives to stimulate competition and better educational results. The government should also make policies easier that support towards handing over public schools to communities in a simplistic and systematic manner. Further, the government should provide more basic infrastructure (like roads) and give incentives to open low cost private schools in the rural areas of the country so that market competition effects can come into play and give rise to higher efficiency.

In this regard, analyzing the effect of private school competition using Levin's (2002) four criteria for evaluating an educational system is contextual. The four criteria for evaluating an 
educational system are: freedom of choice, productive efficiency, equity and social cohesion (Levin, 2002). More private school competition will surely provide better access to the general public. Parents from the rich and middle income families will be more likely to have a higher freedom of choice with more private schools to choose from in the community. However, one cannot guarantee that poor students too will have more freedom of choice unless the government adopts a system such as the voucher scheme (see Friedman, 1962). With a stringent educational budget and heavy dependence on foreign aid for education, adoption of such scheme in near future is challenging in case of Nepal. The productive efficiency, already discussed before, is more likely to improve with private school competition. However, from the equity and social cohesion aspect, the impact of competition could be mixed. For example, if the government is unable to make provisions for the necessary financial assistance to marginalized students to attend the school they like, a mere increase in the number of private schools will not do any good. This might rather increase the gap between the rich and the poor, with the middle class shifting towards the private school system. Nevertheless, as the access to modern education increases, modern and secular ideas will also be propagated in the communities. This could help reduce the discrimination based on caste, ethnicity and religion, and hence schools and communities could be more socially cohesive. Based on these arguments, this study suggests that the benefits of private school competition tend to outweigh its drawbacks, at least in the case of Nepal. 


\section{REFERENCES}

Ahmed, M., \& Nath, S. R. (2005). Quality with equity: the primary education agenda (Dhaka, Campaign for Popular Education, Bangladesh).

Allison, P. D. (2002). Missing Data. Sage Publications, Thousand Oaks, California.

Arum, R. (1996). Do private schools force public schools to compete? American Sociological Review, 61, 29-46.

Assad, R., \& El-Badawy, A. (2004). Private and group tutoring in Egypt: When is the gender inequality. Paper presented at the workshop on Gender, Work, and Family in the Middle East and North Africa.

Bailey, J. (1998). A new SLC for the year 2058 and beyond. Siksa, 86 -90.

Baker, D. P., Akiba, M., LeTendre, G. K., \& Wiseman, A. W. (2001). Worldwide shadow education: Outside-school learning, institutional quality of schooling, and cross-national mathematics achievement. Educational Evaluation and Policy Analysis, 23(1), 1-17.

Baker, D. P. \& LeTendre, G. K. (2005). National differences, global similarities: World culture and the future of schooling. Stanford CA: Stanford University Press.

Becker, S. O. \& Ichino, A. (2002). Estimation of Average Treatment Effects Based on Propensity Scores. The Stata Journal, 2, 358-377.

Beker, S. O. \& Caliendo, M. (2007). Sensivity Analysis for Average Treatment Effects. The Stata Journal, 7, 71-83.

Betts, J. R. (1995). Does School Quality Matter? Evidence from the National Longitudinal Survey of Youth. The Review of Economics and Statistics, 77 (2), 231-250.

Bettinger, E. (1999). The Effects of Charter Schools on Charter Students and Public Schools. NCSPE working paper, Teachers College, Columbia University.

Bhatta, S.D. (2004). A descriptive analysis of the disparities in school performance in the SLC Exams. SLC Study Report \# 1. Kathmandu: The Education Sector Advisory Team, Ministry of Education and Sports, Nepal.

Bhatta, S.D. (2005). Determinants of Student Performance in the SLC Examinations. SLC Study Report \# 13.Prepared for the Ministry of Education and Sports, Kathmandu, Nepal.

Blinder, A. S. (1973). Wage Discrimination: Reduced Form and Structural Estimates. The Journal of Human Resources, 8, 436-455. 
Blair, J. P., \& Staley, S. (1995). Quality competition and public schools: further evidence. Economics of Education Review, 14, 193-98.

Borland, M. V., \& Howson, R. M. (1992). Students' academic achievement and the degree of market concentration in education. Economics of Education Review, 11, $31-39$.

Borland, M. V., \& Howson, R. M. (1993). On the determination of the critical level of market concentration in education. Economics of Education Review, 12, 165-69.

Borland, M. V., \& Howson, R.M. (1995).Competition, expenditures and student Performance in Mathematics: A comment on Crouch et al. Public Choice, 87, 395400.

Bray, M. (1999). The Shadow Education System: Private Tutoring and Its Implications for Planners. Paris: UNESCO International Institute for Educational Planning (IIEP).

Bray, M. (2009). Confronting the Shadow Education System: What Government Policies for What Private Tutoring? Paris: UNESCO-IIEP.

Buchmann, C. (1999). The state and schooling in Kenya: Historical development and current challenges. Africa Today, 46(1), 95-116.

Burtless, G. T. (1996). Does Money Matter?: The effect of school resources on student academic achievement \& adult success. Brookings Institution Press.

Caddell, M. (2006). Private schools as battlefields: contested visions of learning and livelihood in Nepal. A Journal of comparative education, 36 (4), 463-479.

Caddell, M. (2007). Private Schools and Political Conflict in Nepal. In: Srivastava, Prachi and Walford,Geoffrey eds. Private Schooling in Less Economically Developed Countries: Asian and African Perspectives. Oxford Studies in Comparative Education. Didcot, UK: Symposium, pp. 187-207.

Card, D. (1999). The Causal effect of education on earnings. Handbook of Labor Economics, $3(1), 1801-1863$.

Card, D., \& Krueger, A.B. (1996). Labor market effects on school quality: Theory and evidence. In G. Burtless, (Eds.) Does money matter? The effect of school resources on student achievement and adult success. Washington, DC: Brookings Institution.

Carney, S. (2003). Globalization, neo-liberalism and the limitations of school effectiveness research in developing countries; the case of Nepal. Globalization, Societies and Education, 1 (1), 87-101.

Carney, S. , \& Bista, M. B. (2009). Community Schooling in Nepal: A Genealogy of Education Reform since 1990, Comparative Education Review, 53 (2), 189-211. 
CERID. (1996). SLC examination in Nepal: a critical study report.: Kathmandu: Research Center for Educational Innovation and Development.

CERID. (2002a). School effectiveness study in Nepal: a synthesis of indicators. Formative research project study report 5. Kathmandu: Research Center for Educational Innovation and Development.

CERID. (2002b). Effective classroom teaching/learning - phase 1: classroom delivery. Formative research project study report 4 . Kathmandu: Research Center for Educational Innovation and Development.

CBS. (2002). Population Census, 2001 National Report. Central Bureau of Statistics, Kathmandu, Nepal.

CBS. (2003). Nepal in figures. Central Bureau of Statistics, Kathmandu, Nepal.

CBS. (2010). Nepal in figures. Central Bureau of Statistics, Kathmandu, Nepal.

Chow, G. C. (1960). Tests of Equality Between Sets of Coefficients in Two Linear Regressions. Econometrica, 28 (3), 591-605

Cochran. W, \& Rubin, D. B. (1973). Controlling Bias in Observational Studies, Sankyha, 35, 417-446.

Colclugh, C. (1996). Education and the market: Which parts of the neoliberal solution are correct? World Development, 24 (4), 589-610.

Coleman, J. S., Campbell, E.Q., Hobson, C. J., McPartland, J., Mood, A. M., Weinfeld, F. D. \& York, R. L. (1966). Equality of Educational Opportunity. Washington, D.C.: Department of Health Education and Welfare.

Couch, J. E., Shughart, W. F. II., \& Williams, A. L. (1993). Private school enrollment and public school performance. Public Choice, 76, 301-312.

Couch, J. F., \& Shughart. W. F. (1995). Private school enrollment and public school performance: a reply. Public Choice, 82, 375-379.

Cuellar-Marchelli, H. (2003). The Cost-Effectiveness of Educo and Traditional Public Schools in Rural El Salvador. (Doctoral Dissertation), Columbia University, New York.

Dang, H. A. (2007). The determinants and impact of private tutoring classes in Vietnam. Economics of Education Review, 26(6), 684-699.

DANIDA. (2003). Terms of reference for technical assistance to conduct a study on student performance in SLC. Kathmandu: Education Sector Advisory Team, DANIDA.

Dee, T. S. (1998). Competition and the quality of public schools. Economics of Education 
Review, 17, 419-427.

Dehejia, R. H., \& Wahba, S. (1999). Causal Effects in Non-Experimental Studies: ReEvaluating the Evaluation of Training Programmes. Journal of the American Statistical Association, 94, 1053-1062.

Dehejia, R. H. \& Wahba, S. (2002). The Review of Economics \& Statistics, 84 (1), 151-161.

De Silva, W. A. (1994). The present status of private tutoring in Sri Lanka. Economic Review, 20 (2 \& 3), 4-7, 20-24.

Ding, W. \& Lehrer, S. F. (2006). Do peer affect student achievement in China's secondary schools? NBER Working Paper 12305. Cambridge: National Bureau of Economic Research.

Drake, C. (1993). Effects of Misspecification of the Propensity Score on Estimators of Treatment Effect, Biometrics, 49(4), 1231-1236.

EDSC. (1997). National assessment of grade 3 students. A report submitted to the Ministry of Education and Sports by Educational and Developmental Service Center, Kathmandu.

EDSC. (1999). National assessment of grade 5 students. A report submitted to the Academy for Educational Development by Educational and Developmental Service Center, Kathmandu.

EDSC. (2001). National assessment of grade 3 students. A report submitted to the Research and Development Section of the Department of Education, Ministry of Education and Sports by Educational and Developmental Service Center, Kathmandu.

EDSC. (2003). National assessment of grade 5 students. A report submitted to the Research and Development Section of the Department of Education, Ministry of Education and Sports by Educational and Developmental Service Center, Kathmandu.

EFSG. (2009). Financing Education in Federal Nepal. Educational Financing Reference Group, Kathmandu, Nepal, monograph.

Ferguson, R. F., \& H. Ladd. (1996). How and why money matters: An analysis of Alabama schools. In H. F. Ladd, ed., Holding Schools Accountable: Performance-Based Reform in Education, pp. 265-98. Washington, DC: Brookings Institution Press.

Figlio, D. N. (1999). Functional form and the estimated effects of school resources. Economics of Education Review, 18, 241-252.

Figlio, D. N., \& Stone, J. A. (1999). Are private schools really better? Research in Labor Economics, 18, 115-140. 
Friedman, M. (1962). The Role of government in education. In M. Friedman (Ed.), Capitalism and freedom, (chap. VI). Chicago: University of Chicago Press.

Fuller, B., \& Clarke, P. (1994). Raising school effects while ignoring culture? Local conditions and the influence of classroom tools, rules and pedagogy. Review of Educational Research, 64, 119 -157.

Geller, C. (2000). Private schools and public quality: An analysis of the effects of private schools on public school performance. (Doctoral Dissertation), Georgia State University, Atlanta.

Geller, C. R, Sjoquist D. L., \& Walker, M. B. (2001). The effect of private school competition on public school performance. NCSPE Working Paper, Teachers College, Columbia University.

Greene, W. H. (2008). Econometric Analysis, 6th edition, Pearson, Prentice Hall, New Jersey.

Greene, K. V., \& Kang, B. G. (2004). The effect of public and private competition on high school outputs in New York State. Economics of Education Review, 23, 497-506.

Glewwe, P., \& Lambert, S. (2010). Education Production Functions: Evidence from Developing countries. In D. Brewer \& P. McEwan, eds., Economics of Education, Elsevier, Academic Press, 137-147.

Goldhaber, D. D., \& D. J. Brewer. (1997). Evaluating the effect of teacher degree level on educational performance. In W. Fowler, ed., Developments in School Finance, 1996. pp. 197-210. NCES 97-535. Washington, DC: U.S. Department of Education, National Center for Education Statistics.

Hammons, C.W. (2001). The Effects of Town Tuitioning in Vermont and Maine. Mimeo, Milton \& Rose D Friedman Foundation. www.friedmanfoundation.org

Hanushek, E. A. (1986). The economics of schooling: Production and efficiency in public schools. Journal of Economic Literature, 24 (3), 1141-1177.

Hanushek, E. A. (1989). The impact of differential expenditures on school performance. Educational Researcher, May, 45-62.

Hanushek, E. A. (1995). The impact of differential expenditures on school performance. The World Bank Research Observer, 10: 227-46.

Hanushek, E. A. (1997). Assessing the effects of school resources on student performance: An update. Educational Evaluation and Policy Analysis, 19, 141-164.

Hanushek, E. A. (2010). Educational Production Functions: Evidence from Developed Countries. In D. Brewer \& P. McEwan eds., Economics of Education, Elsevier, Academic Press, 132 -136. 
Hanushek, E. A., Rivkin, S. G. \& Taylor, L. L. (1995). Aggregation and the Estimated Effects of School Resources. RCER Working Papers 397, University of Rochester, Center for Economic Research (RCER).

Hanushek, E. A., Rivkin, S. G. \& Taylor, L. L. (1996). Aggregation and the Estimated Effects of School Resources. The Review of Economics and Statistics, MIT Press, vol. 78(4), 611627.

Hanushek, E. A., \& Rivkin, S. G. (2001). Does public school competition affect teacher quality? Mimeo.

Harris, D. N. (2010). Education Production Functions: Concepts. In D. Brewer \& P. McEwan, eds., Economics of Education, Elsevier, Academic Press, 127 -131.

Heckman, J. (1979). Sample selection bias as a specification error. Econometrica, 47 (1), 15361.

Heckman, J., Ichimura, H. \& Todd, P. E. (1998). Matching as an Econometric Evaluation Estimator. Review of Economic Studies, 65, 261-294.

Hedges, L. V., Laine, R. D. \& Greenwald, R. (1994). Does money matter? A meta-analysis of studies of the effects of differential school inputs on student outcomes. Educational Researcher, 23, 5-14.

Henry, G. T., \& Gordon, C. S. (2003). Can Competition Improve Educational Outcomes? Prepared for the National Institute for Early Education Research.

Heyneman, S. P., \& Loxley, W. (1983). The effect of primary school quality on academic achievement across twenty-nine high and low income countries. American Journal of Sociology, 88, $1162-1194$.

Hill, J. L., Reiter, J. P., \& Zanutto, E. L. (2004). A comparisons of experimental and observational data analyses. In Applied Bayesian Modeling and Causal Inference From an Incomplete-Data Perspective (Edited by Andrew Gelman and Xiao-Li Meng), 44-56. Wiley.

Hirschman, A. O. (1970). Exit, Voice, and Loyalty. Responses to Decline in Firms, Organizations, and States, Harvard University Press, Massachusetts.

Hoxby, C. M. (1994). Do Private Schools Provide Competition for Public Schools. NBER Working Paper Series No. 4978, NBER: Cambridge, Massachusetts.

Hoxby, C. M. (2000). Does competition among public schools benefit students and taxpayers? American Economic Review, 90, 1209-1238.

Husted, T. A., \& Kenny. L.W. (2000). Evidence on the impact of state government on 
primary and secondary education and the equity-efficiency trade-off. Journal of Law and Economics, 43, 285-308.

James. E. (1987). The Public/Private Division of Responsibility for Education: An International Comparison. Economics of Education Review, 6(1), 1- 44.

Jann, B. (2008). The Binder-Oaxaca decomposition for linear regression models. The Stata Journal, 8 (4), 453-479.

Jepsen, C. (1999). The effects of private school competition on student achievement. Northwestern University, mimeo.

Kim, J. (2007b). The Determinants of Demand for Private Tutoring in South Korea. NCSPE manuscript. http://www.ncspe.org/list-papers.php

Kim, S. \& Lee, J. (2004). Private tutoring and demand for education in South Korea. Mimeo. Department of Economics, University of Wisconsin, Milwaukee.

Krueger, A. B., \& Lindahl, M. (2001). Education for Growth: Why and for Whom? Journal of Economic Literature, 39, 1101- 1136.

LaLonde, R. (1986). Evaluating the Econometric Evaluations of Training Programs. American Economic Review, 76 (4), 604-620.

Lee, L.F. (2001). Self-selection. In B. Baltagi (ed). Companion to Theoretical Econometrics, Oxford: Blackwell.

Levin, H. M. (1968). The Failure of the Public Schools and Free Market Remedy. The Urban Review, 2, 33-37.

Levin, H. M. (1991). The economics of educational choice. Economics of Education Review, 10, 137-158.

Levin, H.M. (1998). Educational vouchers: Effectiveness, choice and costs. Journal of Policy Analysis and Management, 17, 373-392.

Levin, H. M. (1999). The Public-Private Nexus in Education. The American Behavioral Scientist, 43 (1), 124-137.

Levin, H. M. (2002). A comprehensive Framework for Evaluating Educational Vouchers. Educational Evaluation and Policy Analysis, 24 (3), 159-174.

Levin, H. M., \& Belfield, C. (2002). The Effects of Competition on Educational Outcomes: A Review of US Evidence. Working paper for NCSPE, Teachers College, Columbia University. 
Levin, H. M., \& Belfield, C. (2003). The Marketplace in Education. Working paper for NCSPE, Teachers College, Columbia University.

Maranto, R. , Milliman, S., \& Stevens, S. (2000). Does private school competition harm public schools? Revisiting Smith and Meier's 'The case against school choice'. Political Research Quarterly, 53, 177-192.

Marlow, M. L. (1997). Public education supply and student performance. Applied Economics, 29, 617-626.

Marlow, M. L. (2000). Spending, school structure, and public education quality. Evidence from California. Economics of Education Review, 19, 89-106.

McMillan, R. (1998). Competition, parental involvement and public school performance. (Doctoral Dissertation), Stanford University, California.

METCON. (1995). BPEP strategy for remote areas. Kathmandu: METCON Consultants Pvt. Ltd.

METCON \& ECL. (2000). Secondary education development project evaluation. A report submitted to the Nepal Secondary Education Project (HMGN/DFID/ADB) by METCON Consultants Pvt. Ltd., Kathmandu in association with Education for Change Ltd., Kathmandu.

Michalopoulos, C., Bloom, H. S., \& Hill, C. J. (2004). Can Propensity-Score Methods Match the Findings from a Random Assignment Evaluation of Mandatory Welfare-to-Work Programs? The Review of Economics and Statistics, MIT Press, 86(1), 156-179.

Ministry of Education and Culture of Nepal (MOEC)/USAID. (1988). Nepal: Education and Human Resource Sector Assessment. Improving Efficiency of Education Systems: Florida State University, USA.

Ministry of Education and Sports of Nepal (MOES). (1997). Basic and Primary Education Program Master Plan. Department of Education, Kathmandu, Nepal.

Ministry of Education and Sports of Nepal (MOES). (2003). Education for all 2004-2009. Department of Education, Kathmandu, Nepal.

Ministry of Education and Sports of Nepal (MOES). (2005a). Nepal in educational figures, Department of Education, Kathmandu, Nepal.

Ministry of Education and Sports of Nepal (MOES). (2005b). SLC Study Survey 2004 [Computer file], Kathmandu, Nepal.

Ministry of Education of Nepal (MOE). (2008). Nepal in educational figures, Department of Education, Kathmandu, Nepal. 
Ministry of Education of Nepal (MOE). (2010). Ministry of Education: A Glimpse. Monitoring, Evaluation \& Supervision Division, Kathmandu, Nepal.

Ministry of Finance. (MOF). (2004). Economic Survey. Kathmandu, Nepal.

Morgan, S. L. \& D. J. Harding (2006). Matching Estimators of Causal Effects: Prospects and Pitfalls in Theory and Practice. Sociological Methods and Research, 36, 3-60.

New ERA. (1995). BPEP achievement study. Kathmandu: New ERA.

Newmark, C. M. (1995). Another look at whether private schools influence public school quality: comment. Public Choice, 82, 365-373.

O’Donnell, O., van Doorslaer, E., Wagstaff, A. \& Lindelow, M. (2008). Analyzing Health Equity Using Household Survey Data. A Guide to Techniques and Their Implementation. Washington, DC: The World Bank.

Oaxaca, R. (1973). Male-Female Wage Differentials in Urban Labor Markets. International Economic Review, 14, 693-709.

PABSON. (2002) Private and Boarding School Organization of Nepal: Code of Conduct. (Kathmandu, PABSON).

Pindyck, R. S. \& Rubinfeld, D. L. (2009). Microeconomics, $7^{\text {th }}$ Edition, Prentice Hall.

Pritchett, L. \& Filmer, D. (1999). What education production functions really show: A positive theory of education expenditures. Economics of Education Review, 18, 223240.

Lee, L.F. (2001). Self-selection. In B. Baltagi (ed). Companion to Theoretical Econometrics, Oxford: Blackwell.

Puhani, P. (2000). The Heckman Correction for sample selection and its critique. Journal of Economic Surveys, 14 (1), 53-68.

Rosenbaum, P. R., \& Rubin, D. B. (1983). The Central Role of the Propensity Score in Observational Studies for Causal Effects, Biometrika, 70, 41-55.

Rouse, C. E., \& McLaughlin M. (1998). Can the Invisible Hand Improve Education? A Review of Competition and School Efficiency. Working paper for the Commission on Behavioral and Social Sciences and Education at the National Academy of Sciences.

Royston, P. (2004). Multiple imputation of missing values. Stata Journal, 4, 227-241. 
Rubin, D. B. (1980). Bias Reduction Using Mahalanobis -Metric Matching. Biometrics, 36, 293-298.

Rubin, D. B. (1986). Statistical matching using file concatenation with adjusted weights and multiple imputations. Journal of Business and Economic Statistics, 4, 87-94.

Rubin, D. B. (1996). Multiple imputation after 18+ years. Journal of the American Statistical Association, 91, 473-489.

Sander, W. (1999). Private schools and public school achievement. Journal of Human Resources, 34, 697-709.

Scheerens, P. (2004). Review of school and instructional effectiveness research: contribution to Chapter 3 of the 2004 EFA Global Monitoring Report. (mimeograph).

Schneeweis, N., \& Winter-Ebmer, R. (2007). Peer Effects in Austrian Schools. Empirical Economics, 32, 387-409.

Shadish, W. R., Cook, T. D., \& Campbell, D. T. (2002). Experimental and quasi-experimental designs for generalized causal inference. Boston, MA: Houghton Mifflin.

Silova, I. \& Bray, M. (2006). The hidden marketplace: Private tutoring in former socialist countries. In Silova, Iveta, Virginija Budiene and Mark Bray. (Eds). Education in a Hidden Marketplace: Monitoring of Private Tutoring. New York: Open Society Institute.

Simon, C. A., \& Lovrich, N. P. (1996). Private school performance and public school performance: assessing the effects of competition upon public school student achievement in Washington State. Policy Studies Journal, 24, 666-675.

Singh, G. B. (2004). A comparative study of school leaving examinations in SAARC countries. SLC Study Report \# 2, Kathmandu: The Education Sector Advisory Team, Ministry of Education and Sports.

Smith, A. (1776). Wealth of Nations, edited by C. J. Bullock. Vol. X. The Harvard Classics. New York: P.F. Collier \& Son, 1909-14; Bartleby.com, 2001. www.bartleby.com/10/.

SMAERC. (2008). A comparative study of school cost between community and institutional schools. Final Report, submitted to the Ministry of Education, Nepal, Santwona Memorial Academy Educational Research Center, Kathmandu, Nepal.

SMAERC. (2009). A Study on the Financial Management of Department of Education, District Education Office, School; and Tracking of School Grants, Final Report, submitted to the Ministry of Education, Nepal, Santwona Memorial Academy Educational Research Center, Kathmandu, Nepal.

Smith, K. B., \& Meier, K. J. (1995). Public choice in education - markets and the demand for quality education. Political Research Quarterly, 48, 461-478. 
Stanley, T. D., \& Jarrell, S. B. (1998). Gender Wage Discrimination Bias? A MetaRegression Analysis. The Journal of Human Resources, 33, 947-973.

Stevenson, D. L., \& Baker, D. P. (1992). Shadow education and allocation in formal schooling: transition to university in Japan. American Journal of Sociology, 97(6), 1639-57.

Subedi, B. R. (2004). Predicting Student Achievement: A Multilevel Analysis of Classrooms and Schools. Education and Development, Research Center for Education Innovation and Development, (21), 19 -32.

Tooley, J., \& Dixon, P. (2005). Private Education is Good for the Poor. CATO Institute, Washington, D.C.

Tukey, J. W. (1977). Exploratory Data Analysis, Addison-Wesley.

UNDP (2010). Human Development Report, United Nations Development Program, New York.

Walford, G. (1999). Privatization in industrialized countries. Paper for the conference on Setting the agenda for the National Center for the Study of Privatization in Education, Teachers College, Columbia University, New York.

Weichselbaumer, D., \& Winter-Ebmer, R. (2005). A Meta-Analysis of the International Gender Wage Gap. Journal of Economic Surveys 19: 479-511.

Wooldridge, J. M. (2009). Introductory Econometrics: A Modern Approach, $4^{\text {th }}$ edition, Ohio: Thomson Southwestern.

World Bank. (2003). Project appraisal document for a community school support project, human development sector unit, Nepal Office, Nepal.

World Bank. (2009). Implementation Completion and Results Report on Community School Support Project. World Bank, South Asian Regional Office, Kathmandu, Nepal.

World Bank. (2010). Data Bank, Retrieved from http://worldbank.org/all?qterm=South\%20Asia

Zanzig, B. R. (1997). Measuring the impact of competition in local government education markets on the cognitive achievement of students. Economics of Education Review, 16, 431-41. 


\section{APPENDIX}

Table A.1. Agencies under the Ministry of Education, Nepal

\begin{tabular}{|c|c|c|}
\hline SN & Types & Agencies \\
\hline 1 & Central Level & $\begin{array}{l}\text { 1. Department of Education (DOE) } \\
\text { 2. National Center for Educational Development (NCED) } \\
\text { 3. Curriculum Development Center (CDC) } \\
\text { 4. Office of the Controller of the Examinations (OCE) } \\
\text { 5. Non-formal Education Center (NFEC) } \\
\text { 6. School Teachers' Record Office (STRO) } \\
\text { 7. Education Review Office (ERO) }\end{array}$ \\
\hline 2 & Regional Level & 1. Five Regional Education Directorates (REDs) \\
\hline 3 & District Level & 1. Seventy-five district Education Offices (DEOs) \\
\hline 4 & Local Level & $\begin{array}{l}\text { 1. One thousand fifty-three Resource Centers (RCs) } \\
\text { 2. Thirty-two thousand one hundred and thirty Schools and twenty- } \\
\text { nine thousand eighty-nine ECD/PPC centers }\end{array}$ \\
\hline 5 & Commissions & $\begin{array}{l}\text { 1. University Grants Commission (UGC) } \\
\text { 2. Teacher Service Commission (TSC) } \\
\text { 3. Nepal National commission for Education, Science and Cultural } \\
\text { Organization (NATCOM) }\end{array}$ \\
\hline 6 & Universities & $\begin{array}{l}\text { 1. Tribhuvan University (TU) } \\
\text { 2. Nepal Sanskrit University (NSU) } \\
\text { 3. Kathmandu University (KU) } \\
\text { 4. Purbanchal University (PU) } \\
\text { 5. Pokhara University (PoKU) } \\
\text { 6. Lumbini Buddha University (LBU) } \\
\text { Just approved to open } \\
\text { 7. Agriculture and Forestry Science University } \\
\text { 8. Mid-Western University } \\
\text { 9. Far-Western University }\end{array}$ \\
\hline 7 & Councils/Boards & $\begin{array}{l}\text { 1. Council for Technical Education and Vocational Training } \\
\text { (CTEVT) } \\
\text { 2. Higher Secondary Education Board (HSEB) }\end{array}$ \\
\hline 8 & Libraries & $\begin{array}{l}\text { 1. Kaiser Library (KL) } \\
\text { 2. Nepal National Library (NNL) } \\
\text { 3. Dilliraman Kalyani Regmi Memorial Public Library (DKRMPL) }\end{array}$ \\
\hline 9 & Others & 1. Janak Education Material Centre Limited (JEMCL) \\
\hline
\end{tabular}

Source: MOE (2010) 


\section{Figure A.1. Box Plot Diagrams of Variables used in the Study}
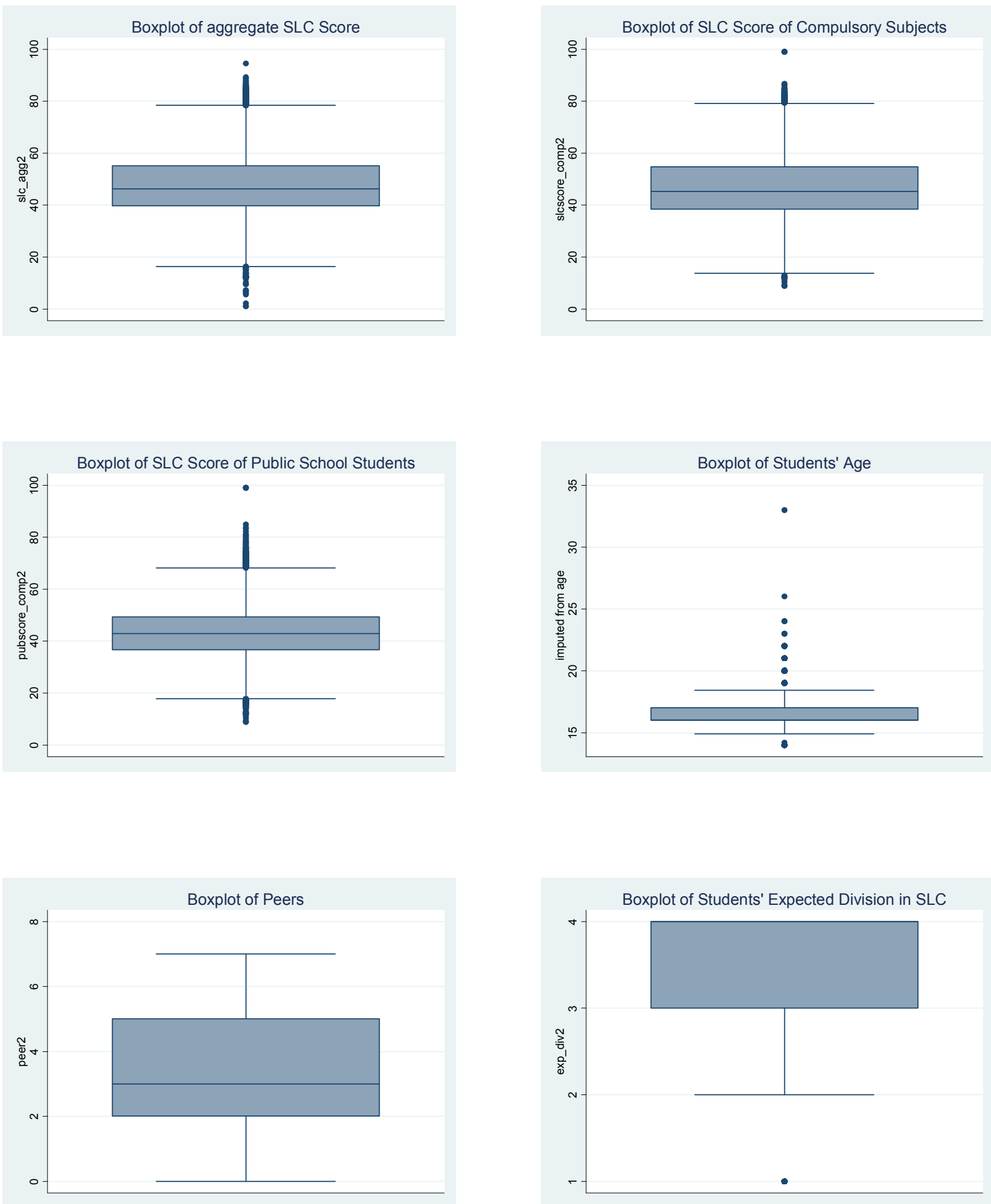

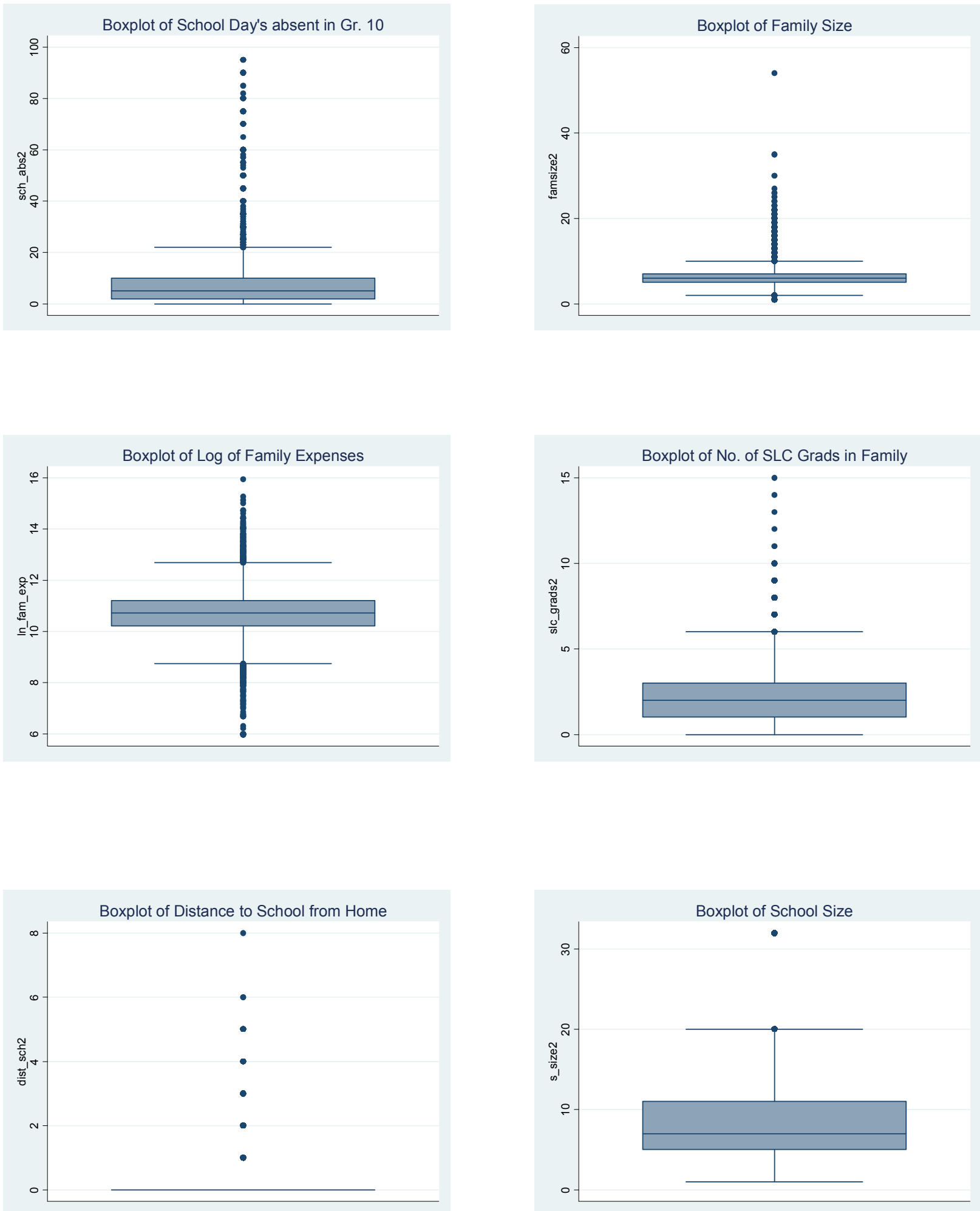

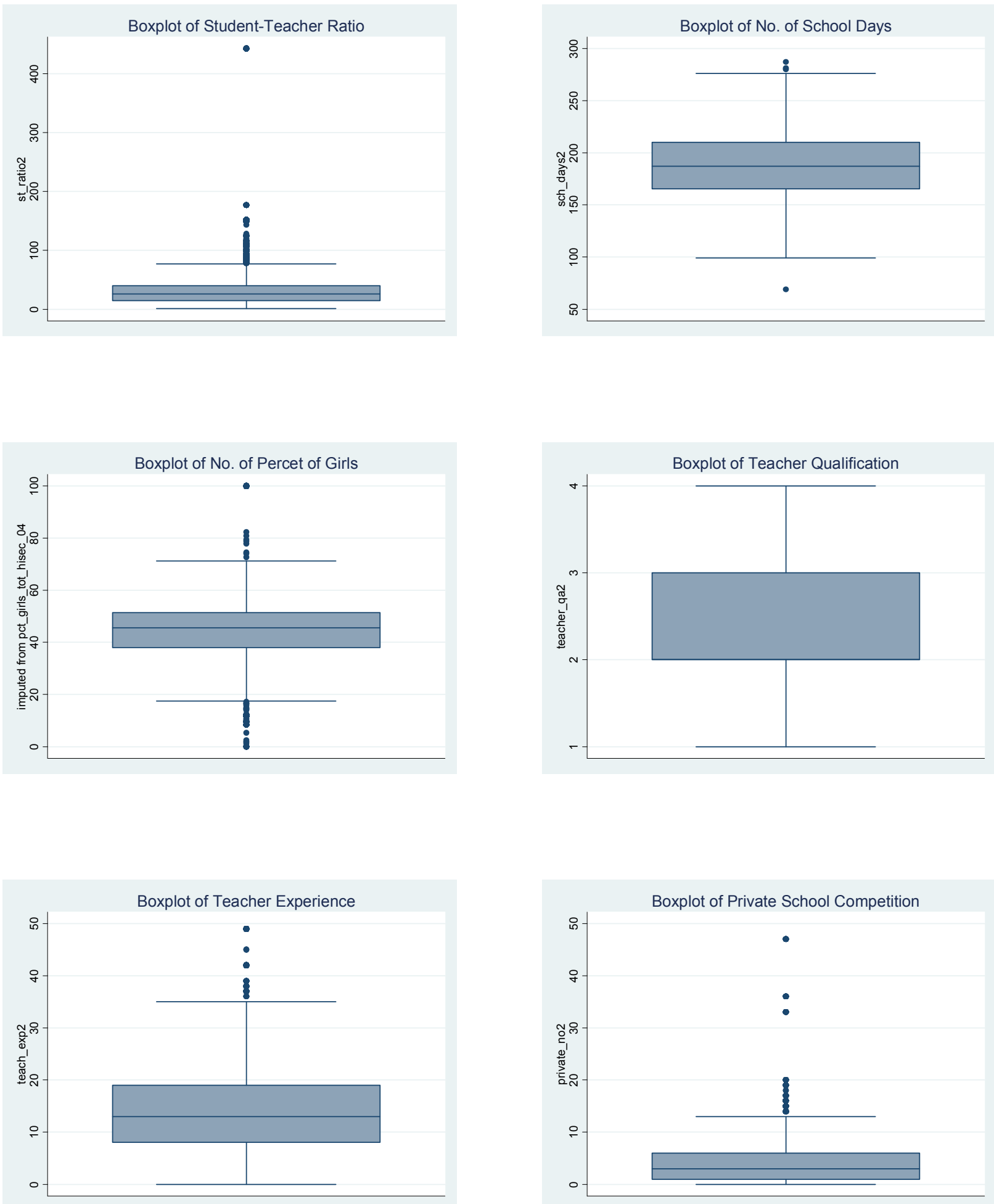
Figure A.2. Histograms of Variables used in the Study
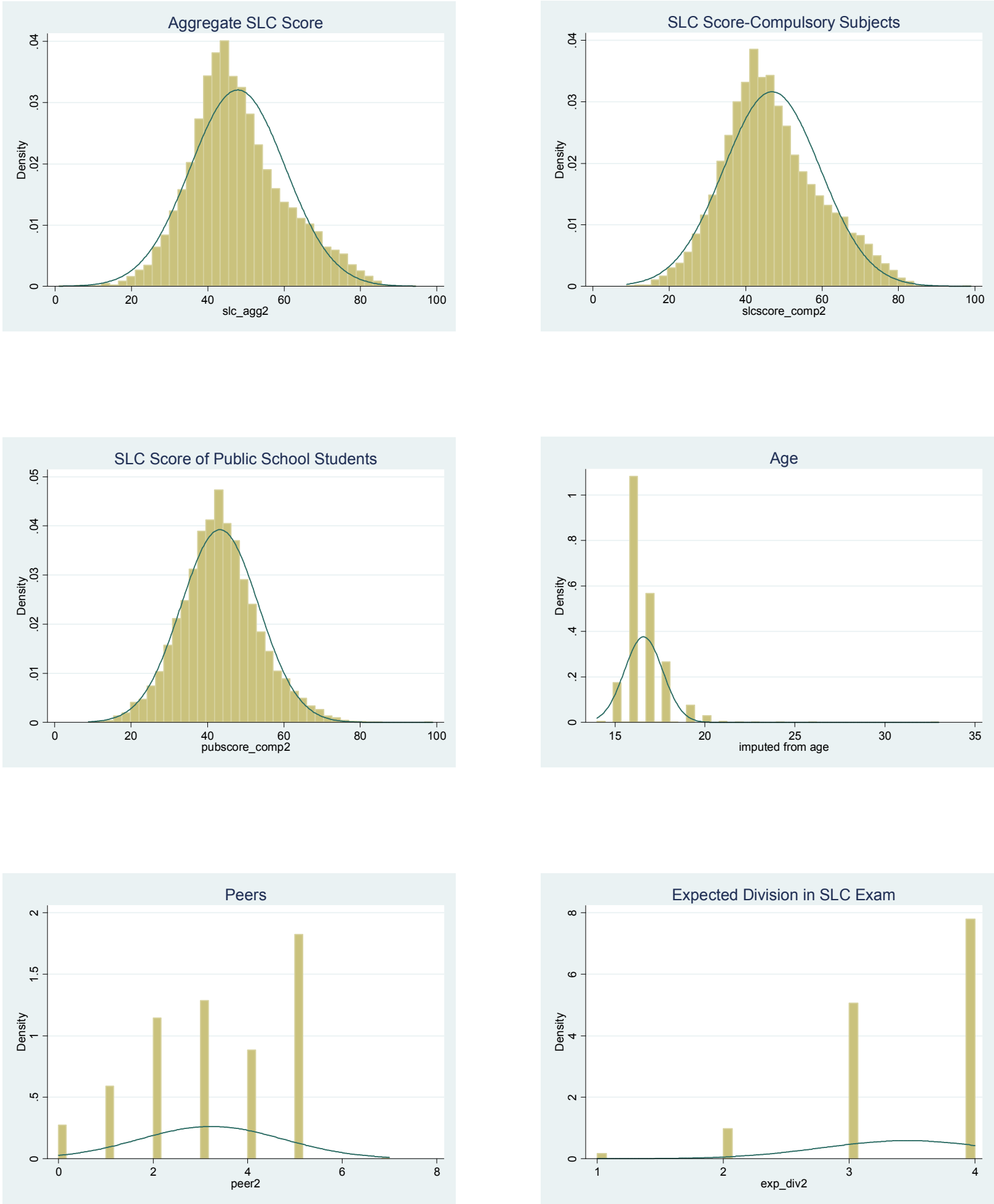

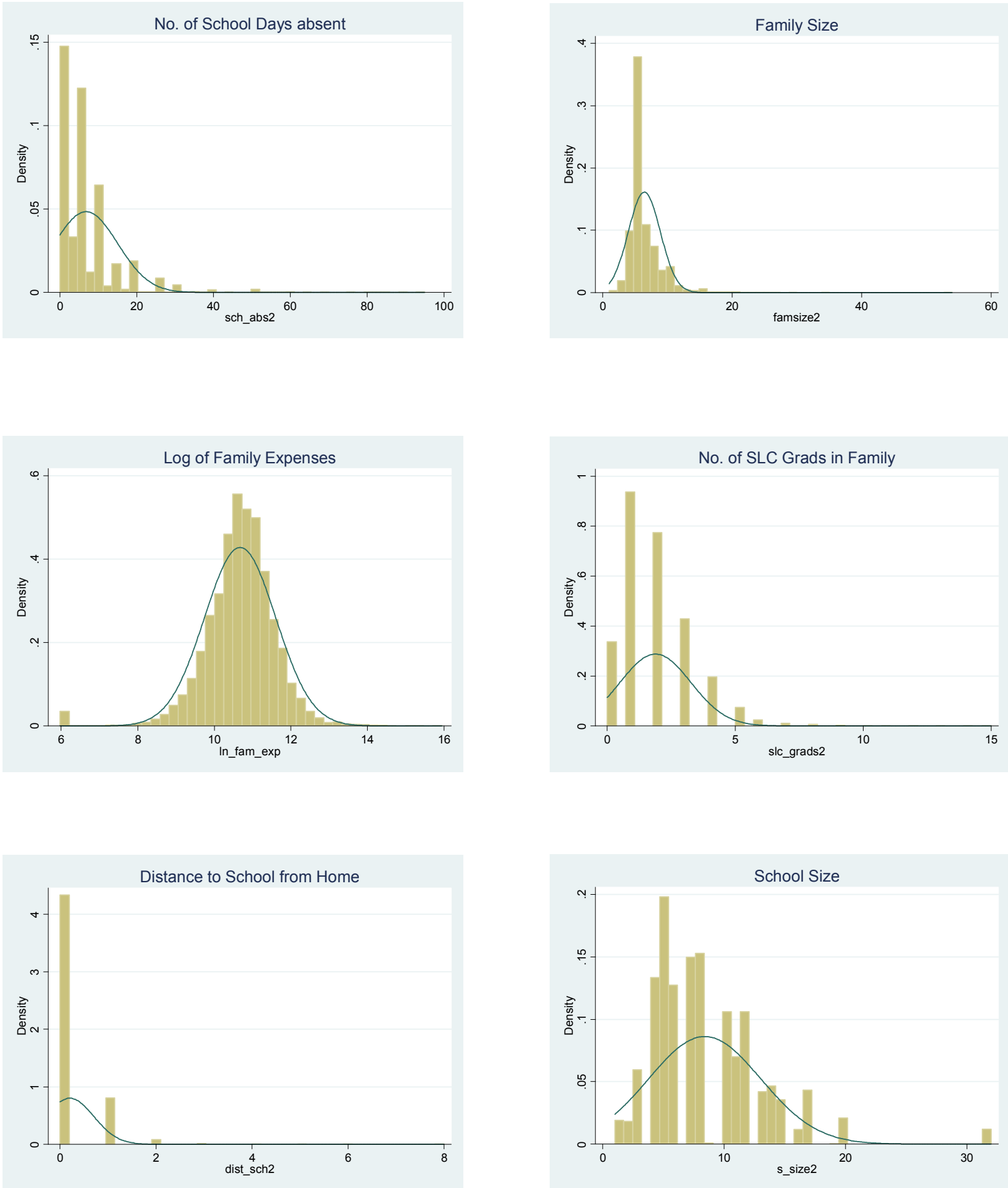

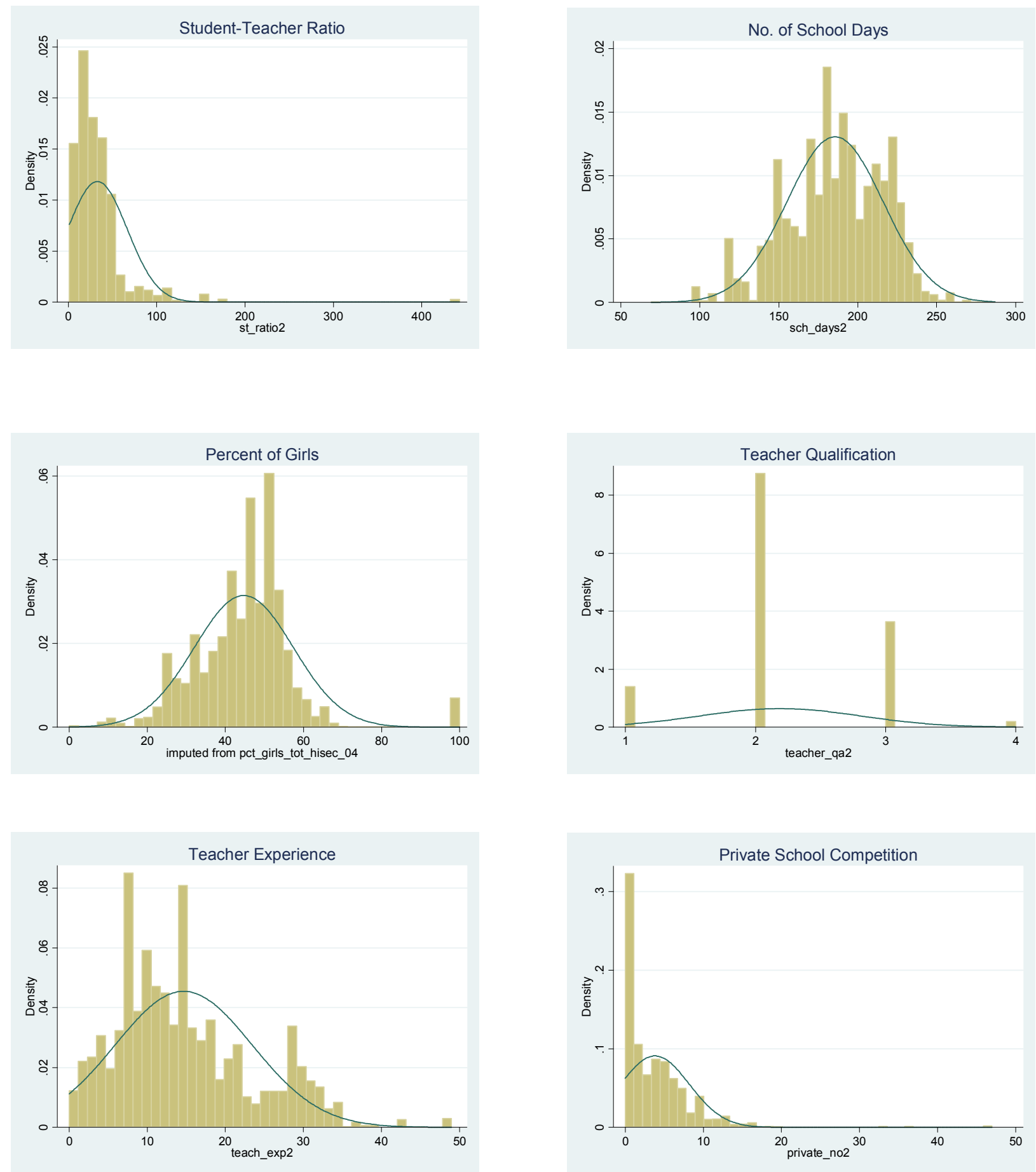